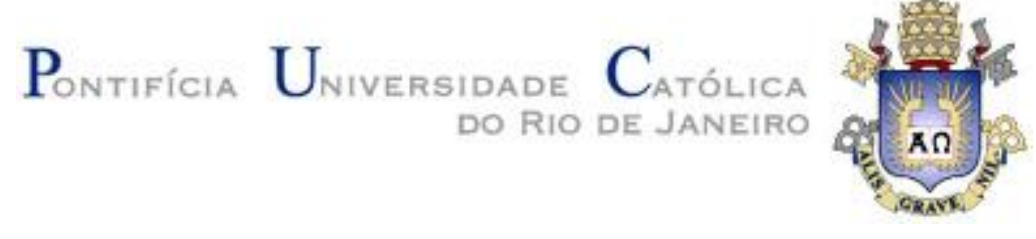

RAMON FREITAS MENDES

\title{
Metodologias de gerenciamento de projetos aplicadas à renovação de linha ferroviária
}

Dissertação apresentada como requisito parcial para obtenção do grau de Mestre pelo Programa de Pós-graduação em Engenharia de Produção, do Departamento de Engenharia Industrial da PUC-Rio.

Orientador: Prof. Fernando Luiz Cyrino Oliveira Co-orientador: Prof. Lupércio França Bessegato 


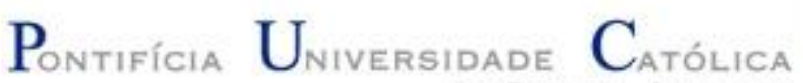

RAMON FREITAS MENDES

\section{Metodologias de gerenciamento de projetos aplicadas à renovação de linha ferroviária}

Dissertação apresentada como requisito parcial para obtenção do grau de Mestre pelo Programa de PósGraduação em Engenharia de Produção da PUC-Rio. Aprovada pela Comissão Examinadora abaixo:

Prof. Fernando Luiz Cyrino Oliveira Orientador Departamento de Engenharia Industrial - PUC-Rio

Prof. Lupércio França Bessegato Coorientador UFJF

Prof. José Eugênio Leal Departamento de Engenharia Industrial - PUC-Rio

Prof. Reinaldo Castro Souza

Departamento de Engenharia Industrial - PUC-Rio 
Todos os direitos reservados. É proibida a reprodução total ou parcial do trabalho sem autorização da universidade, da autora e do orientador.

\section{RAMON FREITAS MENDES}

Engenheiro de Produção formado pela Universidade Federal de Juiz de Fora (2015). Especialista Ferroviário, atua no setor de Transportes e Logística com experiência em Gerenciamento de Projetos, Planejamento, Programação e Controle da Manutenção, além de grande interesse nas áreas de otimização e simulação. Na graduação desenvolveu trabalhos de aplicação acadêmica, tecnológica e de treinamento profissional, realizando também graduação sanduíche na Universidade do Porto, em Portugal, desenvolvendo atividades ligadas ao curso de Engenharia Industrial e Gestão.

Ficha Catalográfica

Mendes, Ramon Freitas

Metodologias de gerenciamento de projetos aplicadas à renovação de linha ferroviária / Ramon Freitas Mendes ; orientador: Fernando Luiz Cyrino Oliveira ; coorientador: Lupércio França Bessegato. -2021.

84 f. : il. color. ; $30 \mathrm{~cm}$

Dissertação (mestrado)-Pontifícia Universidade Católica do Rio de Janeiro, Departamento de Engenharia Industrial, 2021.

Inclui bibliografia

1. Engenharia Industrial - Teses. 2. Gerenciamento de projetos. 3. Linha de balanço. 4. Simulação. 5. Opinião de especialistas. 6. Manutenção ferroviária. I. Oliveira, Fernando Luiz Cyrino. II. Bessegato, Lupércio França. III. Pontifícia Universidade Católica do Rio de Janeiro. Departamento de Engenharia Industrial. IV. Título. 
Para a minha família, a base dos meus valores e busca por conhecimento. 


\section{Agradecimentos}

O presente trabalho foi realizado com apoio da Coordenação de Aperfeiçoamento de Pessoal de Nível Superior - Brasil (CAPES) - Código de Financiamento 001.

Além do apoio das universidades parceiras: PUC-Rio e UFJF. 


\section{Resumo}

Mendes, Ramon Freitas; Oliveira, Fernando Luiz Cyrino; Bessegato, Lupércio França. Metodologias de gerenciamento de projetos aplicadas à renovação de linha ferroviária. Rio de Janeiro, 2021. 84p. Dissertação de Mestrado - Departamento de Engenharia Industrial, Pontifícia Universidade Católica do Rio de Janeiro.

Projetos de renovação ferroviária apresentam características de projetos complexos e repetitivos, dado seu grande número de recursos e fatores de influência e atividades repetitivas para determinadas unidades de produção. Neste contexto o presente trabalho buscou aplicar conceitos relativos a gerenciamento de projetos desse nicho e desenvolver uma forma integrada de trabalhar com a incerteza nesse ambiente. Foi aplicada a metodologia de planejamento de projetos chamada Linha de Balanço, utilizando informações do projeto em fase de concepção em uma empresa ferroviária. Em sequência foi desenvolvido um protocolo para obtenção da opinião de especialistas em informações críticas para o processo e obtidas as distribuições betas que melhor representam as informações elicitadas. A partir dessas entradas, foi desenvolvido um modelo de simulação das atividades do projeto para analisar o seu funcionamento em um ambiente virtual e livre de riscos e usar como ferramenta para aprimorar seu planejamento. Como resultados são apresentadas e analisadas as principais saídas do modelo e propostas formas de controle que possam auxiliar na retroalimentação do planejamento com informações do andamento do projeto após iniciado.

\section{Palavras-chave}

Gerenciamento de Projetos; Linha de Balanço; Simulação; Opinião de Especialistas; Manutenção Ferroviária. 


\section{Abstract}

Mendes, Ramon Freitas; Oliveira, Fernando Luiz Cyrino; Bessegato, Lupércio França. Project management methodologies applied to railway track renewal. Rio de Janeiro, 2021. 84p. Dissertação de Mestrado Departamento de Engenharia Industrial, Pontifícia Universidade Católica do Rio de Janeiro.

Projects of railway renewal have characteristics of complex and repetitive projects, given their large number of resources, influencing factors and recurring activities for certain production units. In this context, the present work sought to research and apply concepts related to project management in this niche and to develop an integrated method of working with uncertainty in this environment. The methodology of Project Planning known as Line of Balance (LoB) was applied, using information from a project in the conception stage of a railway company. Next, a protocol was developed to obtain expert opinion on critical information for the process and beta distributions that best represent the elicited information. From these inputs, it was developed a simulation model of the project activities in order to analyze their operation in a virtual and risk-free environment and optimize their scheduling. As a result, the main outputs of the model are presented and analyzed, in addition with the suggestion of methods of control that can assist in the feedback of the planning process with status information of the ongoing project.

\section{Keywords}

Project management; Line of Balance; Simulation; Expert Elicitation; Railway Maintenance. 


\section{Sumário}

1 Introdução 11

1.1 Contextualização do tema e problemática 13

$\begin{array}{lll}1.2 & \text { Objetivos da pesquisa } & 15\end{array}$

$\begin{array}{lll}1.3 & \text { Estrutura do trabalho } & 15\end{array}$

2 Referencial teórico $\quad 16$

$\begin{array}{llr}2.1 & \text { Linha de Balanço } & 18\end{array}$

2.2 Modelagem e Simulação $\quad 23$

2.3 Opinião de Especialistas $\quad 27$

2.3.1. Elicitando a distribuição Beta $\quad 30$

3 Metodologia de pesquisa $\quad 33$

4 Resultados e discussões

4.1 Estrutura de atividades do projeto $\quad 35$

4.2 Recursos e dados do projeto

4.3 Aplicação da Elicitação de Especialistas 41

4.3.1. Escolha das atividades e parâmetros a serem elicitadas 41

4.3.2. Definição das perguntas e perfil do especialista 42

4.3.3. Elicitação e obtenção das distribuições Beta 44

4.4 Aplicação da Linha de Balanço $\quad 52$

4.5 Modelo de parada programada para manutenção $\quad 57$

4.6 Simulação das atividades do projeto $\quad 59$

4.6.1. Modelo de simulação $\quad 59$

4.6.2. Simulação de duração do projeto e resultados $\quad 63$

4.6.3. Simulação do consumo de dormentes $\quad 64$

4.6.4. Simulação do índice de utilização do intervalo $\quad 67$

4.6.5. Simulação de cenários na Linha de Balanço $\quad 70$

$\begin{array}{lll}4.7 & \text { Perspectivas para controle do projeto } & 71\end{array}$

$\begin{array}{lll}4.8 & \text { Ganhos no processo de gerenciamento } & 73\end{array}$

$\begin{array}{lll}5 & \text { Conclusão } & 77\end{array}$

Referências bibliográficas $\quad 79$

APÊNDICE 1 - Distribuição Beta $\quad 83$ 


\section{Lista de Figuras}

Figura 1 - Modelo de degradação na qualidade da via ferroviária ao longo do tempo. 13

Figura 2 - Corte transversal de uma linha ferroviária. Fonte: Arquivos da empresa. 14

Figura 3 - Representação típica de LOB. 19

Figura 4 - Representação de casos de Divergência e Convergência em LOB. 20

Figura 5 - Tipos de modelos. Adaptado de Borshchev (2013). 25

Figura 6 - Comparação entre o protocolo de elicitação de especialistas e as etapas de gerenciamento de projetos. Fonte: Adaptado das informações de Szwed (2016). 29

Figura 7 - EAP do Projeto de Grandes intervenções de via. 37

Figura 8 - Diagrama unitário para as atividades da frente de renovação de linha. $\quad 38$

Figura 9 - Recursos do projeto. 39

Figura 10 - Histograma de produtividade elicitada da atividade de desguarnecimento de linha. Fonte: Autores (2021). 45

Figura 11 - Curva de distribuição de probabilidade da Beta. 47

Figura 12 - Histograma do tempo elicitado da atividade de Setup de Montagem. 49

Figura 13 - Histograma do tempo elicitado da atividade de Setup de Desmontagem. 49

Figura 14 - Histograma do tempo elicitado da atividade de Setup de Corretiva. $\quad 49$

Figura 15 - Distribuição Beta obtida para a atividade de Setup - Montagem (horas). 51

Figura 16 - Distribuição Beta obtida para a atividade de Setup - Desmontagem (horas). 51

Figura 17 - Distribuição Beta obtida para a atividade de Setup - Corretiva (horas). 52

Figura 18 - Linha de Balanço para os 5 primeiros ativos do projeto de renovação de linha ferroviária. $\quad 54$

Figura 19 - Linha de Balanço para os 28 ativos do projeto de renovação de linha ferroviário. $\quad 56$

Figura 20 - Linha do tempo da sequência de atividades dentro do intervalo para as frentes de desguarnecimento e renovação. $\quad 58$

Figura 21 - Modelo de Simulação das atividades do projeto 60

Figura 22 - Resultado da duração total do projeto simulada 63

Figura 23 - Histograma de probabilidades para a quantidade de dormentes previstos para o mês de junho de 2023

Figura 24 - Histograma de probabilidades do Índice de utilização do intervalo simulado em $\%$.

Figura 25 - Histograma de probabilidades das horas produtivas do intervalo simuladas 69 Figura 26 - Avanço físico das atividades do projeto e os cenários aleatórios para a $\begin{array}{ll}\text { atividade de desguarnecimento } & 70\end{array}$

Figura 27 - Representação esquemática da cadeia de suprimentos do projeto. $\quad 74$ 


\section{Lista de Tabelas}

Tabela 1 - Relação entre os recursos, atividades e dados do projeto. 40

Tabela 2 - Processos a serem elicitados 42

Tabela 3 - Valores e probabilidades elicitadas para as atividades de Setup de máquina

e as probabilidades obtidas. $\quad 48$

Tabela 4 - Valores elicitados e obtidos para a distribuição Beta de cada atividade de setup. 


\section{Introdução}

Muitas técnicas são utilizadas no desenvolvimento do cronograma de projetos. CPM (Critical Path Method - método do caminho critico), PERT (Program Evaluation and Review Technique) e "gráfico de barras" são as técnicas mais comuns, frequentemente orientadas para a duração das atividades. Nesses métodos, as atividades e suas durações são funções da quantidade de recursos necessárias para desenvolvimento de uma tarefa (AMMAR; MOHIELDIN, 2002).

Outro grupo de metodologias criadas para tal fim, são também aquelas orientadas por recursos, como por exemplo a Linha de Balanço (LOB) e a Simulação, onde são consideradas as quantidades de recursos disponíveis para desenvolvimento da atividade, sendo mais eficientes para resolver problemas de alocação de recursos (AMMAR; MOHIELDIN, 2002).

Segundo Ammar e Mohieldin (2002) é comum técnicas como o CPM serem utilizadas para o planejamento em nível de projeto (macro), em contra partida as mesmas não são tão eficientes a nível de processo (micro), onde as taxas de produção, disponibilidades de recursos e fatores que influenciam direta e indiretamente na produção devem ser levados em consideração.

Arditi, Tokdemir e Suh (2002) corroboram que apesar de ser uma ferramenta poderosa para planejamento de projetos, o CPM não é adequado para projetos repetitivos, que são aqueles que possuem atividades que são repetidas para cada unidade de produção considerada, dado ao fato que projetos com essas características normalmente possuem taxas de produção diferentes para atividades em cada contexto. Ammar e Abdel-Maged (2018) complementam que a LOB assim como outras metodologias orientadas para recursos, superam a limitação do CPM de aplicação em projetos repetitivos.

No planejamento de projetos, principalmente aqueles que são considerados complexos, envolvendo muitas atividades, recursos e fatores que influenciam o mesmo direta e indiretamente, a incerteza é um fator recorrente que se não analisada da forma correta e inserida no planejamento do projeto, pode aumentar 
consideravelmente o risco de não cumprimento de prazos e orçamentos definidos para o mesmo.

Quando tratamos de métodos conhecidos para gerenciamento de projetos e definição de cronogramas, normalmente o projeto é descrito como uma sequência discreta de tarefas, sendo assim os prazos e custos totais obtidos normalmente a partir da soma destes eventos. Porém, essas redes podem ser mal interpretadas, dado que nem sempre projetos vão ocorrer de forma linear com tarefas iniciadas e encerradas, mas sim como uma rede de processos interativos que influenciam um nos outros (GOROD et al., 2019).

Neste cenário a simulação de processos se apresenta como uma ferramenta eficaz no apoio ao planejamento de projetos, permitindo a criação de cenários através das informações de entrada, fatores de influência conhecidos e análise dos dados obtidos pela simulação, em um ambiente totalmente livre de riscos, diferentemente de projetos que são desenvolvidos no mundo real. Desta forma, gerentes, engenheiros e pesquisadores podem criar e testar os seus modelos, conhecer melhor as implicações das variáveis de seu projeto e também responder muitas perguntas que possam ainda existir na fase de planejamento (BORSHCHEV, 2013).

O tipo de simulação com maior aplicação na comunidade coorporativa é a simulação de eventos discretos (DES - Discrete-event simulation), baseada em diagramas de fluxo onde são definidas as atividades e recursos e o comportamento dos mesmos no modelo. Além da DES, existem outros tipos de simulação que podem ser usadas para melhor representar um sistema, dentre essas pode ser citada a Simulação baseada em agentes (ABS - Agent-based simulation), e a modelagem de sistemas dinâmicos (SDM - System dynamics modeling) (BORSHCHEV, 2013).

Para definir o método a ser empregado na simulação, cabe o entendimento da situação de cada modelo. Porém no contexto de planejamento de projetos complexos, uma abordagem multimétodos gera a possibilidade de aproximação do modelo da situação real, o que é um dos principais objetivos para o desenvolvimento de um bom modelo de simulação.

Nesse sentido, o presente trabalho busca a integração entre ferramentas já utilizadas no planejamento de projetos, como a Linha de Balanço - utilizada no desenvolvimento do cronograma do projeto - com modelagem e simulação no âmbito de processos, entendendo a interação dos recursos e suas variáveis, bem 
como métodos estatísticos através do tratamento de opinião de especialistas, com o objetivo de trazer a incerteza de cenários para o planejamento e assim aproxima-lo da realidade da execução.

\subsection{Contextualização do tema e problemática}

O presente estudo se aplica na área de gerenciamento de projetos de renovação de linha ferroviária em uma empresa de transporte ferroviário de cargas brasileira.

A renovação de via consiste em uma atividade necessária no ciclo de vida da linha ferroviária, dado que conforme representado na Figura 1, com o passar do tempo a qualidade da via sofre degradações, que são reestabelecidas com manutenções preventivas e corretivas, sem retornar aos níveis iniciais de projeto devido a uma degradação natural da mesma.

Com o avanço do tempo, a qualidade da via ferroviária começa a atingir níveis alarmantes considerando um padrão mínimo de segurança, e os gastos para restabelecê-la vão ficando cada vez maiores, sendo então necessário realizar a renovação de todos os componentes da via, retornando a mesma para o padrão de projeto.

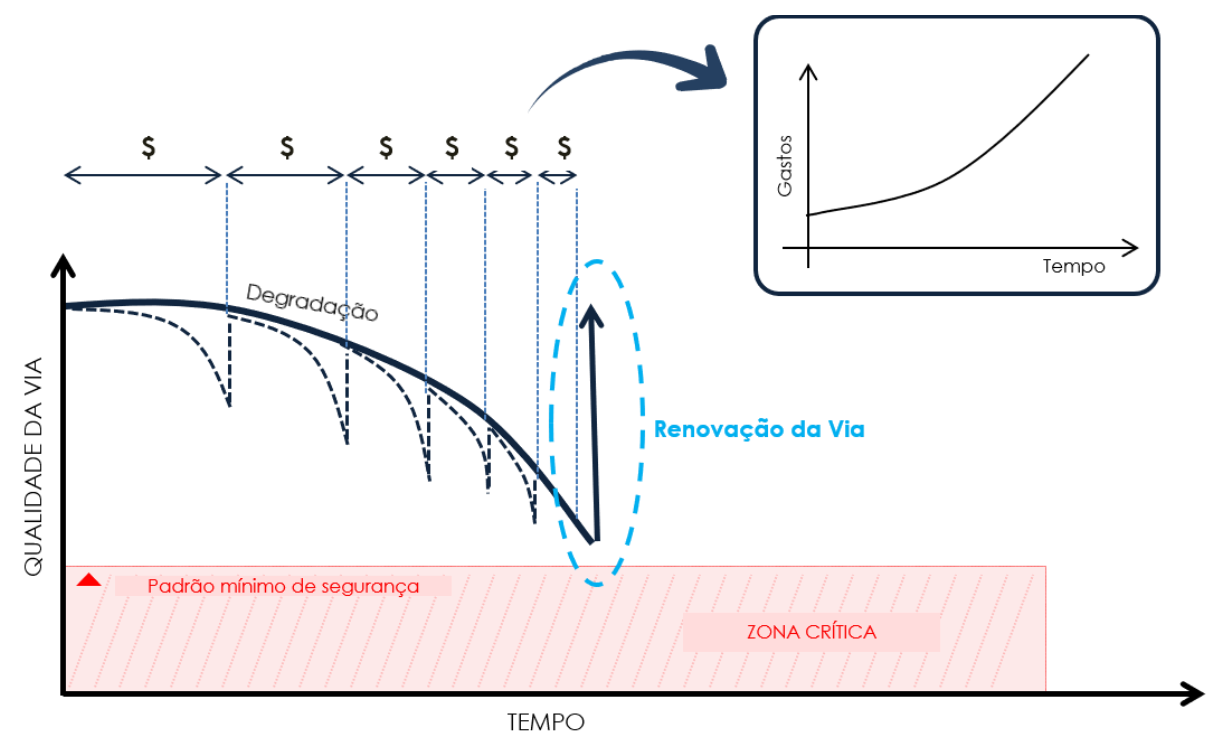

Figura 1 - Modelo de degradação na qualidade da via ferroviária ao longo do tempo.

Fonte: Arquivos da empresa.

A renovação ferroviária consiste na substituição de todos os componentes da linha, sendo esses trilhos, dormentes, lastro e sub-lastro. Através da Figura 2 de 
corte transversal da linha ferroviária é possível identificar os componentes acima mencionados e os fatores que levam esses componentes a indicar a necessidade de intervenção na via através da renovação.

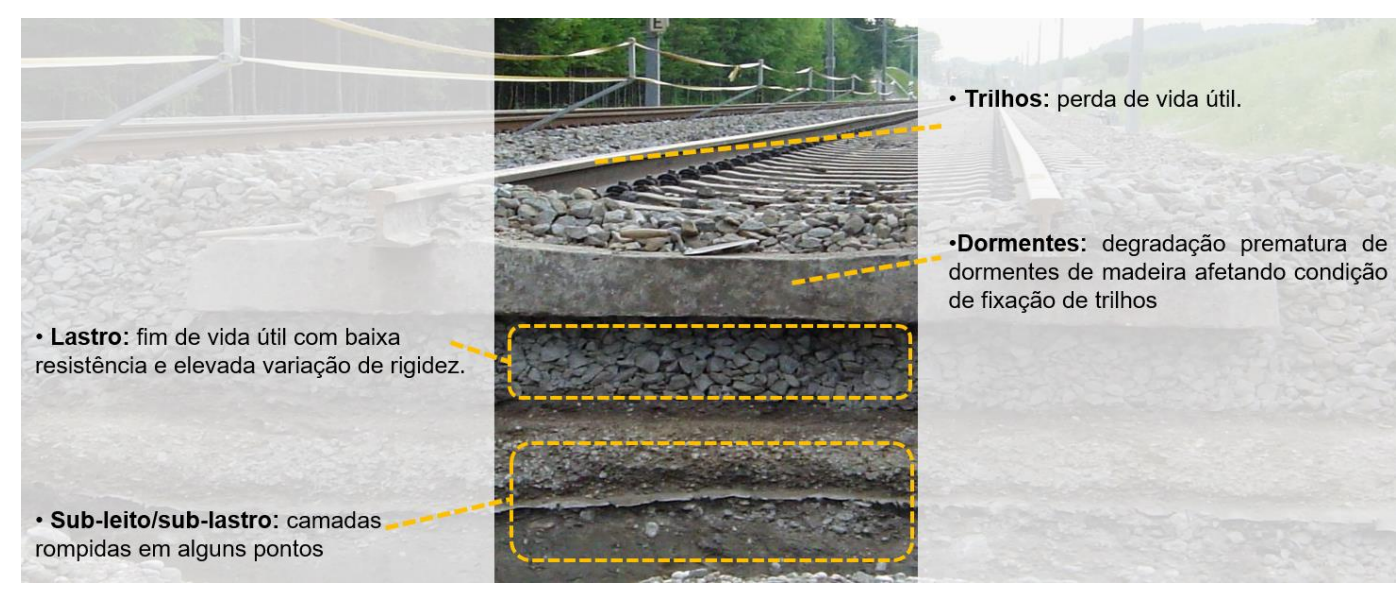

Figura 2 - Corte transversal de uma linha ferroviária. Fonte: Arquivos da empresa.

A renovação de linha, apesar de ser uma atividade de manutenção ferroviária, possui características de projeto, dado que normalmente não faz parte do escopo comum da manutenção, sendo necessária a aquisição de equipamentos especiais, contratação de mão de obra, definição de um modelo de trabalho com datas de início e fim estabelecidas para a intervenção.

Um projeto deste tipo é considerado complexo, dado a sua parcela de mecanização em conjunto com trabalho humano, com um grande número de atividades sequenciadas, muitos fatores que influenciam no desempenho e disponibilidade de recursos, além do modelo de trabalho ser feito com faixas de manutenção programada, que consiste em intervalos de tempo previamente acordados com o Centro de Controle Operacional (CCO) onde a circulação de trens é interrompida naquela faixa ferroviária para que possa ser dada a manutenção, e após o dia de trabalho o trânsito ferroviário deve ser reestabelecido.

Além disso, pela natureza do projeto, é possível identificar no mesmo, características de projetos repetitivos que são aqueles que possuem uma sequência de atividades que devem ser executadas repetitivamente para $\mathrm{k}$ unidades de produção, no caso da renovação ferroviária, quilômetros de via $(\mathrm{km})$ ou mesmo faixas do trecho ferroviário preestabelecidas. 


\subsection{Objetivos da pesquisa}

O objetivo geral deste trabalho foi desenvolver um modelo de planejamento de um projeto de renovação de linha em uma empresa ferroviária, buscando integração de ferramentas que possibilitem a sua aproximação da realidade de execução, através do balanceamento de recursos e inserção da incerteza neste contexto.

Como objetivos específicos, podem ser enumerados os seguintes:

(i ) Aplicar a metodologia de Linha de balanço ao planejamento do projeto;

( ii ) Desenvolver um modelo de simulação que possibilite o estudo do comportamento dos recursos do projeto, em um ambiente virtual, e as influências de fatores que possam impactar o andamento do mesmo;

(iii ) Aplicar estatística Bayesiana para a obtenção da elicitação de especialistas em atividades e/ou fatores de impacto do projeto e desenvolver distribuições de probabilidades para os mesmos para utilização no ambiente simulado.

\subsection{Estrutura do trabalho}

O presente trabalho está subdividido em 5 capítulos: Introdução, Referencial teórico, Metodologia, Resultados e Discussões e Conclusão. Na introdução foram apresentadas as motivações para o presente trabalho, além de também contextualizar o problema e estabelecer quais são os objetivos para o seu desenvolvimento. No referencial teórico é apresentada a pesquisa bibliográfica realizada para os principais assuntos relacionados ao tema deste estudo e outros trabalhos posteriores utilizados de referência conceitual para este. Em Metodologia são apresentados os métodos e protocolos a serem utilizados, e onde o mesmo se encaixa na metodologia científica. Em Resultados e Discussões são levantadas as informações referentes ao projeto, aplicação das ferramentas sugeridas, e resultados obtidos. Por fim são apresentadas considerações finais e indicações de pesquisas relacionadas. 


\section{2 Referencial teórico}

No transporte ferroviário de cargas, a qualidade da via é um fator determinante para garantir a tonelada bruta a ser transportada, a velocidade a ser empregada no trecho e também a segurança dos ativos. A manutenção, apesar de ser recorrente e realizada de forma preventiva e corretiva, não reestabelece o ativo à condição inicial de qualidade, sendo necessária a renovação de via, que é determinada a partir de indícios e parâmetros de controle técnicos.

A maioria dos estudos existentes na literatura a respeito de manutenção ferroviária, e mais especificamente sobre a renovação de via, são relativos a ferramentas e métodos que tratam os parâmetros técnicos de controle que determinam a necessidade de realização de um projeto deste tipo em um trecho de via ferroviária, e não tratam o gerenciamento dos projetos e seus recursos (CAETANO; TEIXEIRA, 2015, 2016; PARGAR; KAUPPILA; KUJALA, 2017).

Em seu trabalho, Caetano e Teixeira (2015) relatam que ferramentas de apoio a decisão que procurem otimizar obras relacionadas a componentes de ferrovia estão cada vez mais ganhando importância, e sugerem um modelo de otimização do planejamento de renovação de via, levando em consideração a degradação dos componentes.

Pargar, Kauppila e Kujala (2017), propõem um modelo que integra a manutenção preventiva da ferrovia com a renovação de linha, buscando assim reduzir custos, otimizando a sua realização. Assim como o estudo anterior, este não leva em consideração o gerenciamento dos recursos do projeto, imprevistos e incertezas dos mesmos, mas sim se baseiam em critérios técnicos para apoio da decisão sobre onde e quando realizar a renovação de linha.

Em um contexto onde a defesa técnica da necessidade de renovação já é reconhecida, é necessário a aplicação de ferramentas e metodologias voltadas para o gerenciamento de um projeto desta magnitude, e garantir o sequenciamento de suas atividades, a alocação efetiva de seus recursos e um planejamento assertivo considerando as variáveis existentes no seu desenvolvimento. 
Neste sentido, devido às atividades que são realizadas de forma repetitiva para os quilômetros de via a serem renovados, e expandindo o horizonte de aplicação, um projeto de renovação de via ferroviária muito se assemelha a projetos repetitivos de construção, como por exemplo a construção de estradas, túneis, pontes, prédios de vários andares, redes de gasodutos, entre outros, onde os mesmos possuem características comuns, e possuem incertezas que são inerentes e geralmente encontradas na fase de execução do projeto, devido a variações na produtividade do trabalho, clima, condições do local e disponibilidade de equipamentos (HASSAN, 2019).

Nos trabalhos da literatura cientifica de projetos repetitivos de construção, é indicado o uso de técnicas orientadas aos recursos ou localização, diferente daquelas orientadas a duração das atividades (AMMAR; ABDEL-MAGED, 2018; HASSAN, 2019; POLAT; BUYUKSARACOGLU; DAMCI, 2009; TOMAR; BANSAL, 2019).

Para atender às necessidades de projetos repetitivos, como possibilitar a continuidade do trabalho de equipes e equipamentos, em unidades repetitivas de produção, foram desenvolvidos vários modelos de planejamento orientados por recursos, sendo eles determinísticos ou estocásticos, com base na propriedade de considerar riscos e incertezas relativas ao projeto (HASSAN, 2019).

Entre os modelos desenvolvidos para projetos repetitivos, Hassan (2019), cita como determinísticos, a Linha de Balanço (LOB), que será melhor detalhada em uma sessão abaixo, o método de agendamento linear (Linear Scheduling Method LSM) que possui a mesma forma gráfica da LOB, mas é mais adequado para lidar com atividades repetitivas e não repetitivas que podem existir no projeto e os modelos de agendamento matemáticos (Mathematical Scheduling Models), que são aqueles problemas que por conta de sua complexidade são dificilmente reproduzidos de forma gráfica, logo é desenvolvido um modelo matemático para execução do agendamento.

Hassan (2019) também levanta exemplos de técnicas com agendamento de atividades repetitivas não determinísticas, e entre elas são mencionadas: os modelos de agendamento baseados em probabilidade (Probability-Based Scheduling Models), são aqueles que consideram uma representação estatística de dados históricos de projetos similares para construir o cronograma, os modelos baseados 
em PERT (Project Evaluation and Review Technique) e por último os modelos de Simulação, que também serão melhor detalhados em um tópico especifico.

Muitas variáveis podem interferir na execução das atividades dos projetos, e muitas vezes a percepção desses impactos não é mensurável de forma quantitativa, mas sim através da experiência de especialistas a respeito de projetos semelhantes ou de características do local onde o projeto está sendo aplicado.

Na ferrovia o uso da opinião de especialistas de forma qualitativa é muito comum, devido ao conhecimento acumulado por experiência em anos trabalhando no mesmo trecho ferroviário, conhecendo a fundo as atividades de manutenção e também os impactos em produtividade de cada trecho.

Dessa forma, é importante uma metodologia que permita a transformação da opinião desses especialistas em um dado qualitativo que possa integrar o planejamento e ser entrada para modelos de simulação.

$\mathrm{Na}$ literatura cientifica esse termo é tratado como opinião, julgamento ou elicitação de conhecimento de especialistas e vários estudos, abordam metodologias e protocolos indicando formas de realizar a aplicação do conceito em gerenciamento de projetos (CHARISSE FARR et al., 2019; HANEA et al., 2018; HANEA; NANE, 2019; HEMMING et al., 2018; O’HAGAN, 2019).

\subsection{Linha de Balanço}

As metodologias de planejamento de projetos podem ser subdivididas em duas categorias, aquelas que são orientadas a duração das atividades, como o método do caminho critico (Critical Path Method - CPM), e aquelas que são relativas aos recursos, e dentre estas podemos citar a Linha de Balanço (Line of Balance - LOB) (ZOU; ZHANG, 2020).

A Linha de Balanço é uma técnica vastamente empregada para planejamento de projetos repetitivos, e com ampla utilização no setor da construção civil. A sua representação é feita de forma gráfica, onde cada linha corresponde a um conjunto de atividades repetitivas e a relação de interdependência entre as mesmas deve ser respeitada, evitando assim que as linhas de atividades que são interdependentes se cruzem. Analisando os possíveis casos, respeitando as interdependências e considerando as taxas de produção de cada atividade é possível definir cenários para 
a realização das atividades dentro dos limites de disponibilidade de recursos estabelecidos (TOMAR; BANSAL, 2019).

A Figura 3 demonstra uma das representações mais comuns de LOB, em que cada atividade é representada por uma barra inclinada, onde é possível através da interpretação do gráfico, obter informações tais como: a duração da unidade k na atividade $\mathrm{A}\left(\mathrm{dA}_{\mathrm{k}}\right)$; tempo de início da unidade $\mathrm{k}$ na atividade $\mathrm{A}\left(\mathrm{SA}_{\mathrm{k}}\right)$; tempo final da unidade $\mathrm{k}$ na atividade $\mathrm{A}\left(\mathrm{FA}_{\mathrm{k}}\right)$.

Em projetos repetitivos, o método apresentado proporciona maior flexibilidade aos planejadores, permitindo o uso múltiplos das equipes (recursos) e possibilitando uma análise rápida dos efeitos da mudança nos recursos, facilitando a tomada de decisão, principalmente em projetos com restrição de tempo (AMMAR; ABDEL-MAGED, 2018).

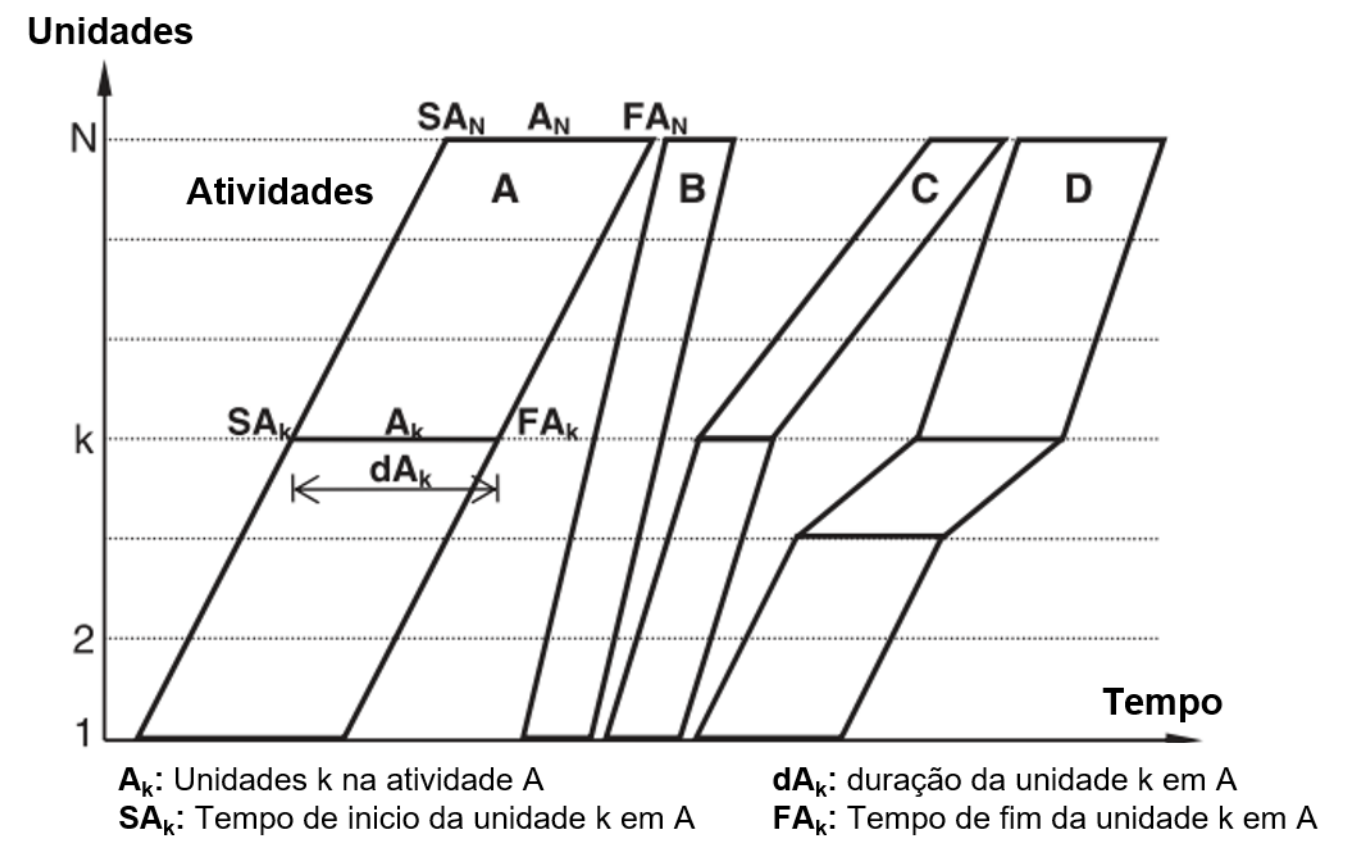

Figura 3 - Representação típica de LOB.

Adaptado de Ammar e Abdel-Maged (2018).

Desta forma, apesar do CPM ser uma técnica de planejamento utilizada de forma mais ampla, ele não é adequado para o planejamento de projetos repetitivos, por conta da sua dificuldade em representação das múltiplas equipes em múltiplas unidades de produção. Para essa representação, LOB e outras ferramentas para projetos repetitivos são alternativas viáveis para suprir essa incapacidade do CPM e métodos mais tradicionais (ZOU; ZHANG, 2020). 
Ammar e Abdel-Maged (2018) também frisa que uma das vantagens da LOB sobre o CPM é conseguir manter a continuidade do trabalho das equipes em unidades consecutivas de atividades repetitivas, sendo um dos principais objetivos da LOB equilibrar as taxas de produção entre as atividades consecutivas, minimizando a diferença entre essas, sempre com o objetivo geral de reduzir a duração do cronograma, e o melhor aproveitamento dos recursos.

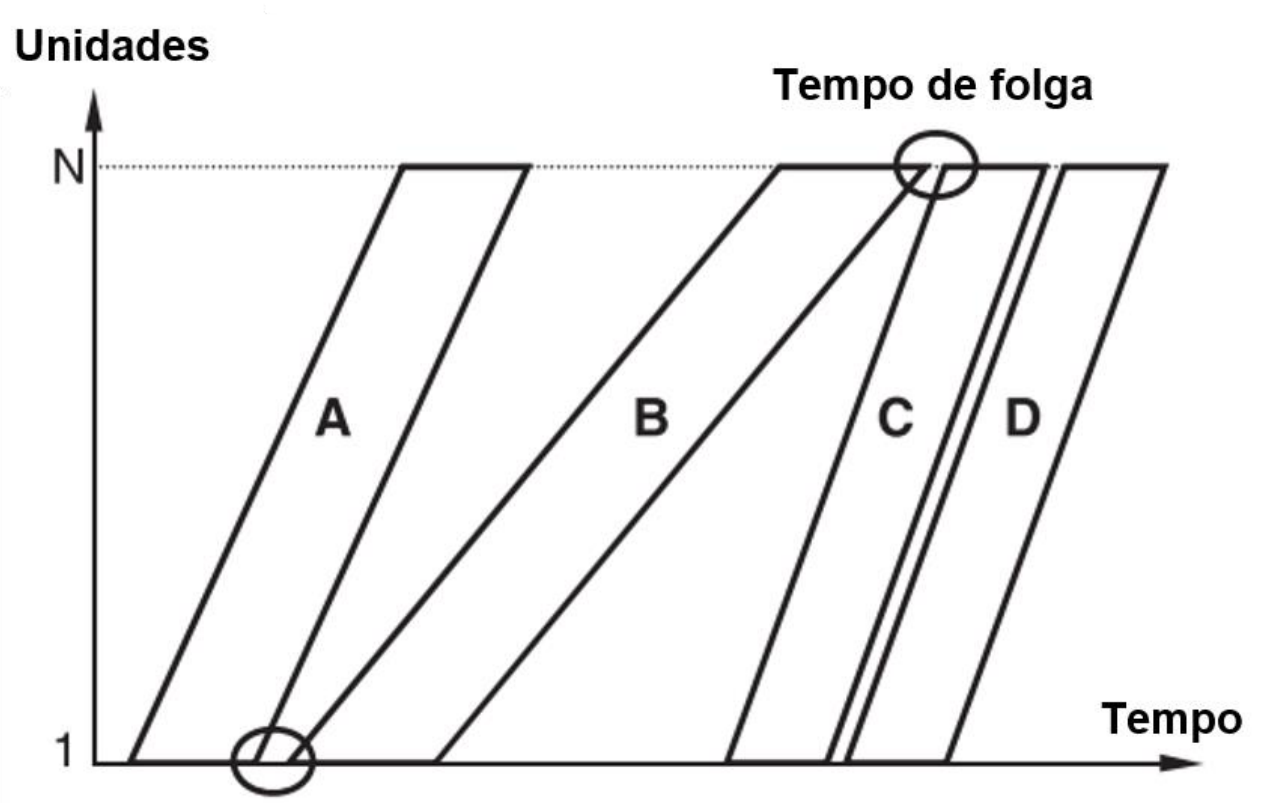

Figura 4 - Representação de casos de Divergência e Convergência em LOB. Adaptado de Ammar e Abdel-Maged (2018).

Ainda, segundo Ammar e Abdel-Maged (2018) para fazer o primeiro esboço de um cronograma de LOB é preciso entender as relações de dependência entre as atividades consecutivas, comparando a taxa de progresso de cada atividade com a subsequente, e assim analisar entre três possíveis tipos de relação entre as atividades, conforme demonstrados abaixo:

i) Divergência: quando uma atividade mais lenta é sucessora de uma atividade mais rápida, nesse caso a atividade seguinte pode ser desenhada a partir da primeira unidade da atividade anterior. Normalmente nesses casos o tempo de folga (buffer) é adicionado antes da primeira unidade da atividade sucessora. Como exemplo desse caso podemos citar as atividades A e B da Figura 4.

ii) Convergência: consiste no caso em que uma atividade tem uma atividade sucessora que é mais rápida, ou seja, tem uma taxa de produção maior, como por exemplo as atividades B e C da Figura 4, 
dessa forma a atividade $\mathrm{C}$ é desenhada a partir da última unidade da atividade $\mathrm{B}$, considerando entre elas o tempo de folga, e garantindo assim que todas as unidades predecessoras vão obedecer a dependência entre as duas.

iii) Paralelismo: para o caso de duas atividades que tem taxa de produção idênticas, nesse caso as atividades são paralelas, como o exemplo das atividades $\mathrm{C}$ e D da Figura 4.

Conforme é levantado por Arditi, Tokdemir e Suh (2002) em seu estudo, realizar o planejamento utilizando a LOB não é uma tarefa simples, principalmente quando trata-se de um projeto de construção que é dividido em muitas atividades que possuem complicados relacionamentos e outras restrições a serem consideradas.

Logo para facilitar a aplicação alguns princípios importantes devem ser entendidos e levados em consideração, e entre eles podemos destacar os seguintes:

(1) Existência de um prazo de projeto preestabelecido: normalmente a LOB é orientada a partir de uma data de entrega preestabelecida e com a alocação dos recursos disponíveis, almejando para todas as atividades pelo menos a taxa alvo de entrega definida;

(2) A interdependência entre as atividades deve ser levada em consideração na construção do gráfico, e normalmente para auxiliar nessa atividade anteriormente ao início do planejamento é realizado um diagrama unitário, que consiste nas relações de interdependência das atividades considerando uma unidade de entrega, levando em consideração que as dependências podem ser de tempo - uma atividade não pode ser realizada antes da outra - ou mesmo espacial - aquela atividade para a unidade sequente depende da anterior nesses casos normalmente as taxas de produção devem ser alinhadas entre si;

(3) Para o sucesso da LOB é necessário realizar com critério as análises prévias para a sua execução, como calcular os tempos de início e fim de todas as $\mathrm{k}$ unidades, e também os caminhos possíveis para o diagrama, para garantir uma análise completa é necessário comparar as atividades por pares conforme os seus graus de relação (Divergência ou Convergência) mencionados acima; 
(4) Outro ponto a ser considerado para o sucesso da LOB é lidar com as restrições impostas às atividades. Quanto mais diversificados os tipos de restrição, maior a dificuldade. Dentre possíveis restrições podemos citar: distribuição de recursos, limitação de recursos, marcos de entregas parciais contratuais, e também atividades discretas não lineares - que são aquelas que possuem operações repetitivas, porém a taxa de saída das mesmas não é uniforme, conforme previsto normalmente no desenho da linha de balanço;

(5) Alocação eficiente dos recursos e dos custos também é um fato muito importante a ser levado em consideração ao se desenvolver a linha de balanço. Uma alternativa para o aumentar a produtividade e a alocação novos recursos, porém o impacto financeiro deve ser analisado, dado que podem existir gastos fixos previstos em contrato que apesar de tornar a alocação vantajosa produtivamente, pode não ser uma boa escolha financeiramente.

Seguidos os princípios enumerados acima, a linha de balanço tem um forte potencial para aplicação em projetos de construção, permitindo a utilização da sua forma gráfica que deu nome à ferramenta, para fazer um balanceamento das atividades analisando aquelas que tem produtividade aquém do esperado. No gráfico da LOB as atividades com taxa de produção fora da esperada são claramente visíveis e comparáveis a taxa alvo estabelecida (LUCKO; GATTEI, 2016).

O levantamento realizado por Tomar e Bansal (2019) levando em consideração estudos realizados entre 2008 e 2018 mostra que a LOB tem sido usada principalmente para planejamento de projetos de construção repetitivos, com alguns trabalhos propondo integração de LOB com CPM e outras variantes, porém grande maioria usando da aplicação de LOB propriamente dita.

Para esboçar a Linha de Balanço é importante calcular também as informações que serão usadas na sua construção. Segundo Ammar (2020), o primeiro ponto de partida é formular uma estratégia para cumprimento do prazo de projeto pré-estabelecido calculando a taxa alvo de entrega do projeto $\left(\boldsymbol{R}_{T}\right)$ através da Equação ( 1 ), sendo n o número de unidades repetitivas, e $\boldsymbol{T}_{\boldsymbol{P}}$ é a duração desejada do projeto, e $\boldsymbol{T}_{\mathbf{1}}$ é a duração da primeira unidade.

Em sequência, com a Equação ( 2 ) podemos calcular o número de equipes necessárias para manter a taxa de progresso por atividade, onde é $\boldsymbol{C}_{\boldsymbol{t} \boldsymbol{i}} \mathrm{o}$ número 
teórico de equipes a serem utilizadas para a atividade i e $\boldsymbol{d}_{\boldsymbol{i}}$ é a sua duração unitária. Como por questões práticas o número de equipes deve ser um número inteiro, é obtido o número inteiro de equipes $\left(\boldsymbol{C}_{\boldsymbol{a} i}\right)$ através da Equação ( 3 ), sendo o menor número inteiro que seja maior ou igual a fração obtida, desde que este seja menor ou igual ao número máximo de equipes disponível para a atividade i $\left(\boldsymbol{N} \boldsymbol{E}_{\boldsymbol{i}_{\max }}\right)$. Logo é calculado também a taxa real de progresso do projeto por atividade $\left(\boldsymbol{R}_{\boldsymbol{a} i}\right)$ através da Equação ( 4 ).

$$
\begin{aligned}
& \frac{(n-1)}{\left(T_{P}-T_{1}\right)} \\
& C_{t i}=d_{i} x R_{T_{i}} \\
& C_{a i}=\left\lceil C_{t i}\right\rceil=\min \{n \in \mathbb{Z} \mid n \geq x\}, \quad C_{a i} \leq N E_{i_{\text {max }}} \\
& R_{a i}=\frac{C_{a i}}{d_{i}}
\end{aligned}
$$

Em seu estudo Ammar (2020) ainda frisa que a Linha de Balanço, como o próprio nome sugere, auxilia no problema de nivelamento dos recursos do projeto, já partindo de uma data desejada estabelecida, porém ela não realizada a alocação desses recursos, sendo necessário a utilização de outras ferramentas, complementando a linha de balanço que proporcionem a realização desta atividade.

\subsection{Modelagem e Simulação}

As técnicas de modelagem e simulação foram desenvolvidas principalmente nos anos 50 como uma ferramenta de apoio para análises, desenvolvimento e melhoria de processos em empresas de grande porte (GOLDSMAN; NANCE; WILSON, 2010), e com a evolução tecnológica, de softwares e hardwares e bem como ampliação de acesso a esses, o uso de simulação se tornou cada vez mais ampliado para diversos segmentos empresariais com aplicação em processos e projetos.

Em seu estudo os autores Goienetxea Uriarte, Ng e Urenda Moris (2020) realizaram uma revisão sistemática da literatura para os assuntos "Simulation" e 
“Lean”, e após uma mineração textual dos termos dos trabalhos identificaram a aplicação de Simulação na área de manufatura, como esperado, mas também em outras áreas como Educação, Saúde e Construção Civil.

Mesmo com a simulação já sendo aplicada na manufatura desde a década de 50/60, apenas na década de 1980 que a simulação começou a ganhar força no ambiente de projetos, com os primeiros modelos específicos para esse fim. Desde a década de 1990 até os dias atuais, muitos trabalhos vêm sendo publicados aplicando a abordagem de simulação na gestão de projetos. A maioria desses estudos tem por objetivo entender e antecipar os motivos que levam a falha de projetos e a extrapolação de custo nos mesmos (GOROD et al., 2019).

Segundo Gorod et al. (2019) as primeiras aplicações de simulação em gerenciamento de projetos, advém da Modelagem de Sistemas Dinâmicos (SDM), introduzindo fluxos de trabalho do projeto e buscando entender o descolamento entre o progresso percebido e o real. Na sequência foram incluídos conceitos como retrabalho, progresso percebido, produtividade real e outros fatores que poderiam influenciar o andamento de projetos complexos.

As ferramentas tradicionais de gerenciamento de projetos, como aquelas baseadas no CPM, retratam o projeto como uma rede de atividades $\mathrm{e}$ acontecimentos discretos e o tempo total do projeto como a soma desses eventos planejados. Porém especialmente em horizontes de prazo maiores e/ou em projetos com grande intervenção humana essa interpretação de sequência de atividades pode não retratar a realizada do projeto, dado que este é um processo interativo de realização e não apenas uma sequência de atividades (GOROD et al., 2019).

O primeiro passo para desenvolver a simulação de um processo é a modelagem do mesmo. Existem vários tipos de modelos como: modelos mentais; de caixas e flechas, para reproduzir processos; organogramas empresariais; modelos físicos, muito utilizados na indústria de construção civil; fórmulas, planilhas e modelos de simulação computacional, como ilustrado na Figura 5. 


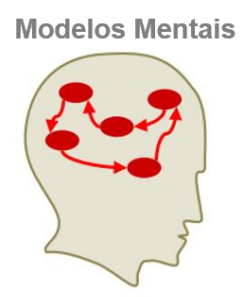

Fórmulas

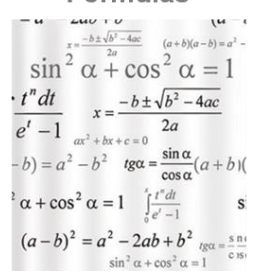

Modelos Físicos

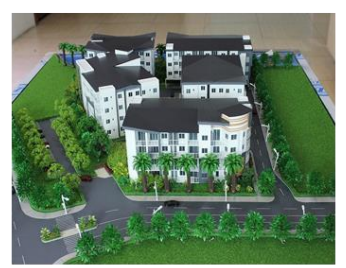

Planilhas

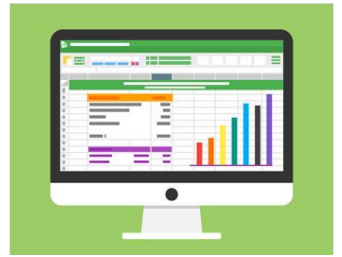

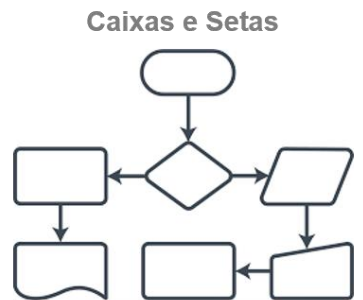

Modelos de simulação

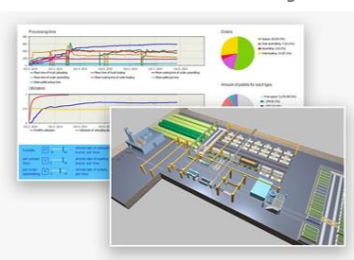

Figura 5 - Tipos de modelos. Adaptado de Borshchev (2013).

Apesar da modelagem ser amplamente utilizada, no ambiente empresarial é mais comum existirem modelos analíticos aos de simulação, porém Borshchev (2013) frisa que existem diferenças significativas entre eles. No modelo analítico, as entradas e saídas analisadas são conectadas por fórmulas e processos preestabelecidos pelo usuário, e já na modelagem de simulação existem outras possíveis condições que não são atendidas no ambiente analítico, como comportamento não linear, memória de informações ao rodar cenários, influências entre variáveis que não sejam intuitivas, dependências de tempo e causais, e também a incerteza de grande parte dos parâmetros.

Os modelos de simulação computacional podem variar desde modelos com um baixo nível de abstração (grande quantidade de detalhes, nível micro e operacional) onde se aplicam simulação envolvendo sistemas de controle, movimentação de pedestres, comportamento de objetos individuais e etc, a modelos com médio nível de abstração (nível tático) que se aplica a modelos de aeroportos, transporte, terminais multimodais, processos empresariais); como até modelos com grande nível de abstração (com uma quantidade mínima de detalhes e no nível estratégico), aplicados normalmente a estudos econômicos, interação em ecossistemas, recursos humanos e outros. Gerenciamento de Projetos se encontra entre os níveis alto e médio de abstração, dependendo do grau das informações e do horizonte de análise (BORSHCHEV, 2013).

A simulação de eventos discretos (DES) é o tipo mais tradicional de simulação, e também a mais utilizada em grandes softwares do ramo. A ideia principal do DES é considerar o sistema como um processo, ou seja, uma sequência 
de operações sendo realizadas entre as entidades e assim simular a interação entre esses processos e seus parâmetros (GOROD et al., 2019).

Já a simulação baseada em agentes (ABS) é um tipo mais recente de simulação que vem gerando interesse da comunidade científica desde 2005. Um agente corresponde a uma entidade autônoma, inserida em um ambiente de simulação e pode ser influenciada por esse ambiente ou por outros agentes e tomar decisões com base em informações e parâmetros adotados. Na simulação baseada em agentes, cada agente possui estados em que eles podem se encontrar e também um conjunto de regras básicas e atributos que determinam o seu comportamento. Um agente pode ser uma pessoa, veículos, máquinas, equipes de trabalho, uma organização, basicamente qualquer entidade que possa ser representada pelos conceitos acima (LAW et al., 2014).

A modelagem de sistema dinâmicos (SDM) é considerada um tipo de modelagem contínua, que é definida por Law et al. (2014), como uma forma de simulação que analisa os sistemas em um nível mais agregado, usada comumente para a definição de estratégias e políticas empresariais, de governos ou militares.

Apesar de ser majoritariamente utilizada em ambientes mais estratégicos, a simulação de sistemas dinâmicos também vem sendo fortemente utilizada no gerenciamento de projetos de construção civil, dado que projetos podem ser vistos como um sistema complexo, e a SDM pode ajudar a entender como subsistemas estão interrelacionados e influenciam na obtenção dos objetivos do projeto. Muito estudos tem sugerido o uso de SDM para o planejamento de atividades de projetos, gerenciamento de riscos da construção, e também entender e identificar causas de retrabalhos D(LIU et al., 2019).

Muito utilizada na análise de probabilística de riscos, a Simulação de Monte Carlo consiste em uma técnica de onde os parâmetros propensos a risco são monitorados através de distribuições de probabilidade e a interação entre esses parâmetros de resultados é medida através do uso de variáveis randômicas dentro dos limites e probabilidades estabelecidos, e são rodadas várias interações para a obtenção e análise dos resultados(TOKDEMIR; EROL; DIKMEN, 2019).

O resultado da simulação de Monte Carlo consiste na obtenção de uma distribuição de probabilidades para os valores de resultados estabelecidos, após as iterações. O resultado obtido possibilita o gerente do projeto e/ou tomadores de decisão comparar cenários, estimar metas e marcos do projeto, definir cronogramas 
de atuação comparando os cenários de base do gerenciamento com os resultados aleatórios obtidos e suas probabilidades (TOKDEMIR; EROL; DIKMEN, 2019).

Para a definição do melhor modelo de simulação a ser utilizado é sempre importante levar em consideração o nível de complexidade do projeto bem como o tipo das informações de entrada para o modelo, dessa forma é possível adaptar o modelo a sua necessidade de projeto, podendo adapta-lo no decorrer de seu desenvolvimento.

\subsection{Opinião de Especialistas}

As primeiras aplicações formais da representação da incerteza de julgamentos subjetivos através de probabilidades, para auxiliar na tomada de decisão, remetem as décadas de 1960 e 1970 (O’HAGAN, 2019).

Desde então metodologias e protocolos vem sendo propostos com o objetivo de quantificar e validar informações importantes obtidas para processos e projetos, através da opinião e o julgamento de especialistas, que segundo O’Hagan (2019) são aplicadas na prática de inferência estatística e de tomada de decisão de várias formas.

As técnicas desenvolvidas para tratar o julgamento de especialistas são usadas para quantificar informações que por dificuldades técnicas, alto custo ou ausência de dados históricos, são necessárias informações especializadas para aplicar no planejamento. Em outras aplicações, os julgamentos de especialistas podem ser usados na estimativa de incertezas de parâmetros, ou na probabilidade de ocorrência de eventos (LINDLEY; BEDFORD; COOKE, 2002).

$\mathrm{Na}$ literatura científica, vários termos são usados para designar a informação que é obtida a partir de especialistas com protocolos sugeridos. O’Hagan (2019) usa o termo elicitação de especialistas, e em seu estudo estabelece uma série de práticas que fazem parte de um protocolo para abordar e minimizar os vieses cognitivos aos quais os especialistas são propensos ao fazer julgamentos probabilísticos.

Na mesma linha, Hemming et al. (2018) sugerem a utilização do protocolo IDEA para melhorar a precisão dos julgamentos de especialistas, abrangendo passos-chave, abordando um procedimento Delphi modificado e a aplicação dos 4 passos do IDEA: Investigar, Discutir, Estimar e Agregar. 
Hanea et al. (2018) também indicam a aplicação do protocolo IDEA em seu estudo para julgamento de especialistas estruturado, ressaltando que apesar da utilização desses ser de grande aplicabilidade em estudos diversos, e muito difundido na área de análise de riscos, a uso de ferramentas para lidar com esses julgamentos de forma transparente ainda é relativamente recente.

Hanea et al. (2018) também buscam demonstrar em seu estudo como agregar matematicamente informações de especialistas a partir de suas estimativas individuais, que vai ao encontro da pesquisa realizada também por Charisse Farr et al. (2019), que propõem a utilização de conceitos da estatística bayesiana para a obtenção e tratamento de julgamentos de especialistas e também prevê um protocolo que possibilite a combinação da opinião de vários especialistas utilizando um modelo proposto de erro de medição, obtendo bons resultados em relação a outros modelos existentes de combinação de opiniões.

Independentemente do método aplicado, ou mesmo dos protocolos sugeridos para conduzir a pesquisa, todos os estudos analisados são unanimes ao reconhecer a importância da opinião de especialistas no seu setor - seja ao conduzir pesquisas acadêmicas ou processos empresariais - e também a importância da aplicação de protocolos que visem a diminuição do viés existente da subjetividade da elicitação.

No gerenciamento de projetos a criação de modelos que levam em consideração a incerteza das variáveis de um mundo real, em um ambiente virtual e probabilístico são essenciais para aproximar o planejamento da realidade da execução. A modelagem de dados é uma ferramenta muito poderosa para melhorar a comunicação entre as pessoas nas fases iniciais de planejamento de um projeto, permitindo discussões objetivas, sem deixar de levar em consideração a opinião das pessoas envolvidas, desenvolvendo quantitativamente essas informações através de resultados modelados que possam suportar essa opinião (GOROD et al., 2019).

Ao ser considerada a opinião de especialistas em um dado modelo, conforme é levantado por Vose (2008), deve ser considerado no valor estimado a incerteza da informação obtida através da opinião do especialista se somando a incerteza randômica inerente do processo, devendo ser consideradas ambas na análise do modelo.

Logo, a variabilidade de processos é melhor tratada se incluída em algum tipo de modelo estocástico, integrada às distribuições de incerteza dos parâmetros analisados. Normalmente, na criação de modelos para análise de dados em projetos, 
quando não temos dados suficientes disponíveis para especificar a incerteza de uma variável, opta-se por consultar especialistas que possam oferecer sua opinião sobre essa incerteza (VOSE, 2008), e existem protocolos sugeridos sobre como quantificar essa informação dadas as peculiaridades dos parâmetros.

Szwed (2016) realizou uma pesquisa bibliográfica em aproximadamente 41 artigos sobre elicitação de especialistas e a partir da comparação dos processos definidos para estruturar o julgamento de especialistas em 5 trabalhos principais, esse autor chega a um protocolo de 7 etapas genéricas para o desenvolvimento de um estudo neste ramo, são elas:

1. Defina o problema

2. Planeje a elicitação

3. Selecione os especialistas

4. Treine os especialistas

5. Obtenha os julgamentos

6. Analise e compile os julgamentos

7. Documente e comunique os resultados

Conforme levantando também por Szwed (2016) o protocolo definido acima pode ser comparado com as fases do gerenciamento de projetos definidas pelo Guia PMBOK®, conforme demonstrado na Figura 6.

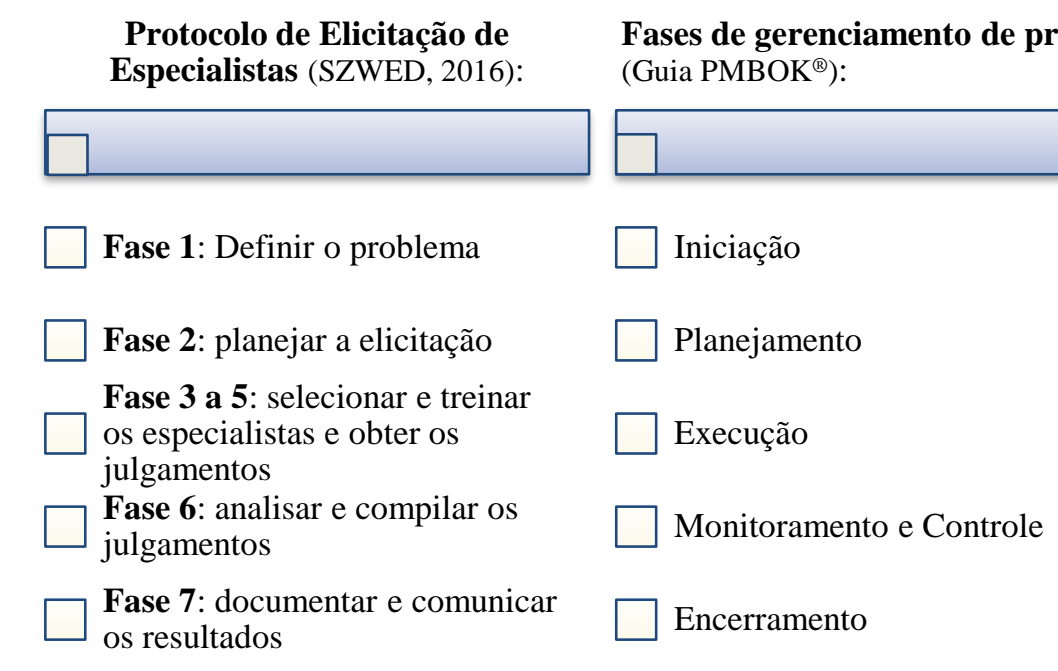

Figura 6 - Comparação entre o protocolo de elicitação de especialistas e as etapas de gerenciamento de projetos. Fonte: Adaptado das informações de Szwed (2016).

Na primeira fase, é muito importante a clara definição do que será elicitado sendo, por exemplo, valores quantitativos ou probabilidades de ocorrência de 
determinados eventos (SZWED, 2016). A partir desta definição, já na Fase 2, o protocolo IDEA prevê duas alternativas de formato de questões, levando em consideração se o valor elicitado será uma quantidade ou uma probabilidade (HEMMING et al., 2018).

Um fator importante que deve ser considerado e tratado ao ser elaborado um protocolo de elicitação de especialista são os vieses existentes a partir das respostas dadas, levando em consideração a forma como as pessoas fazem julgamentos (O’HAGAN, 2019).

Ao elaborar a questão o pesquisador deve procurar contornar esses vieses, usando táticas já estabelecidas e estudadas previamente na forma como a questão é estruturada, bem como o procedimento como um todo é conduzido.

\subsubsection{Elicitando a distribuição Beta}

O uso de métodos bayesianos para a análise de dados e a obtenção de resultados a partir de informações de um processo vem crescendo muito em uso nas mais diversas áreas de aplicação desde a psicologia (ANDREWS; BAGULEY, 2013), no desenvolvimento e análise de ensaios clínicos (AZZOLINA et al., 2021), ao gerenciamento de projetos na obtenção de elicitações para construção de cronogramas e orçamento (FIROUZI; KHAYYATI, 2020; KHAMOOSHI; ABDI, 2017; KIM; REINSCHMIDT, 2009; REZAKHANI, 2020).

O método parte do uso de informações iniciais, que conforme levantado por Kim \& Reinschmidt (2009), podem ser obtidas através de estimativas randômicas para uma elicitação a priori, mas apenas quando essa informação não é relevante para a performance do processo atual. No caso do planejamento de um projeto em fase de concepção, sabe-se que o resultado da informação é importante para o processo de planejamento de recursos, logo é sugerido o uso da elicitação de especialista, conforme sugerido por Kim \& Reinschmidt (2009) em seu modelo com o uso da distribuição Beta, utilizando a elicitação de uma distribuição PERT, definindo um cenário otimista, mais provável e pessimista, na sequência para obtenção dos parâmetros da Beta para aplicação do modelo.

Um método sugerido por O’Hagan (1998) em seu trabalho consiste na obtenção de estimativas para os limites superior (U), inferior (L) e da moda (M) ou valor mais provável - através da elicitação dos especialistas. 
$\mathrm{Na}$ sequência são obtidas 5 probabilidades também indicadas pelos especialistas, sendo elas as probabilidades de um valor não conhecido $\mathrm{X}$ se encontrar entre os seguintes intervalos:

$$
\begin{aligned}
& \rho_{1}=\mathrm{P}(L<X<M) \\
& \rho_{2}=\mathrm{P}\left(L<X<\frac{L+M}{2}\right) \\
& \rho_{3}=\mathrm{P}\left(\frac{M+U}{2}<X<U\right) \\
& \rho_{4}=\mathrm{P}\left(L<X<\frac{L+3 M}{4}\right) \\
& \rho_{5}=\mathrm{P}\left(\frac{U+3 M}{4}<X<U\right)
\end{aligned}
$$

As probabilidades devem ser solicitadas ao especialista na ordem apresentada a fim de mitigar o possível vício nos valores estimados, e permitem que o especialista concentre a sua elicitação nos valores do centro da distribuição, evitando que o mesmo elicite pequenas probabilidades onde é maior a chance de erro.

$\mathrm{Na}$ sequência, os valores estimados são transformados em seis probabilidades, conforme abaixo:

$$
\begin{aligned}
& q_{1}=\mathrm{P}\left(L<X<\frac{L+M}{2}\right)=\rho_{2} \\
& q_{2}=\mathrm{P}\left(\frac{L+M}{2}<X<\frac{L+3 M}{4}\right)=\rho_{4}-\rho_{2} \\
& q_{3}=\mathrm{P}\left(\frac{L+3 M}{4}<X<M\right)=\rho_{1}-\rho_{4} \\
& q_{4}=\mathrm{P}\left(M<X<\frac{U+3 M}{4}\right)=1-\rho_{1}-\rho_{5} \\
& q_{5}=\mathrm{P}\left(\frac{U+3 M}{4}<X<\frac{M+U}{2}\right)=\rho_{5}-\rho_{3} \\
& q_{6}=\mathrm{P}\left(\frac{M+U}{2}<X<U\right)=\rho_{3}
\end{aligned}
$$

Durante a elicitação é indicado que as probabilidades obtidas de $q_{1}, \ldots, q_{6}$ sejam apresentadas para os especialistas na forma de um histograma, para que possa ser confirmado por eles se a forma apresentada representa o que eles acreditam. 
Finalizando, O’Hagan (1998) sugere que uma distribuição Beta de limites (L, U), seja obtida a partir da determinação do par de valores $(\alpha, \beta)$ parâmetros da distribuição Beta que minimize a soma de quadrados das diferenças entre as probabilidades obtidas a partir da elicitação $q_{1}, \ldots, q_{6}$ e as probabilidades da distribuição Beta $(\alpha, \beta)$. Na sequência aconselha-se mostrar a distribuição Beta obtida para o especialista e questioná-lo se ela também representa o seu conhecimento acerca da informação elicitada para decidir continuar com a Beta obtida. 


\section{3 \\ Metodologia de pesquisa}

Para a elaboração do presente trabalho, levando em consideração o contexto de sua aplicação, a possibilidade de repercussões da pesquisa no ambiente empresarial aplicado, bem como suas características, foi realizada uma pesquisaação.

Segundo Coughlan e Coghlan (2002), a metodologia chamada Action Research, é uma metodologia participativa, onde a investigação ocorre paralelamente à ação, sendo também uma sequência de ferramentas, eventos e abordagens cientificas usadas para solucionar problemas, caracterizada como um estudo longitudinal.

Coughlan e Coghlan (2002) também frisam que a metodologia se trata de uma pesquisa em ação que é diferente de realizar pesquisa sobre ações, que seria a aplicação de estudo de caso.

De acordo com Willis (2014), a pesquisa-ação pode ser classifica em 15 diferentes tipos, sendo organizadas nos grupos por nível, propósito e processo. Levando em consideração as categorias sugeridas por Willis (2014), o presente trabalho se clássica por nível como uma pesquisa-ação organizacional, e por propósito a resolução de um problema do mundo real.

A pesquisa-ação se aplica em casos onde o objetivo é compreender como é possível mudar ou melhorar o funcionamento de alguns aspectos de um sistema, e compreender o processo de mudança e as melhorias para aprender com o mesmo (COUGHLAN; COGHLAN, 2002).

Como o projeto onde o estudo foi aplicado está em fase de concepção e planejamento para iniciar as atividades no próximo ano, permite à pesquisa influenciar diretamente nas metodologias aplicadas ao projeto, e consequente exercer ação sobre o seu gerenciamento.

Como parte integrante também do estudo foi também desenvolvido um protocolo para tratar opiniões de especialistas, seguindo o protocolo IDEA (Investigar, Discutir, Estimar e Agregar), sugerido por Hemming et al. (2018) em 
seu estudo, e uma adaptação do protocolo sugerido por O’Hagan (1998), integrado às etapas de elicitação definidas por Szwed (2016).

Posteriormente a produtividade e tempos estimados foram aplicados com a simulação do cronograma do projeto para um trecho de atuação de cerca de $95 \mathrm{~km}$ de extensão e 28 ativos ferroviários. Foi utilizada a Simulação de Monte Carlo com o uso do software @Risk@ através do modelo desenvolvido de sequenciamento das atividades, com base nos tempos e produtividades elicitadas. 


\section{4 \\ Resultados e discussões}

\subsection{Estrutura de atividades do projeto}

O projeto de renovação de via, também chamado internamente na empresa de Projeto de Grandes Intervenções de Via (GIV), pode ser dividido em duas etapas de forma macro: o desguarnecimento e a renovação.

O projeto também possui características e recursos definidos, conforme o seu local de atuação, sendo dividido em dois grupos de locais: linha, AMV ou locais confinados.

Um AMV (Aparelho de Mudança de Via), consiste em uma região da linha onde é realizada a troca entre a linha principais e as secundárias ou vice-versa, através da máquina de chave e demais componentes do AMV é possível estabelecer em qual linha o trem irá continuar o seu trajeto a partir daquele ponto. Já os locais confinados são aqueles onde não existe espaço suficiente para os equipamentos que trabalham na linha executarem as suas atividades, sendo necessários equipamentos especiais para trabalhar nesses locais assim como nos AMVs. São eles túneis, viadutos ou mesmo cortes da via onde os taludes ou mesmo outras interferências com a comunidade como casas e instalações são muito próximos da via, não oferecendo espaço ideal para os equipamentos que trabalham na linha executarem as suas atividades.

Desta forma, em um grupo macro de atividades o projeto se divide em quatro grandes áreas: desguarnecimento de linha, renovação de linha, desguarnecimento de AMV e locais confinados e renovação de AMV e locais confinados.

As atividades ligadas à frente de desguarnecimento de linha consistem em peneiramento do lastro retirando todos os finos provenientes de sua degradação, finos provenientes da degradação da plataforma ferroviária e finos provenientes de minério advindos do volume transportado ao longo dos anos e subsequente restabelecimento da curva granulométrica de um lastro padrão juntamente com perfil de projeto. Estas atividades deverão ser realizadas por desguarnecedora total 
de linha de alta produção juntamente com descarga de lastro/brita (conforme necessidade), realizada por uma frota de descarga composta por locomotiva e vagões próprios para o fim e a correção geométrica, que é realizada por uma dupla de equipamentos chamado de socadora e reguladora e tem a função de reestabelecer o alinhamento e nivelamento da linha ferroviária.

A frente de renovação de linha consiste na realização da atividade de substituição de dormentes a eito, fixações (que estarão pré-aplicadas no dormente) e trilho por condição. Além da necessidade de renovação dos componentes da linha, esta atividade também se deve por motivo da alteração da matriz de dormente existente, realizando a troca de dormentes de madeira/aço por dormentes de concreto, que possuem um ciclo de vida maior, sendo assim mais vantajosos financeiramente. Estas atividades deverão ser realizadas por renovadora de linha de alta produção juntamente com descarga de brita (conforme necessidade) e correção geométrica, utilizando para as duas últimas atividades os mesmos recursos mencionados no desguarnecimento de linha.

Para a frente de AMV e locais confinados, os processos são semelhantes, porém os recursos são diferentes. Para o desguarnecimento não será realizado o peneiramento do lastro sendo necessário a reposição de sua totalidade conforme curva granulométrica padrão juntamente com perfil de lastro de projeto. Essas atividades serão realizadas por uma desguarnecedora à vácuo, que tem capacidade de sugar o lastro em locais confinado, e na sequência a descarga de lastro e correção geométrica, com uma dupla de socadora e reguladora própria para esse fim.

Por fim, a renovação de AMV na troca de dormentes especiais a eito, fixações, trilhos e peças/componentes do AMV. Essa atividade deverá ser realizada por equipes de produção, com apoio de guindaste rodoferroviário, e na sequência a descarga de brita e correção geométrica também devem acontecer.

A Figura 7 demonstra a Estrutura Analítica do Projeto (EAP) para os primeiros níveis da mesma, sendo possível analisar as diferentes atividades que compõem as frentes de desguarnecimento e renovação. 


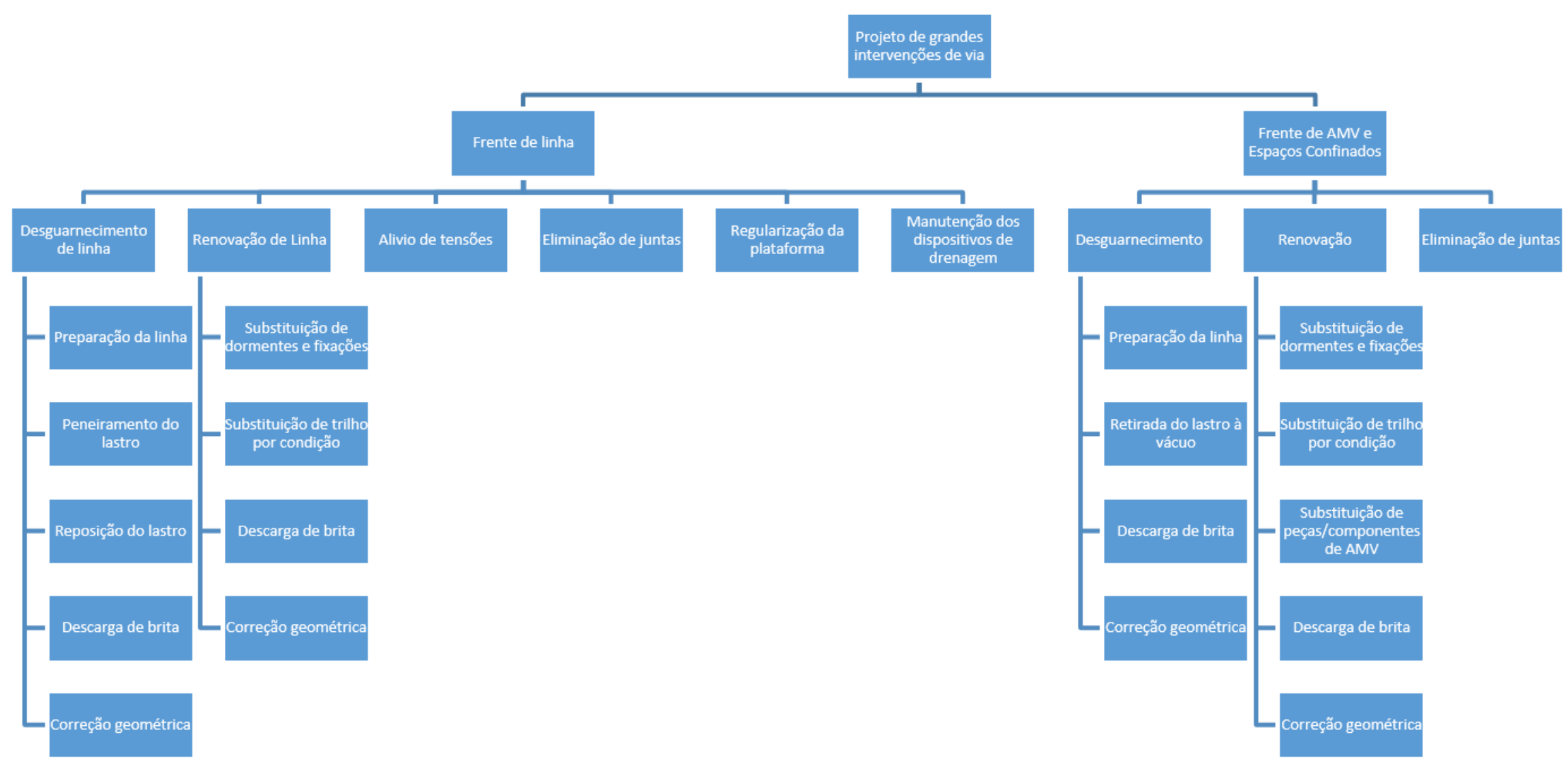

Figura 7 - EAP do Projeto de Grandes intervenções de via. 
O diagrama unitário demonstrado na Figura 8, conforme sugerido na metodologia LOB, demonstra as relações de interdependência para cada unidade de produção (quilômetros) das principais atividades da frente de linha, considerando que as frentes de desguarnecimento e renovação de linha e de AMV possuem recursos cativos e podem acontecer paralelamente, não existindo interdependência entre as mesmas.

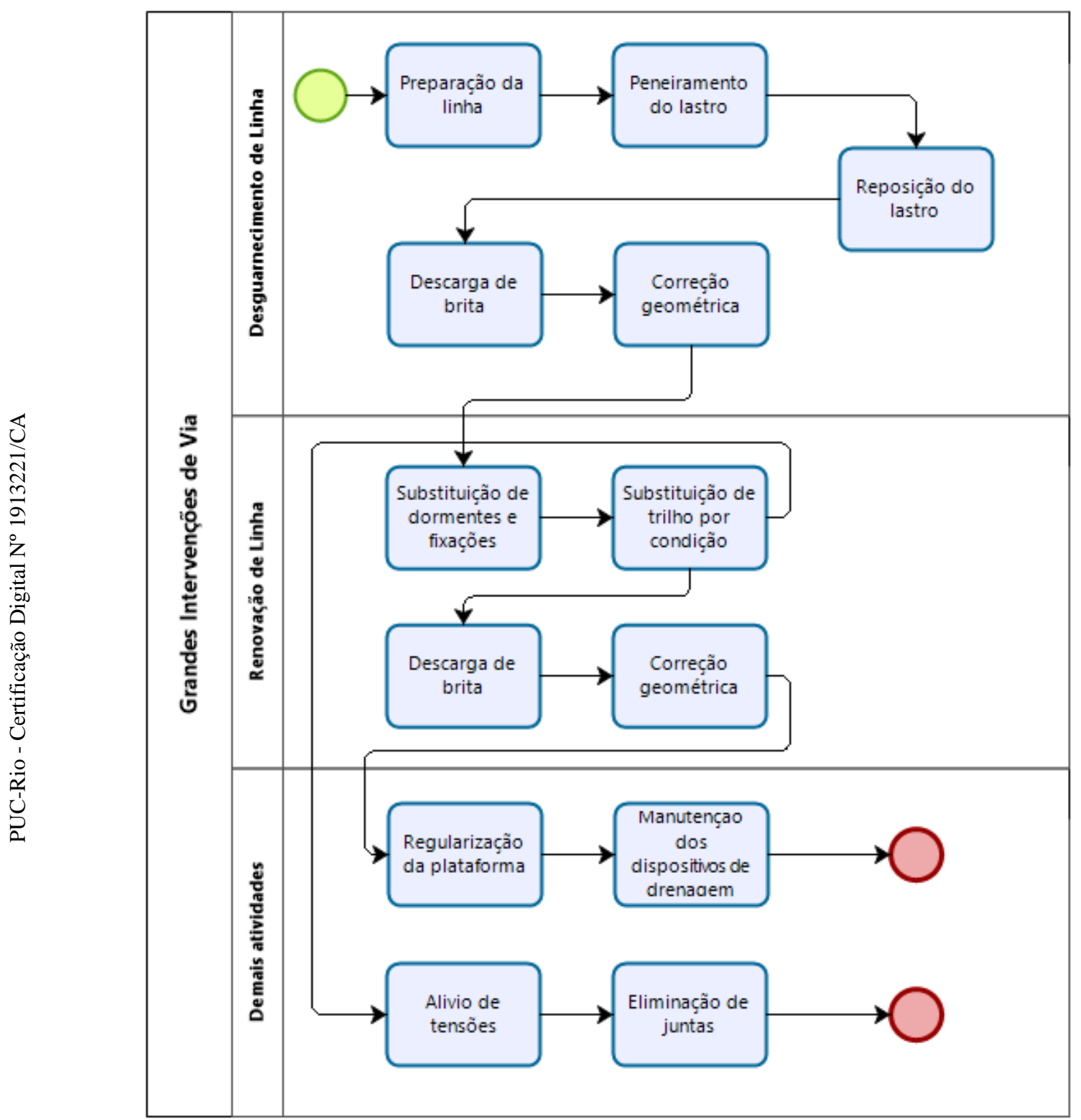

Figura 8 - Diagrama unitário para as atividades da frente de renovação de linha.

As relações de interdependências são conforme demonstradas na Figura 8, com destaque para as atividades de alívio de tensões e eliminação de juntas que já podem acontecer normalmente após a substituição de trilho por condição e a manutenção dos dispositivos de drenagem que não dependem das demais 
atividades, acontece normalmente paralelamente às demais com finalização após a realização de todas as outras.

A linha de balanço e a simulação serão realizadas a partir das atividades acima mencionadas, utilizando-se das informações de produtividade e disponibilidade dos recursos e fatores que influenciam no andamento do projeto.

\subsection{Recursos e dados do projeto}

A Figura 9 demonstra um diagrama com os principais recursos do projeto, levando em consideração principalmente aqueles que serão modelados e informações monitoradas para a simulação das atividades.
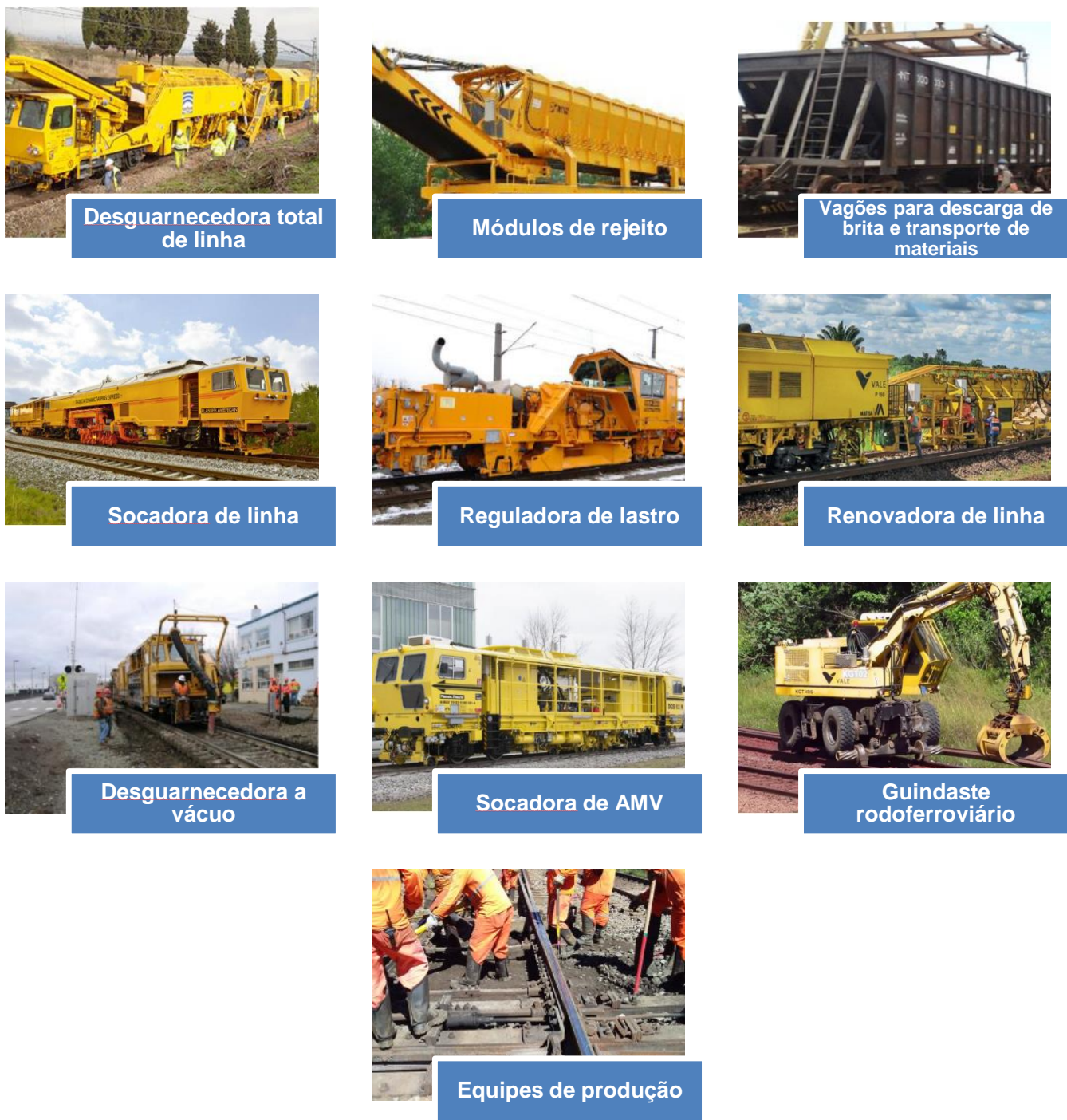

Figura 9 - Recursos do projeto. 


\begin{tabular}{|c|c|c|}
\hline Recursos & Atividades & Dados \\
\hline $\begin{array}{l}\text { Desguarnecedora } \\
\text { total de linha }\end{array}$ & $\begin{array}{l}\text { Peneiramento do } \\
\text { lastro; } \\
\text { Reposição do lastro }\end{array}$ & $\begin{array}{l}\text { Taxa de produção nominal; } \\
\text { Disponibilidade do equipamento; } \\
\text { Taxa projetada de quebra de máquina; } \\
\text { Fatores externo de influência na } \\
\text { atividade: } \\
\text { Previsão climática; } \\
\text { Características do trecho; }\end{array}$ \\
\hline Módulos de rejeito & $\begin{array}{l}\text { Armazenamento de } \\
\text { rejeito }\end{array}$ & $\begin{array}{l}\text { Velocidade das esteiras; } \\
\text { Capacidade de armazenamento; } \\
\text { Taxa de carga e descarga; } \\
\text { Disponibilidade do equipamento; }\end{array}$ \\
\hline $\begin{array}{l}\text { Vagões para } \\
\text { descarga de brita e } \\
\text { transporte de } \\
\text { materiais }\end{array}$ & $\begin{array}{l}\text { Descarga de brita } \\
\text { (Vagão HNT) } \\
\text { Transporte de } \\
\text { materiais (demais } \\
\text { vagões) }\end{array}$ & $\begin{array}{l}\text { Taxa de produção da atividade; } \\
\text { Disponibilidade do equipamento; }\end{array}$ \\
\hline Socadora de linha & Correção geométrica & $\begin{array}{l}\text { Taxa de produção nominal; } \\
\text { Disponibilidade do equipamento; } \\
\text { Taxa projetada de quebra de máquina; }\end{array}$ \\
\hline $\begin{array}{l}\text { Reguladora de } \\
\text { lastro }\end{array}$ & Correção geométrica & $\begin{array}{l}\text { Taxa de produção nominal; } \\
\text { Disponibilidade do equipamento; } \\
\text { Taxa projetada de quebra de máquina; }\end{array}$ \\
\hline $\begin{array}{l}\text { Renovadora de } \\
\text { linha }\end{array}$ & $\begin{array}{l}\text { Substituição de } \\
\text { dormentes e fixações; } \\
\text { Substituição de trilho } \\
\text { por condição }\end{array}$ & $\begin{array}{l}\text { Taxa de produção nominal por } \\
\text { atividade; } \\
\text { Disponibilidade do equipamento; } \\
\text { Taxa projetada de quebra de máquina; }\end{array}$ \\
\hline $\begin{array}{l}\text { Desguarnecedora a } \\
\text { vácuo }\end{array}$ & $\begin{array}{l}\text { Retirada do lastro à } \\
\text { vácuo }\end{array}$ & $\begin{array}{l}\text { Taxa de produção nominal; } \\
\text { Disponibilidade do equipamento; } \\
\text { Taxa projetada de quebra de máquina; }\end{array}$ \\
\hline Socadora de AMV & Correção geométrica & $\begin{array}{l}\text { Taxa de produção nominal; } \\
\text { Disponibilidade do equipamento; } \\
\text { Taxa projetada de quebra de máquina; }\end{array}$ \\
\hline $\begin{array}{l}\text { Guindaste } \\
\text { rodoferroviário }\end{array}$ & $\begin{array}{l}\text { Substituição de } \\
\text { dormentes e fixações, } \\
\text { trilho e peças em } \\
\text { AMVs ou espaços } \\
\text { confinados }\end{array}$ & $\begin{array}{l}\text { Taxa de produção nominal; } \\
\text { Disponibilidade do equipamento; } \\
\text { Taxa projetada de quebra de máquina; }\end{array}$ \\
\hline $\begin{array}{l}\text { Equipes de } \\
\text { produção }\end{array}$ & $\begin{array}{l}\text { Atividades de apoio } \\
\text { aos equipamentos; } \\
\text { Alivio de tensões; } \\
\text { Eliminação de juntas; } \\
\text { Regularização da } \\
\text { plataforma; } \\
\text { Manutenção dos } \\
\text { dispositivos de } \\
\text { drenagem }\end{array}$ & $\begin{array}{l}\text { Taxa de produção das equipes; } \\
\text { Fatores externos que influenciam na } \\
\text { produtividade das equipes; }\end{array}$ \\
\hline
\end{tabular}

Tabela 1 - Relação entre os recursos, atividades e dados do projeto.

A Tabela 1 faz uma relação entre os recursos, as atividades do projeto (mencionadas na Figura 7) que são executadas por esses recursos e também os 
dados utilizados de cada um para a construção do modelo de simulação. Na tabela são sinalizados também dados que são fatores externos de influência do andamento do projeto, que não são inerentes aos equipamentos, porém influenciam na sua execução.

\subsection{Aplicação da Elicitação de Especialistas}

As informações obtidas através da pesquisa bibliográfica foram aplicadas a um projeto de desguarnecimento e renovação de linha em uma empresa ferroviária. Um projeto como esse prevê a troca do lastro ferroviário, que corresponde a brita que dá suporte para os trilhos e dormentes - vigas de madeira, concreto ou aço normalmente que sustentam os trilhos. A partir do peneiramento e substituição desse lastro é realizada na sequência também a renovação dos componentes anteriormente citados, como dormentes, trilho e toda a fixação.

Todo o processo é quase inteiramente mecanizado com equipamentos ferroviários específicos para cada atividade, existindo uma sequência estabelecida para atuação de cada equipamento considerando o avanço do projeto em quilômetros ferroviários, muito semelhante a projetos de origem repetitiva como construção ou revitalização de estradas, gasodutos e outros.

Para aplicação do estudo foram seguidas as fases sugeridas por Szwed (2016) e apresentadas no referencial teórico do presente trabalho, estabelecendo as atividades e parâmetros estimados e preparando os especialistas para obter a opinião dos mesmos evitando possíveis viés ou vícios intrínsecos ao processo de elicitação, garantindo o entendimento e participação direta do especialista no processo.

\subsubsection{Escolha das atividades e parâmetros a serem elicitadas}

Na Fase 1 foi definido que o foco da aplicação da elicitação de especialistas seria obedecendo dois critérios na seguinte ordem: (i) processos que não possuem produtividade muito clara e influenciada por fatores difíceis de serem quantificados de forma independente, sendo necessário o uso da experiência de especialistas ligados àquelas atividades; e também (ii) processos críticos para o andamento do projeto por serem considerados caminho crítico do mesmo em seu cronograma, ou gargalos de grande impacto nas demais atividades planejadas. 
Desta forma foram definidos dois processos para serem elicitados, conforme Tabela 2.

\begin{tabular}{|c|c|c|}
\hline Valor a ser elicitado & $\begin{array}{c}\text { Atividade ligada } \\
\text { ao processo }\end{array}$ & Justificativa \\
\hline $\begin{array}{c}\text { Produtividade da atividade } \\
\text { de desguarnecimento de } \\
\text { linha levando em } \\
\text { consideração a sazonalidade } \\
\text { das chuvas na região } \\
\text { (km/dia) }\end{array}$ & $\begin{array}{c}\text { Desguarnecimento } \\
\text { de linha }\end{array}$ & $\begin{array}{l}\text { Processo crítico por ser } \\
\text { o carro chefe que "abre } \\
\text { frente" de trabalho para } \\
\text { os demais processos e } \\
\text { por sofrer grande } \\
\text { influência de chuvas. }\end{array}$ \\
\hline $\begin{array}{c}\text { Tempos de Setup dos } \\
\text { equipamentos da frente de } \\
\text { Desguarnecimento de Linha }\end{array}$ & $\begin{array}{c}\text { Desguarnecimento } \\
\text { de linha e } \\
\text { Renovação de } \\
\text { Linha }\end{array}$ & $\begin{array}{l}\text { Processo crítico e } \\
\text { tempos incertos que } \\
\text { podem impactar } \\
\text { diretamente na } \\
\text { produtividade do } \\
\text { equipamento. }\end{array}$ \\
\hline
\end{tabular}

Tabela 2 - Processos a serem elicitados

\subsubsection{Definição das perguntas e perfil do especialista}

Na Fase 2 de Planejamento da elicitação foi definido que as perguntas seriam formuladas usando o procedimento sugerido por O'Hagan (1998) para obter os valores da produtividade da atividade de desguarnecimento de linha, na unidade de medida de metros por hora $(\mathrm{m} / \mathrm{h})$. Essa atividade foi escolhida considerando o impacto nas demais etapas do projeto, e por sua produtividade variar bastante dependendo de fatores internos, como quebra de máquina, qualidade do lastro no local, e também externos como chuva ou interferências com comunidades, fatores esses que muitas vezes são conhecidos, mas difíceis de quantificar.

O método desenvolvido por O'Hagan (1998) foi confirmado por Moala e Penha (2016) como o melhor método a ser aplicado, se comparado com outros três estudados, onde O'Hagan (1998) possui um desempenho superior quando a imprecisão do especialista aumenta, e se mostrou um método robusto para garantir a elicitação da distribuição de probabilidade, dado que 5 probabilidades são 
levantadas a partir da obtenção do maior valor, valor mais provável e do menor valor fornecido pelo especialista.

Devido ao estágio de concepção e planejamento que o projeto se encontra, foi possível realizar a elicitação apenas com um especialista, que possuiu experiência prévia na atividade e que fornece todas as informações técnicas para o planejamento de longo e médio prazo do projeto, levando em consideração informações de processos similares agregado ao seu conhecimento do trecho ferroviário onde o projeto será aplicado.

Para esse estudo foi selecionado um especialista com mais de 15 anos de experiência no setor de manutenção ferroviária e em projetos semelhantes a esse, conhecendo na prática a execução da atividade em questão.

O uso da opinião de apenas um especialista procura ser contornado com a técnica sugerida por Szwed (2016), com o uso de um brainstorming com a presença do líder do projeto, coordenador de planejamento, e dois outros especialistas com conhecimento de atividades de manutenção ferroviária, não necessariamente do mesmo processo, para que possam a partir das informações fornecidas pelo especialista principal, contribuírem com ajustes nas probabilidades de ocorrência dos tempos relativos às atividades de setup de máquina, com o objetivo de minimizar o viés de julgamento de apenas uma pessoa para as atividades elicitadas.

Durante a reunião realizada com eles de forma online e com a presença de todos foi chegado em um consenso de qual seriam as probabilidades que melhor representassem as variações nos tempos de setup, a partir das informações usadas para o planejamento do projeto, e assim geradas melhorias nas informações elicitadas.

Além disso, após a contratação dos operadores de máquinas e supervisões de trecho e o início da execução do projeto em seus primeiros meses, pretende-se agregar mais distribuições Beta elicitadas a partir das informações de outros perfis de especialistas, como o operador da máquina, o responsável pela manutenção da mesma, os fiscais das atividades no trecho, entre outras, usando as técnicas mencionadas por (SZWED, 2016) e Charisse Farr et al. (2019) para combinar as elicitações desses profissionais e agregar ao planejamento mais informações com a atualização das distribuições Beta. 


\subsubsection{Elicitação e obtenção das distribuições Beta}

A distribuição beta foi a escolhida para representar os dados estimados, dado a sua vasta aplicação em gestão de projetos e a capacidade de representação das informações elicitadas. As suas características e propriedades como distribuição de probabilidade são apresentadas no APÊNDICE 1 - Distribuição Beta.

A metodologia para obtenção de informações elicitadas foi aplicada para a obtenção da produtividade da atividade de desguarnecimento de linha através das informações obtidas em reunião com um especialista que conhece a fundo os detalhes da atividade no dia-a-dia e os fatores internos e externos que levam a variação da sua produtividade.

Depois de devidamente esclarecido sobre as fases e treinado para obter as elicitações, o especialista iniciou definindo os limites inferior (L), superior (U) e o valor mais provável, a moda (M). Na sequência foi solicitado ao mesmo que definisse os valores para as probabilidades $\rho_{1}$ a $\rho_{5}$ definidas a partir dos limites e moda informados, conforme abaixo:

$$
\begin{aligned}
& L=50 \\
& U=160 \\
& M=100 \\
& \rho_{1}=\mathrm{P}(L<X<M)=\mathrm{P}(50<X<100)=0,40 \\
& \rho_{2}=\mathrm{P}\left(L<X<\frac{L+M}{2}\right)=\mathrm{P}(50<X<75)=0,05 \\
& \rho_{3}=\mathrm{P}\left(\frac{M+U}{2}<X<U\right)=\mathrm{P}(130<X<160)=0,05 \\
& \rho_{4}=\mathrm{P}\left(L<X<\frac{L+3 M}{4}\right)=\mathrm{P}(50<X<87,5)=0,1 \\
& \rho_{5}=\mathrm{P}\left(\frac{U+3 M}{4}<X<U\right)=\mathrm{P}(115<X<160)=0,2
\end{aligned}
$$

A partir dos valores estimados, foram calculadas as probabilidades $q_{1}$ a $q_{6}$, que representam as subdivisões da distribuição de probabilidade elicitada, desde o valor inferior informado ao valor superior, conforme demonstrado nas formulas 24 a 29. 


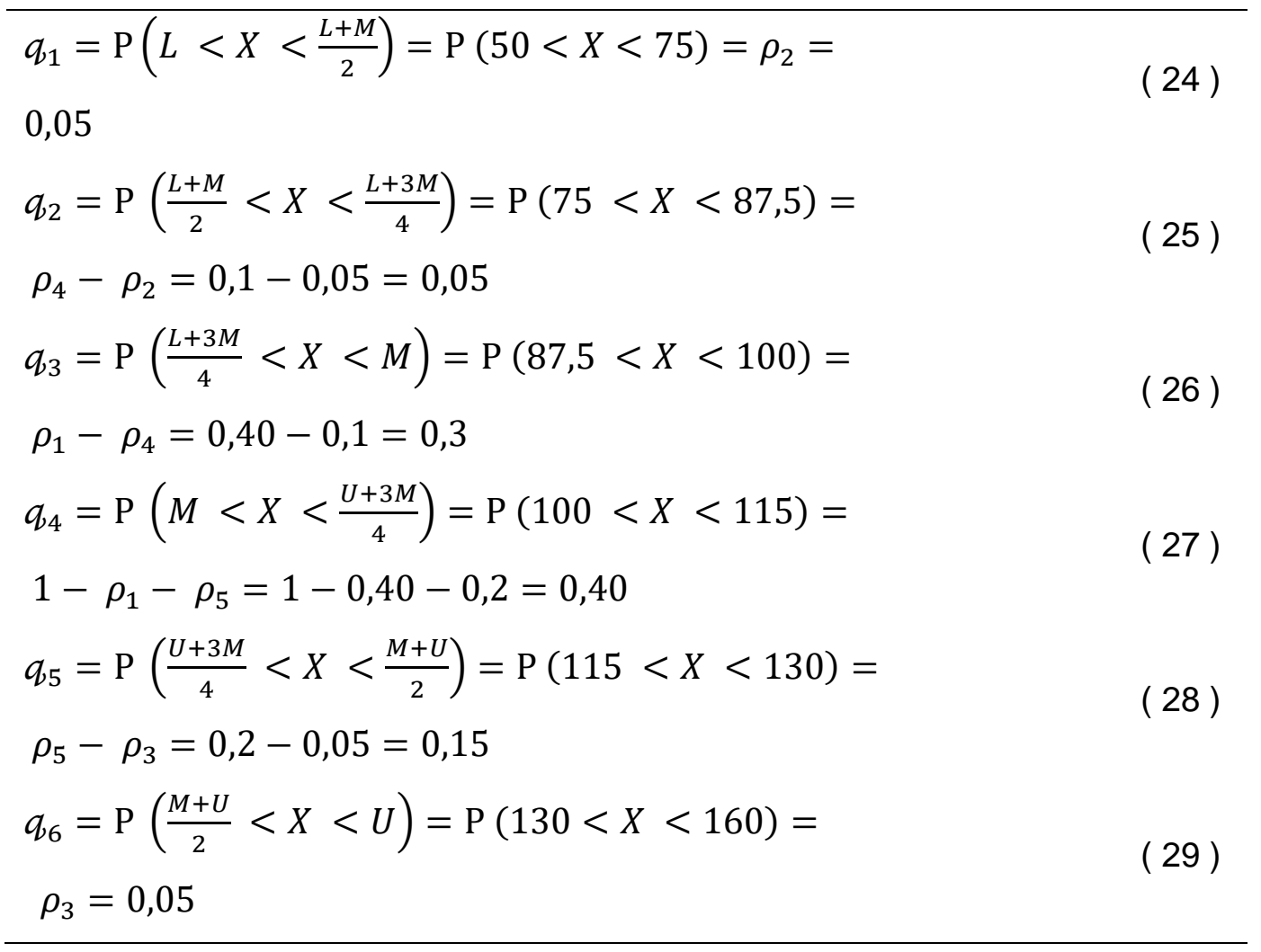

Com os valores de $q_{1}$ a $q_{6}$ foi possível construir o histograma das probabilidades obtidas na elicitação conforme demonstrado na Figura 10.

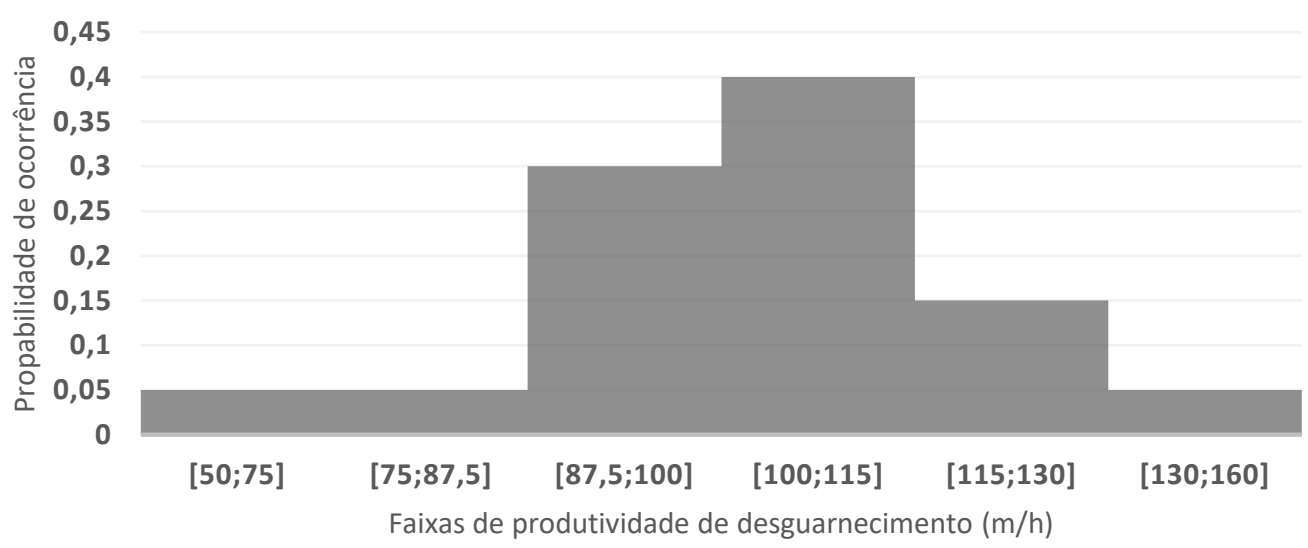

Figura 10 - Histograma de produtividade elicitada da atividade de desguarnecimento de linha. Fonte: Autores (2021).

Após definido o histograma das probabilidades, o próximo passo foi a obtenção dos parâmetros $\alpha$ e $\beta$ da distribuição Beta que melhor represente as probabilidades elicitadas, através da minimização do erro quadrático entre as 
probabilidades acima e as probabilidades da Beta obtidas para os mesmos pontos, método proposto por Moala e Penha (2016) em seu estudo.

Para a minimização do erro quadrático foi implementado um modelo de otimização conforme demonstrado matematicamente abaixo:

$$
\text { MIN FO }=\sum_{i}^{6}\left(q_{i}-f\left(x_{i} ; \alpha, \beta\right)\right)^{2}
$$

Sujeito a:

$\alpha \geq 1$

$\beta \geq 1$

Sendo:

$q_{i}$ as probabilidades obtidas a partir dos valores $\rho_{i}$ elicitados;

$f\left(x_{i} ; \alpha, \beta\right)$ a função de densidade de probabilidade (PDF) da distribuição Beta para uma variável qualquer $x$ demostrada por Kim e Reinschmidt (2009) e melhor detalhada no APÊNDICE 1 - Distribuição Beta.

O problema de otimização acima foi resolvido através do método não linear Gradiente Reduzido Generalizado (GRG) (ABADIE, 1969) e obtidos os valores de $\alpha$ e $\beta$ para a distribuição que melhor atendesse as condições impostas. De acordo com Köksoy e Yalcinoz (2006) este é um método muito utilizado para a otimização de problemas com múltiplas respostas por aproximação e pelo mesmo ser disponibilizado no pacote Solver do software Microsoft Excel®.

Para contornar a limitação levantada por Köksoy e Yalcinoz (2006) de que a estimativa inicial do parâmetro seja próxima ao valor obtido para acontecer a convergência para o ponto ótimo, no modelo matemático foi definido que $\alpha$ e $\beta$ deveriam ser maiores que 1 (um) já levando em considerando o estudo do formato do histograma obtido na Figura 10 e analisados as parâmetros de $\alpha$ e $\beta$ que se aproximavam em forma do histograma obtido anteriormente. Os valores obtidos, arredondados para 2 casas decimais, foram $\alpha=7,75$ e $\beta=8,12$ e a curva de densidade de probabilidade da Beta conforme demonstrado na Figura 11. 


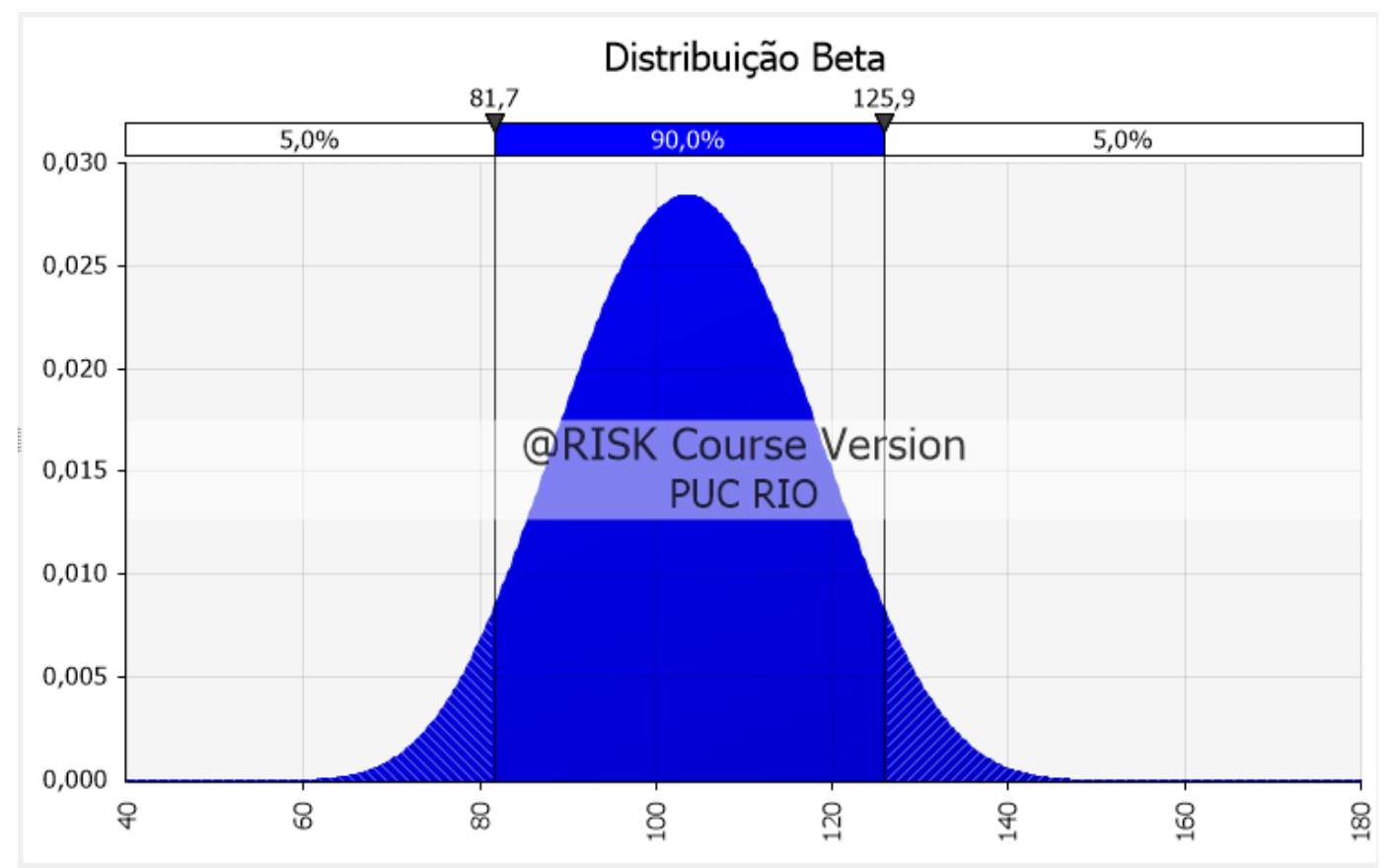

Figura 11 - Curva de distribuição de probabilidade da Beta.

Após definida a curva da Beta foi confirmado com o especialista se a mesma representada a informação elicitada, sendo recomendado executar esse procedimento mostrando a curva, mas também trazendo informações relevantes sobre os resultados da probabilidade, como por exemplo o limite inferior de 5\%, que seria 81,7 metros/hora e o superior de $95 \%$ que corresponde a 125,9 metros/hora, traduzindo a curva em informações do dia-a-dia que são melhor entendidas por ele.

O mesmo procedimento de elicitação foi realizado para os tempos de Setup de máquina, sendo eles: a montagem do equipamento no trecho, que acontece diariamente antes da realização das atividades; a desmontagem do mesmo ao final das atividades antes da circulação para o pátio de desvio; e o tempo de corretiva do equipamento no trecho, podendo esse não ser necessário todos os dias, porém importante a reserva de capacidade no planejamento.

A Tabela 3 demonstra o valor mais provável (M), limite inferior (L) e limite superior (U) para cada uma das atividades elicitadas, bem como as probabilidades $\rho_{1}$ a $\rho_{5}$ obtidas da elicitação e os valores de probabilidade $q_{1}$ a $q_{6}$ calculadas. 


$\begin{array}{ccccc}\text { Atividade } & & \text { Montagem } & \text { Desmontagem } & \text { Corretiva } \\ \text { Valores elicitados } & \mathrm{L} & 0: 15 & 0: 10 & 0: 20 \\ \text { (horas:minutos) } & \mathrm{M} & 0: 45 & 0: 45 & 0: 30 \\ & \mathrm{U} & 1: 30 & 1: 30 & 2: 00 \\ & \rho_{1} & 0,30 & 0,60 & 0,45 \\ \text { Probabilidades } & \rho_{2} & 0,05 & 0,05 & 0,03 \\ \text { elicitadas } & \rho_{3} & 0,10 & 0,01 & 0,02 \\ & \rho_{4} & 0,15 & 0,20 & 0,10 \\ & \rho_{5} & 0,35 & 0,10 & 0,15 \\ & q_{1} & 0,50 & 0,05 & 0,03 \\ & q_{2} & 0,10 & 0,15 & 0,07 \\ \text { Probabilidades } & q_{3} & 0,15 & 0,40 & 0,35 \\ \text { calculadas } & q_{4} & 0,35 & 0,30 & 0,40 \\ & q_{5} & 0,25 & 0,09 & 0,13 \\ & q_{6} & 0,10 & 0,01 & 0,02\end{array}$

Tabela 3 - Valores e probabilidades elicitadas para as atividades de Setup de máquina e as probabilidades obtidas.

A partir das probabilidades $q_{1}$ a $q_{6}$ obtidas para cada uma das atividades, foram construídos os histogramas para cada elicitação e os mesmos apresentados ao especialista para validação se as informações refletiam a sua percepção acerca de cada atividade.

As Figura 12, Figura 13 e Figura 14 representam os histogramas de probabilidade das atividades de Montagem, Desmontagem e Corretiva, respectivamente. 


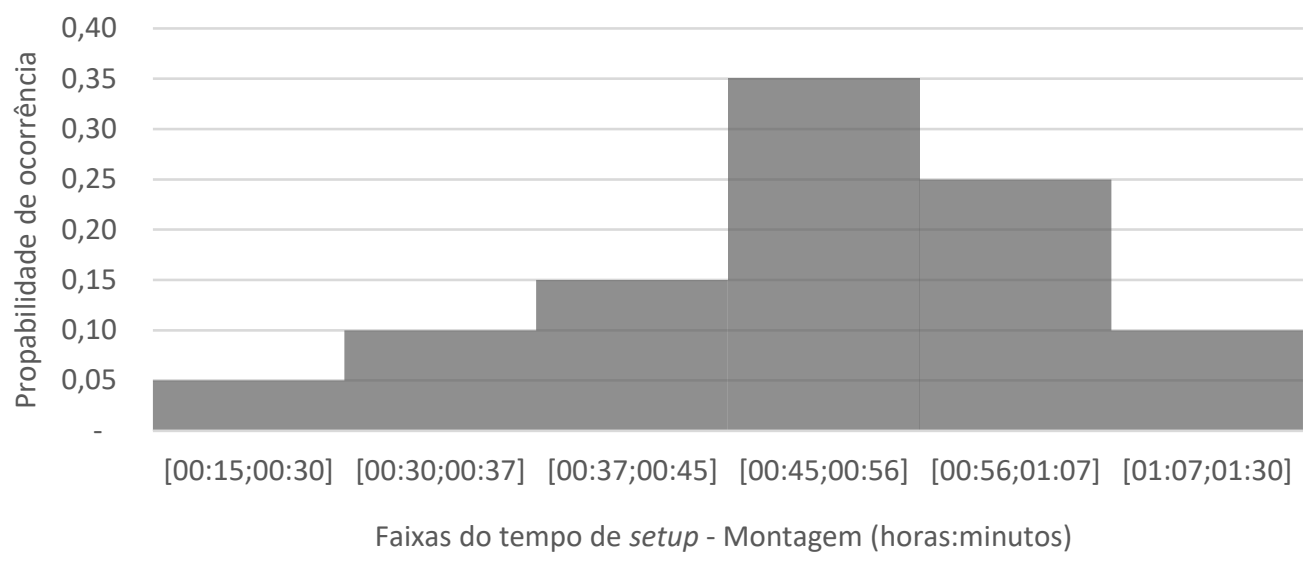

Figura 12 - Histograma do tempo elicitado da atividade de Setup de Montagem.

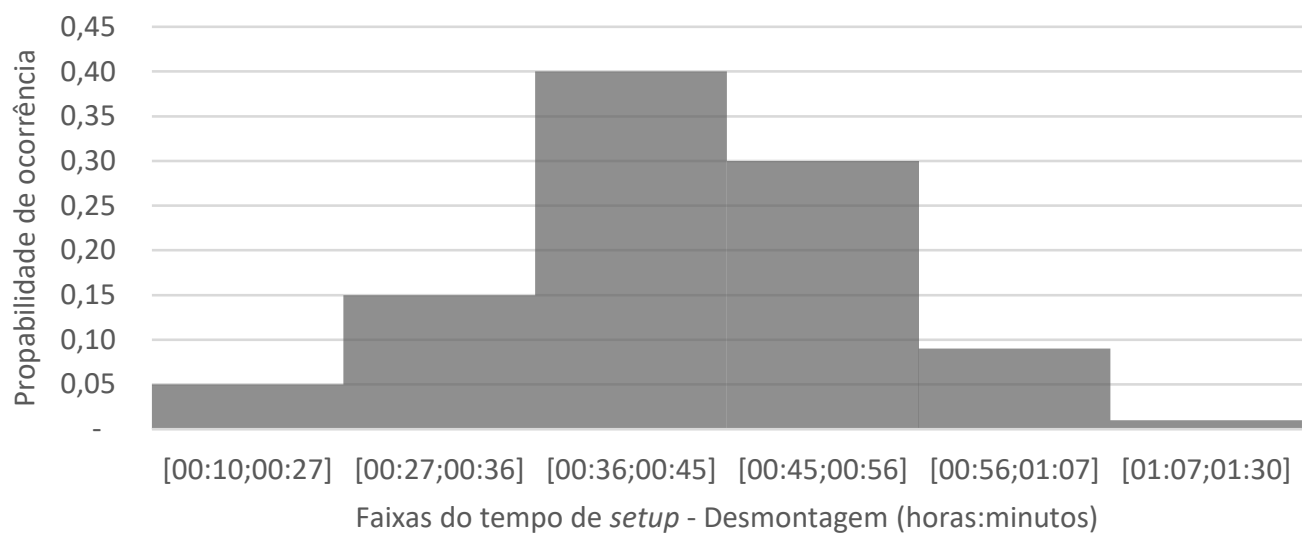

Figura 13 - Histograma do tempo elicitado da atividade de Setup de Desmontagem.

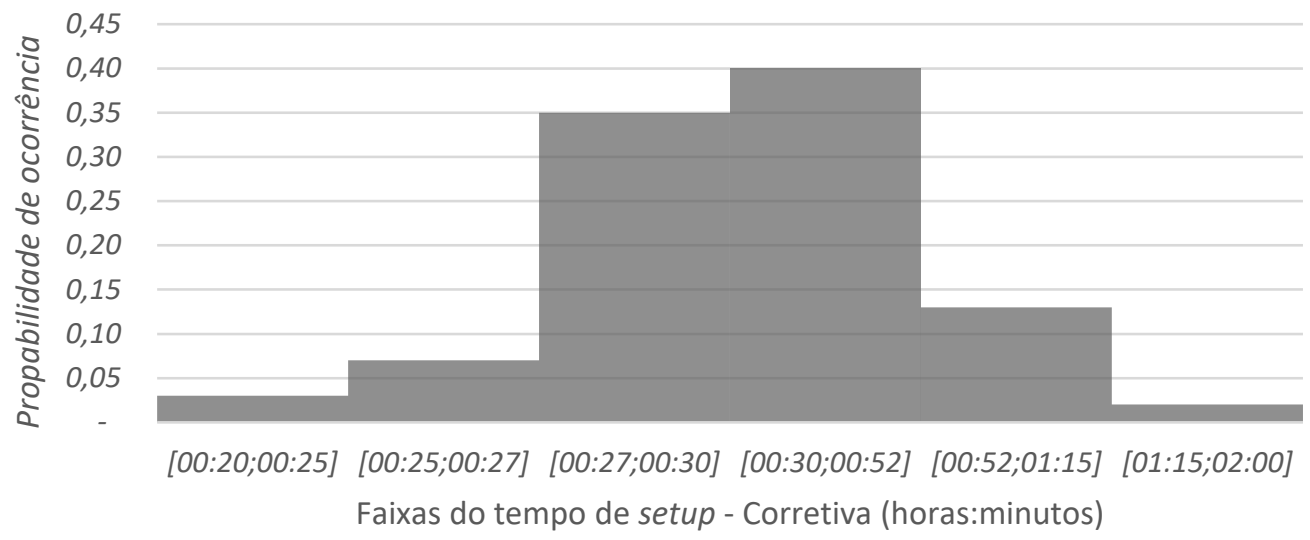

Figura 14 - Histograma do tempo elicitado da atividade de Setup de Corretiva.

É importante mencionar que durante o processo de elicitação ajustes foram feitos por solicitação do especialista nas probabilidades elicitadas para que o histograma melhor refletisse as suas percepções sobre os tempos das atividades. 
As atividades de Montagem e Desmontagem, por exemplo, possuem o mesmo valor mais provável (M) de 45 minutos, porém a atividade de Montagem tem uma massa de probabilidade maior acima do valor mais provável, por necessitar de maior cautela na hora do acoplamento dos engates do equipamento, podendo assim ser uma atividade mais demorada que o previsto durante mais vezes. Já a atividade de Desmontagem, possui uma massa de probabilidade maior para valores menores que o valor mais provável, reflexo este da menor probabilidade de complicações durante o desengate e afastamento dos equipamentos, sendo um processo relativamente mais simples de ser realizado.

Para atividades corretivas, foi definido junto ao especialista que o limite superior seria maior, devido a complicações não esperadas no dia-a-dia que poderia fazer a corretiva ser mais demorada, porém dadas as ações existentes para controle dos equipamentos e as manutenções preventivas semanais, essa não é uma situação esperada com tanta frequência, logo o histograma de probabilidades elicitado para essa atividade possui um limite superior alongado, porém com uma probabilidade baixa de atingir tempos maiores que 1 hora e 15 minutos.

Após o especialista chegar ao consenso final a respeito das probabilidades elicitadas, e o histograma para cada atividade ser aprovado pelo mesmo, é o momento de, assim como foi realizado para a atividade de Desguarnecimento, encontrar os valores de $\alpha$ e $\beta$ da distribuição Beta que melhor represente as probabilidades elicitadas através da minimização do erro quadrático entre a distribuição beta esperada e os valores de probabilidade $q_{1}$ a $q_{6}$ encontrados.

\section{Atividade Montagem Desmontagem Corretiva}

\begin{tabular}{ccccc}
$\begin{array}{c}\text { Valores das } \\
\text { distribuições }\end{array}$ & $\alpha$ & 4,06 & 7,74 & 1,92 \\
$\begin{array}{c}\text { Beta obtidas } \\
\text { Valores }\end{array}$ & $\beta$ & 4,30 & 10,81 & 9,42 \\
$\begin{array}{c}\text { elicitados de } \\
\text { limites (horas) }\end{array}$ & Superior & 1,50 & 0,17 & 0,33 \\
\hline
\end{tabular}

Tabela 4 - Valores elicitados e obtidos para a distribuição Beta de cada atividade de setup. 
A Tabela 4 demonstra os valores de $\alpha$ e $\beta$ encontrados para cada atividade e as Figura 15, Figura 16 e Figura 17 a representação gráfica da Beta obtida para as atividades de Montagem, Desmontagem e Corretiva respectivamente.

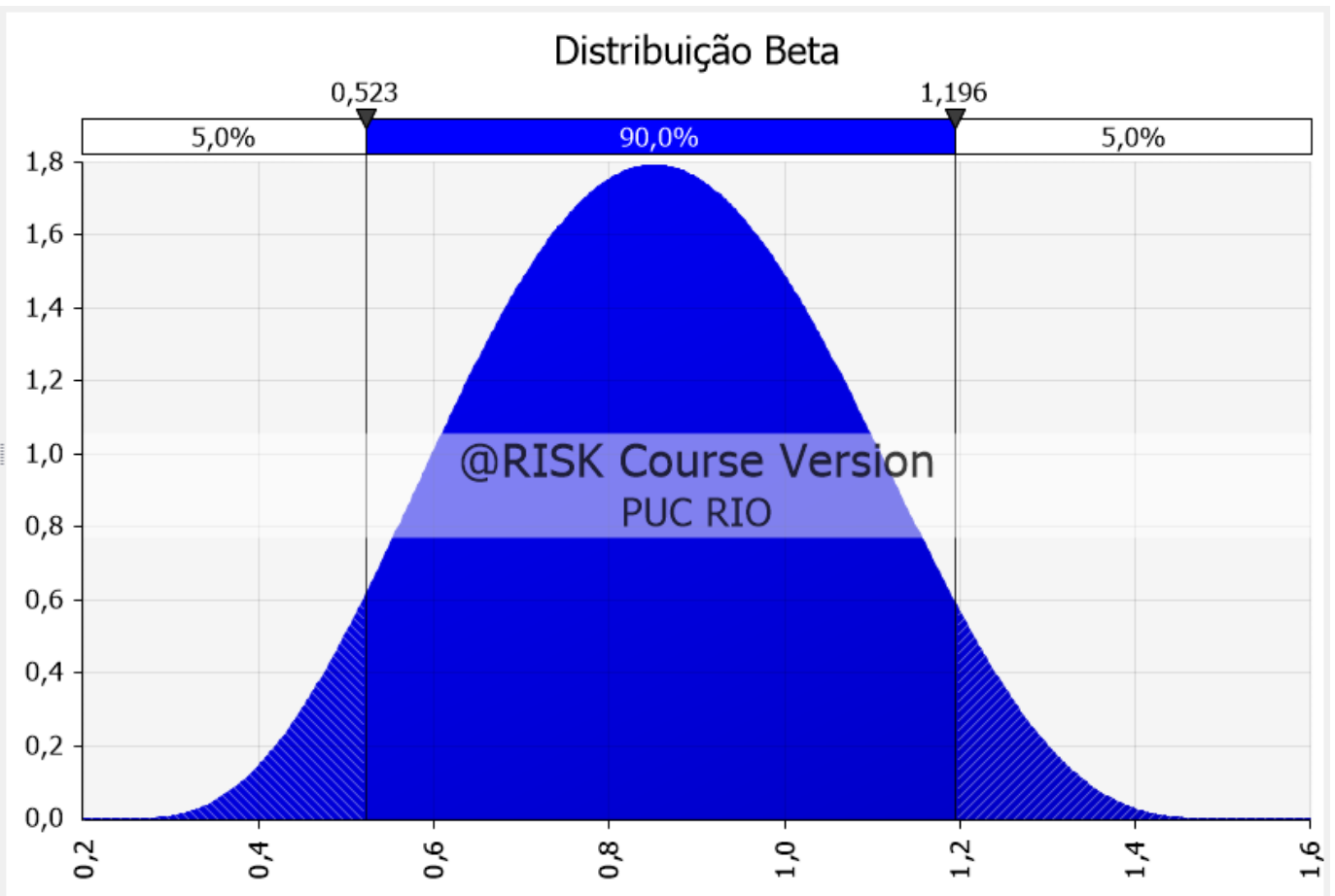

Figura 15 - Distribuição Beta obtida para a atividade de Setup - Montagem (horas).

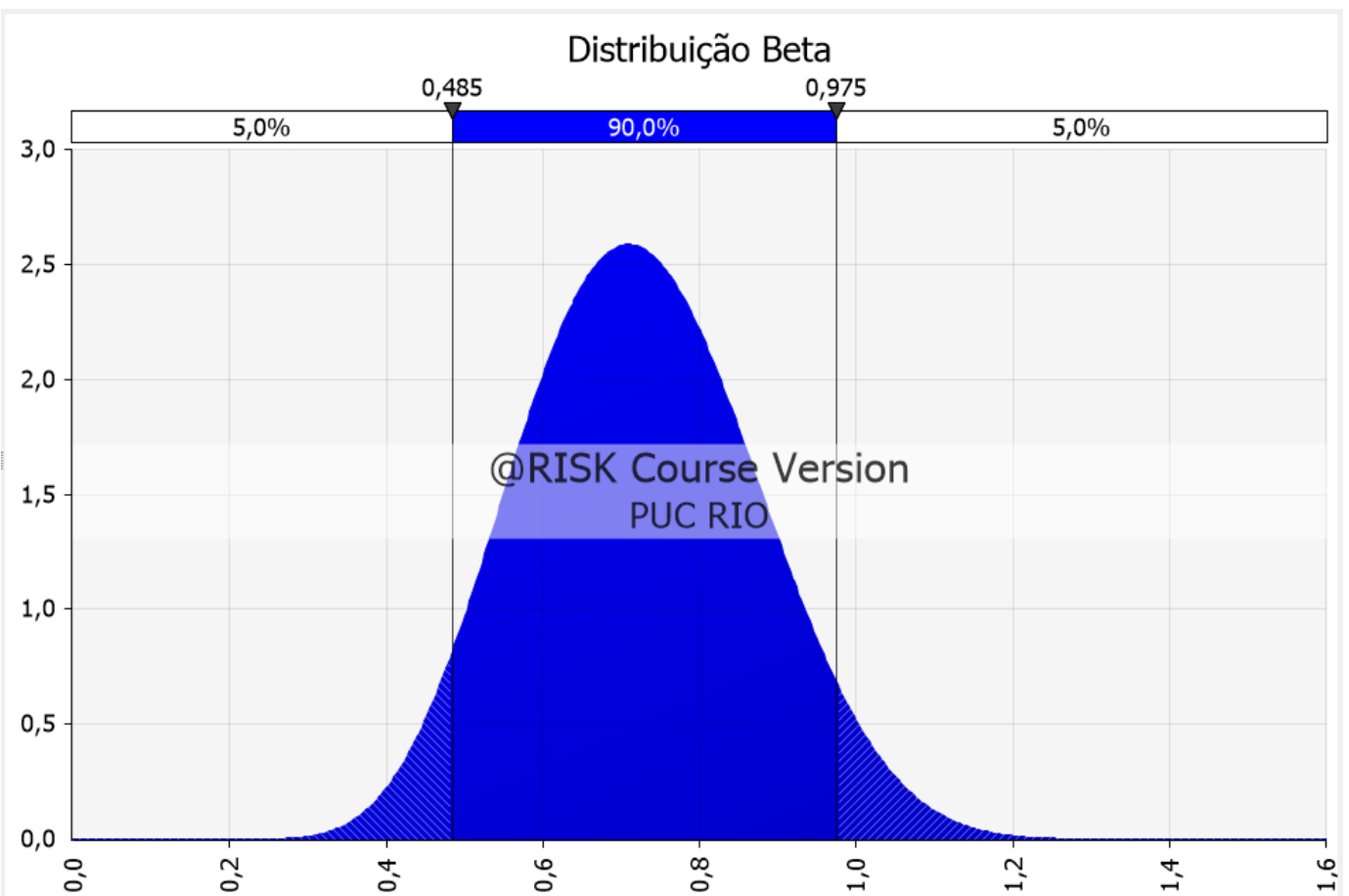

Figura 16 - Distribuição Beta obtida para a atividade de Setup - Desmontagem (horas). 


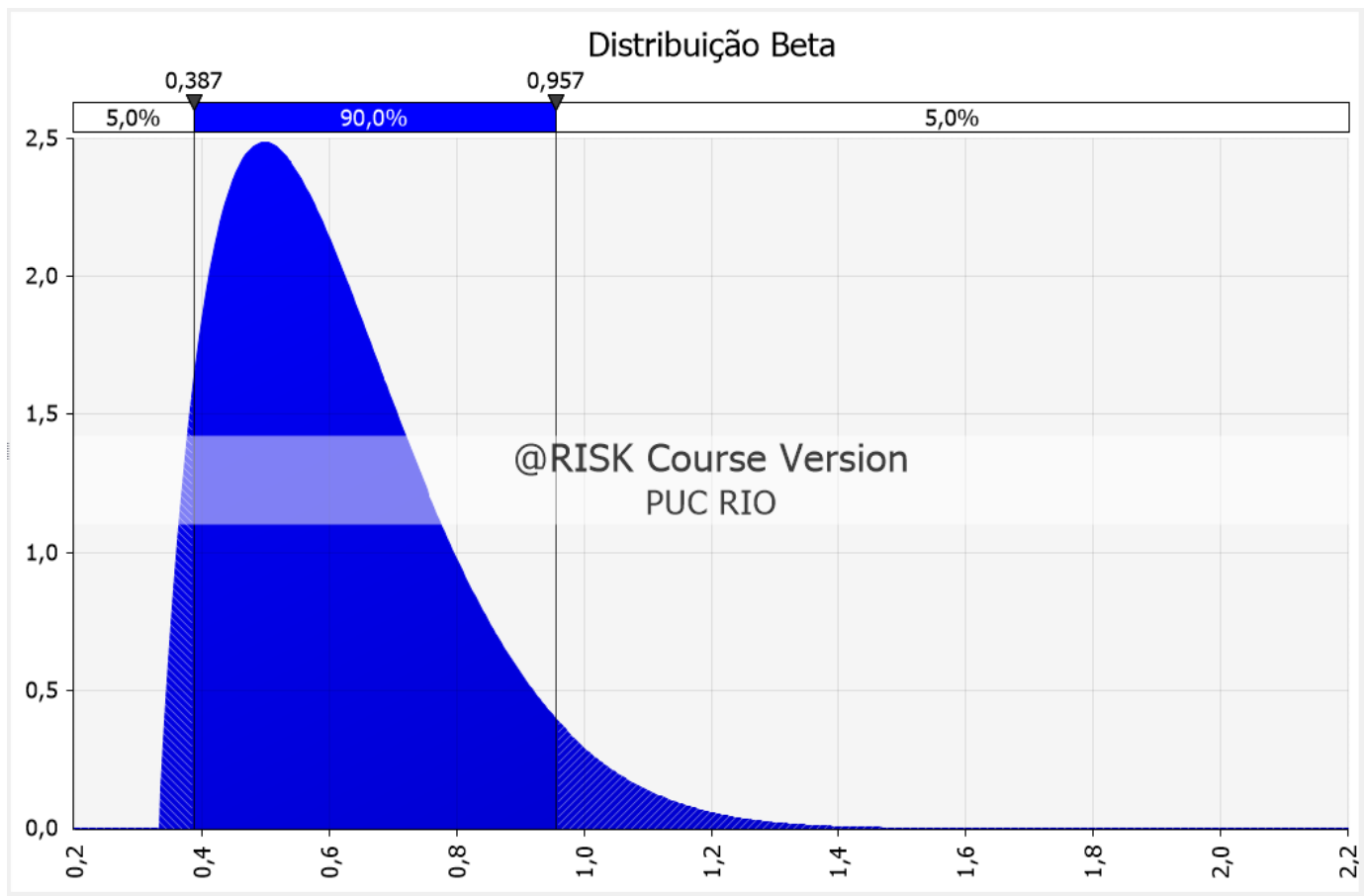

Figura 17 - Distribuição Beta obtida para a atividade de Setup - Corretiva (horas).

A partir das distribuições de probabilidade obtidas, amplia-se o campo de aplicações da produtividade e tempos estimados no contexto do planejamento do projeto, usando a informação para estimativa de cronogramas com o uso de simulação, obtenção de horas previstas de máquina trabalhando para a previsão de paradas para a manutenção, definição de estoques mínimos e máximos necessários dentro de uma porcentagem de incerteza agregada ao modelo, dentre outros.

Além disso, também é previsto com o avanço do projeto, a utilização de informações reais de produtividade e tempos para as dadas atividades correlacionadas às distribuições beta definidas a priori, podendo assim aprimorar os seus parâmetros e atualizar as estimativas para os processos controlados.

\subsection{Aplicação da Linha de Balanço}

Com a aplicação dos conceitos de Linha de Balanço às atividades do projeto de renovação de linha ferroviária, foi possível obter as datas de início e fim das atividades de desguarnecimento de linha, renovação de linha e infraestrutura, no caso, manutenção de dispositivos de drenagem, considerando essas três grandes frentes de atividades. As demais frentes como alivio de tensão e eliminação de juntas (realização de soldas elétricas) não foram incluídas nesse estudo por serem 
atividades que são realizadas sob demanda, não havendo levantamento inicial de quantitativo para essas atividades, a serem implementadas dentro do planejamento mais a curto prazo com prospecções no campo.

O primeiro ponto a ser elaborado para a Linha de Balanço é o sequenciamento das atividades e conforme é demonstrado na Figura 8 a frente de Desguarnecimento de linha é realizada antes Renovação de linha e na sequência, ou paralelamente a essa última, a manutenção dos dispositivos de drenagem (Frente de Infra).

As atividades devem acontecer na ordem acima mencionada para cada quilômetro de linha ferroviária. Além disso as atividades de desguarnecimento e renovação de linha que precisam de intervalo de manutenção com a paralização da circulação, devem ser realizadas sempre na mesma sessão de trabalho, logo enquanto uma atividade não for totalmente finalizada em uma dessas sessões o próximo comboio não pode avançar para a próxima. Essa condição gera certa ociosidade entre as frentes de trabalho, porém é fator negociado com o Centro de Controle Operacional (CCO) e necessária para garantir um menor impacto operacional na circulação de trens enquanto o projeto está trabalhando em uma das linhas.

Para a terceira frente de manutenção de dispositivos de drenagem, por sua atuação ser às margens da linha não é necessário parar a circulação de trens, logo apesar de a mesma ter que ser realizada preferencialmente após a renovação da linha, condição que foi inserida na Linha de Balanço, ela não tem que se limitar à mesma sessão de trabalho.

A partir das condições acima mencionadas foi elaborada a linha de balanço do projeto conforme a Figura 19.

Obtendo apenas parte fracionada da Linha de Balanço do projeto para 5 ativos, aproximadamente $20 \mathrm{~km}$ de linha ferroviária, é possível ver com maior detalhe as interdependências citadas e a relação entre o início e fim de cada frente de trabalho do projeto. Essa visão seccionada da linha de balanço é demonstrada na Figura 18.

Tanto para a Figura 18 quanto para a Figura 19, as demarcações na horizontal do gráfico são para demonstrar os tempos de realização de cada um dos ativos do 
projeto, sendo para o primeiro a realização dos 5 primeiros ativos, e para a linha de balanço completa a realização dos 28 ativos do projeto.

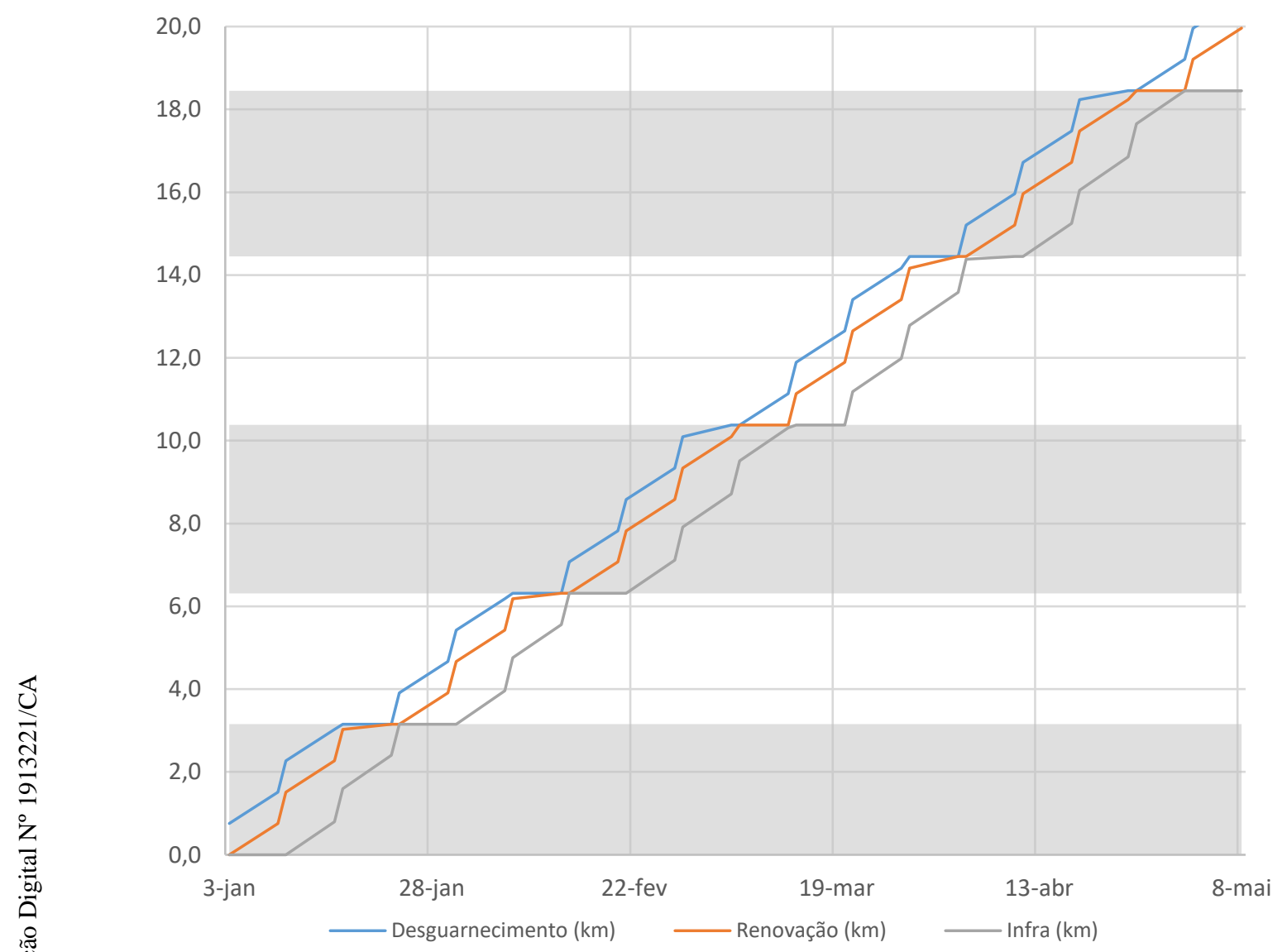

Figura 18 - Linha de Balanço para os 5 primeiros ativos do projeto de renovação de linha ferroviária.

Para o cenário demonstrado na Figura 18 trazemos os valores mais prováveis para a duração das atividades e produtividade estimados, e já mesmo nesse cenário determinístico é possível analisar as relações entre o início de uma atividade e outra em cada trecho, e os períodos que existem folgas maiores ou menores entre a realização de cada atividade.

Pela análise da Linha de Balanço é evidenciado que o desguarnecimento de linha é o gargalo do processo, até mesmo porque ele possui uma produtividade em metros por hora menor que as demais atividades e essa abre frente para a realização das demais, logo a partir da análise deste sequenciamento medidas de controle da execução podem ser estabelecidas como: (i) maior agilidade para reestabelecer a desguarnecedora de linha do que é necessário pra a renovadora, inclusive investimentos em $\mathrm{HH}$ e materiais sobressalentes para a máquina; (ii) deslocamento 
do conjunto de socadoras da renovação sempre que for necessário atuar em algum retrabalho ou atuações pontuais e priorizar manter o da desguarnecedora sempre abrindo frente de trabalho; (iii) monitoramento mais de perto da execução nos momentos que há aproximação das duas frentes de trabalho, conforme demonstrado na linha de balanço, para mitigar ao máximo a ociosidade dos equipamentos; (iv) alocação de equipes para a manutenção dos dispositivos de drenagem conforme a perspectiva de frente aberta indicada, alocando melhor os recursos e podendo deixar as equipes prontas para atendimentos em outros pontos quando a demanda nesta frente estiver menor; dentre outras análises a partir das informações. 


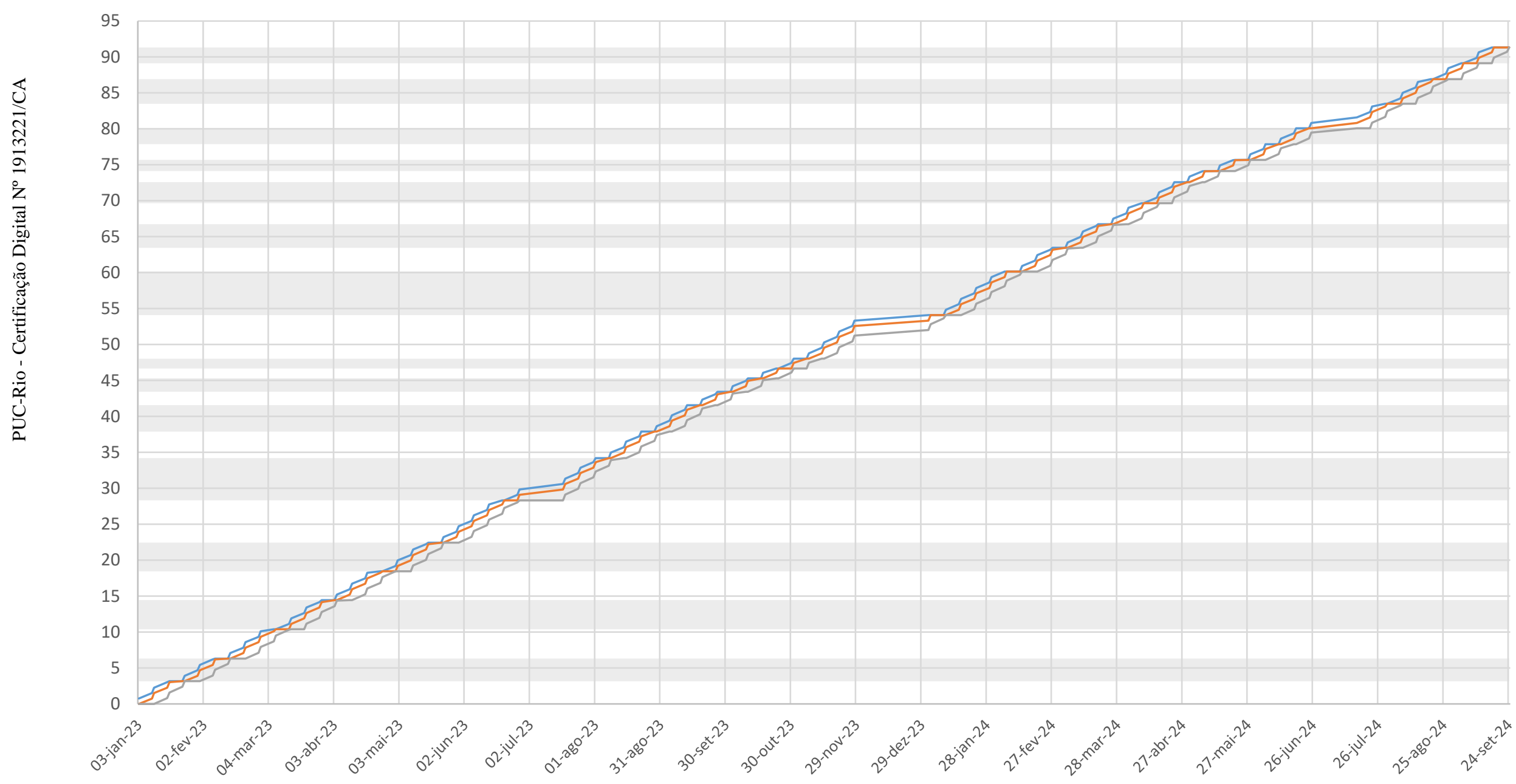

Figura 19 - Linha de Balanço para os 28 ativos do projeto de renovação de linha ferroviário. 


\subsection{Modelo de parada programada para manutenção}

O modelo de trabalho do projeto consiste em paradas programadas para manutenção com o bloqueio de uma sessão de linha férrea em trechos duplicados, onde a circulação continua em ambos os sentidos em apenas uma das linhas enquanto a outra é bloqueada por exatas 12 horas para a atuação do projeto.

Nessas 12 horas de trabalho estão inclusos os tempos de circulação para a frente de trabalho, estimados até 1 hora para ida e volta, montagem das máquinas, valor provável aproximadamente 51 minutos, desmontagem, 43 minutos, atuação para corretivas 36 minutos, e o tempo reservado para acabamento, 1 hora e 30 minutos, sendo apenas o tempo restante considerado como produtivo com avanço físico das atividades do projeto.

Esse modelo requer um acompanhamento diário das atividades muito grande, porque toda a grade de trens da empresa é programada para o dia considerando o intervalo com essa duração especificada, logo qualquer atraso não planejado para a entrega acarreta em transtornos para operação e impactos de trens parados, estouro de jornadas de maquinistas, não cumprimento das programações de entrega em terminais de carga e descarga, dentre outros.

Outro ponto importante é que caso ocorram imprevistos como quebras de máquina ou fatores internos que impeçam a continuidade das atividades no dia do intervalo é necessária a atuação rápida para reestabelecer os equipamentos, bem como gatilhos de controle relacionados aos tempos de cada atividade para definir quando é o momento de parar a continuidade de uma atividade para que exista tempo hábil para a continuação da próxima e entrega do intervalo dentro do prazo estabelecido.

A Figura 20 demonstra a linha do tempo para um intervalo padrão de 12 horas onde as produtividades e tempos de atividades ocorrem conforme os valores mais prováveis definidos. As atividades representadas por linhas horizontais são aquelas de setup que não estão relacionadas ao avanço físico do projeto, como circulação, montagem dos equipamentos, corretivas e desmontagem. Já as demais atividades são consideradas a partir das produtividades definidas para as mesmas e iniciadas na sequencia definida conforme a abertura de frente mínima para os equipamentos começarem a trabalhar na sequência. 


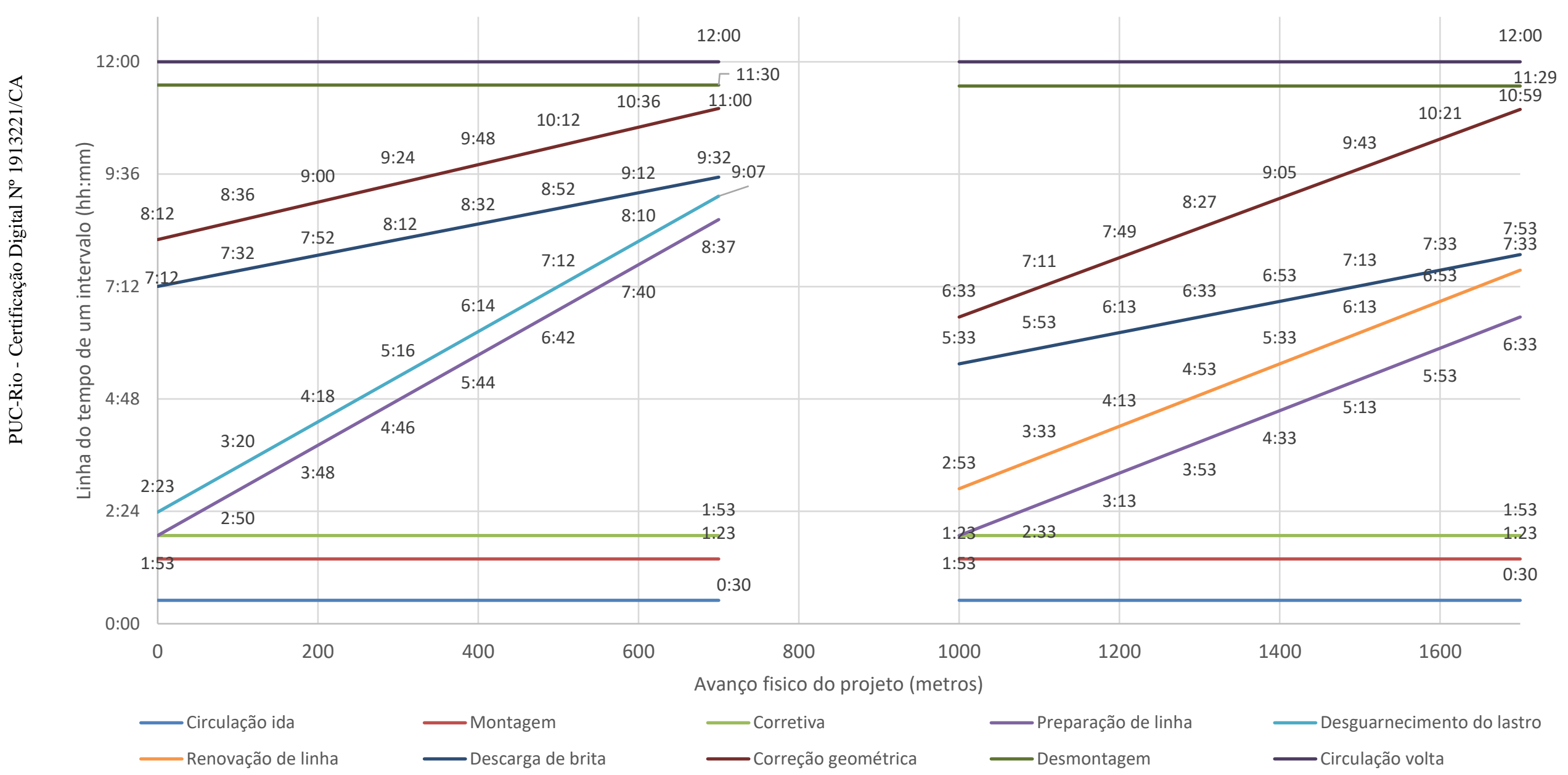

Figura 20 - Linha do tempo da sequência de atividades dentro do intervalo para as frentes de desguarnecimento e renovação. 
O controle da sequência de atividades e das curvas de produtividade realizadas para as mesmas permite a definição de gatilhos reativos a partir da frente aberta por uma atividade e o tempo necessário reservado para as atividades sucessoras sabendo a partir do acompanhamento real de frente aberta o momento necessário para parar com as atividades daquela frente para permitir a atuação das próximas antes do tempo de finalização do intervalo.

\subsection{Simulação das atividades do projeto}

Subsequente às distribuições de probabilidade elicitadas, bem como com as atividades sequenciadas conforme as diretrizes da linha de balanço, foi possível com a utilização do software @Risk integrar o planejamento de sequenciamento das frentes de trabalho com os parâmetros probabilísticos para os tempos e produtividades estimados.

A partir dessa integração foi aplicada a simulação de processos através do uso da simulação de Monte Carlo com a aplicação de 10 mil interações, definindo os seguintes outputs do modelo de simulação:

(i) O tempo total em dias úteis para finalização dos 28 ativos priorizados para o projeto;

(ii) O consumo esperado médio de dormentes por mês;

(iii) $\mathrm{O}$ índice de utilização médio dos intervalos, considerando as variações nos tempos de setup;

(iv) Cenários aplicados à Linha de Balanço, e os limites de variação aceitáveis com impacto minimizado;

Nos próximos tópicos são detalhados o modelo de simulação desenvolvido e os resultados obtidos para cada um dos 4 pontos levantados acima e suas repercussões para o gerenciamento do projeto.

\subsubsection{Modelo de simulação}

Levando em consideração a Estrutura Analítica do Projeto com suas atividades, bem como as distribuições de probabilidade para as atividades críticas elicitadas e aplicando os conceitos de Linha de Balanço para projetos de caráter repetitivo, foi desenvolvido um modelo de simulação para o projeto em questão, 
com foco na Frente de Linha e em uma das regiões geográficas de atuação, com o objetivo de restringir o foco de atuação, permitindo analisar melhor as informações geradas.

O modelo de simulação desenvolvido pode ser representado pelo fluxo presente na Figura 21 onde são representadas as atividades consideradas no sequenciamento de frentes de trabalho, bem como os tempos de setup e a produtividade do desguarnecimento estimados.

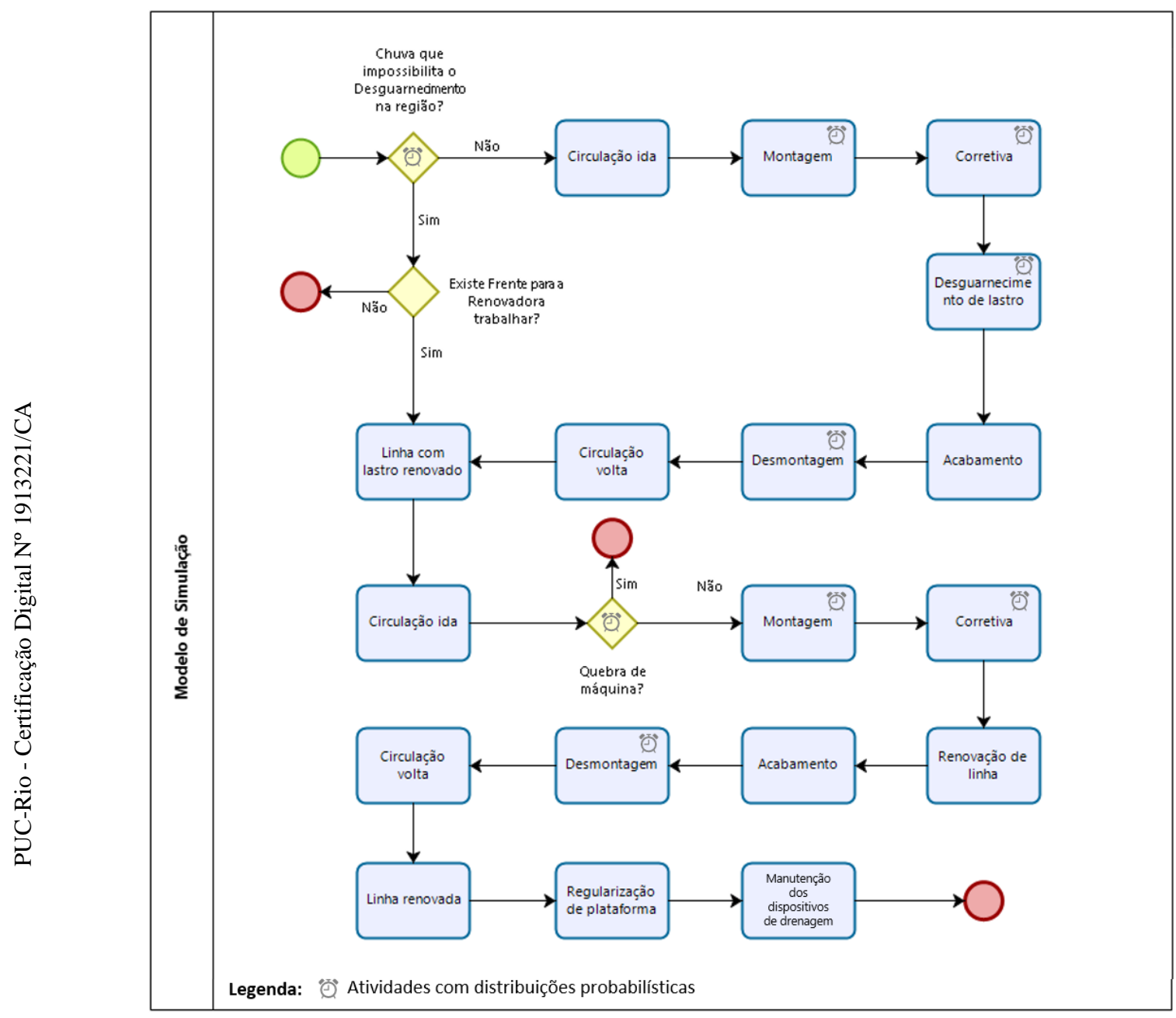

Figura 21 - Modelo de Simulação das atividades do projeto

O modelo de simulação consiste no desenvolvimento do fluxo da Figura 21 para cada dia de atividade realizada no projeto, partindo da análise das condições climáticas no local, caso esteja chovendo que impossibilite a execução da atividade de desguarnecimento, é verificado se existe frente aberta em quilômetros para a próxima atividade que é a renovação de linha, caso exista é dado andamento no 
fluxo com da atividade de renovação, caso não, a produtividade das atividades no dia é zero.

A probabilidade de chuva que impeça a realização das atividades foi inserida diariamente no modelo como uma distribuição de Bernoulli onde 0 é dada pela probabilidade de chover e não ser possível realizar a atividade de desguarnecimento no dia e 1 é a atividade acontecer normalmente. A distribuição é representada por $X \sim$ Bernoulli $(0,95)$, sendo então $5 \%$ a probabilidade de chuva que impossibilite o trabalho e o valor a priori foi definido como referência utilizando opinião especializada para um evento que acontece com frequência baixa.

Continuando é realizada a Circulação de ida para o local de trabalho e a Montagem dos equipamentos já na frente de trabalho. O tempo dessa atividade é representado pela distribuição beta dada por X Beta $(4,06 ; 4,30)$ de limites $[0,25 ; 1,50]$ em horas.

Na sequência corresponde ao tempo reservado para atividades de manutenção corretivas no equipamento antes do início das atividades, sendo que a mesma pode acontecer também durante a realização das atividades caso ocorra alguma parada de máquina. $\mathrm{O}$ tempo dessa atividade é representando também por uma beta $\mathrm{X}$ Beta $(1,92 ; 9,42)$ de limites $[0,33 ; 2,00]$ em horas.

Posteriormente é calculada a produtividade diária da atividade de desguarnecimento, através da produtividade elicitada da atividade representada por uma distribuição beta de notação $X \sim \operatorname{Beta}(7,75 ; 8,12)$ de limites $[50 ; 160]$ em metros/hora sendo na sequência realizadas as atividades de acabamento que consistem na descarga de brita e correção geométrica.

Após o acabamento é realizada a desmontagem do equipamento, atividade representada pela beta elicitada de notação $\mathrm{X} \sim \operatorname{Beta}(7,74 ; 10,81)$ e limites $[0,17 ; 1,50]$ em horas, para então ser realizada a circulação de volta para o pátio de apoio e serem finalizadas as atividades da frente de desguarnecimento do projeto.

Após essas atividades, a linha está pronta para ser renovada com a troca de dormentes e fixações a eito e trilhos sob condição. Num próximo dia de trabalho é continuado o fluxo de atividades a partir da Linha com lastro renovado. Para a simulação da renovação de linha a produtividade foi considerada determinística, porém foi inserido uma distribuição de Bernoulli que represente os dias que a máquina quebra e não tem produção por conta de indisponibilidade do equipamento. A distribuição é representada por X Bernoulli $(0,97)$ considerando 
também informação especializada a priori de disponibilidade de equipamentos similares para sortear na simulação os dias que acontece a quebra da máquina, não havendo produtividade nesses dias.

$\mathrm{Na}$ sequência os mesmo tempos de setup de máquina estimados são considerados para o cálculo de horas disponíveis para trabalho para obtenção da linha renovada, abrindo frente para a atuação das atividades de regularização de plataforma e manutenção dos dispositivos de drenagem, atividades ligadas à frente de infraestrutura e que são realizadas ao final do projeto, não necessitando de parar a circulação ferroviária para realização, $\log o$ as mesmas não foram elicitadas as probabilidades e foram consideradas como referência um valor determinístico para as suas produtividades.

No modelo de simulação também foram consideradas as sessões de trabalho, que consiste em subdivisões do trecho ferroviário, normalmente entre pátios ferroviários, permitindo a circulação dos trens pela outra linha enquanto esta sessão está bloqueada, dado que todo o trecho do projeto consiste em linha duplicada.

São 28 sessões de trabalho no projeto com extensões que variam de 1300 a 6000 metros de linha, e um fator importante para a simulação é que não é permitido ao projeto trabalhar em duas sessões ao mesmo tempo, logo quando o comboio de desguarnecimento termina todo o trabalho dentro de uma sessão ele tem que aguardar a finalização por parte do comboio de renovação e ao entrar em uma nova sessão a renovação deve aguardar a abertura de frente pelo desguarnecimento para conseguir trabalhar. Este ponto foi considerado no modelo de simulação e é crucial para garantir menor impacto na circulação de trens enquanto o projeto estiver atuando em um trecho.

O modelo foi desenvolvido para 200 dias de atividade, considerando cobrir todas as variações possíveis da simulação em número de dias do projeto, possuindo desta forma 1200 inputs para cada distribuição de probabilidade de entrada e dia previsto do projeto; e como resultado possui 29 outputs do modelo de simulação, entre eles a duração do projeto total em dias, a duração das atividades de desguarnecimento e renovação também em dias, o índice de utilização do projeto em \% e o consumo mensal de dormentes de concreto para todos os meses de duração do projeto. 
Os resultados obtidos e suas repercussões para o gerenciamento do projeto são melhor discutidos nos grupos que se seguem para os principais outputs do modelo de simulação desenvolvido.

\subsubsection{Simulação de duração do projeto e resultados}

O primeiro resultado analisado no modelo de simulação proposto foi a duração total do Projeto em dias úteis. A partir dos inputs definidos no modelo e a lógica definida para o sequenciamento das atividades, foi obtida a distribuição de probabilidade da duração total do projeto entre o mínimo de 160 dias e máximo de 190 dias, existindo uma probabilidade de $90 \%$ do projeto durar entre 166 e 178 dias.

O controle desse resultado é muito importante para o gerenciamento do projeto, dado que a sua duração está diretamente interligada a várias outras atividades que o atendem, como contratos de prestação de serviços, aluguel de equipamentos, concessão de intervalos para trabalho pela operação.

A sustentabilidade da via permanente que é mantida levando em consideração o momento de atuação do projeto em um determinado trecho e atrasos na entrega podem afetar diretamente esta estratégia podendo gerar necessidade de atuações corretivas não planejadas ou até mesmo risco operacional para o trecho ferroviário em atraso.

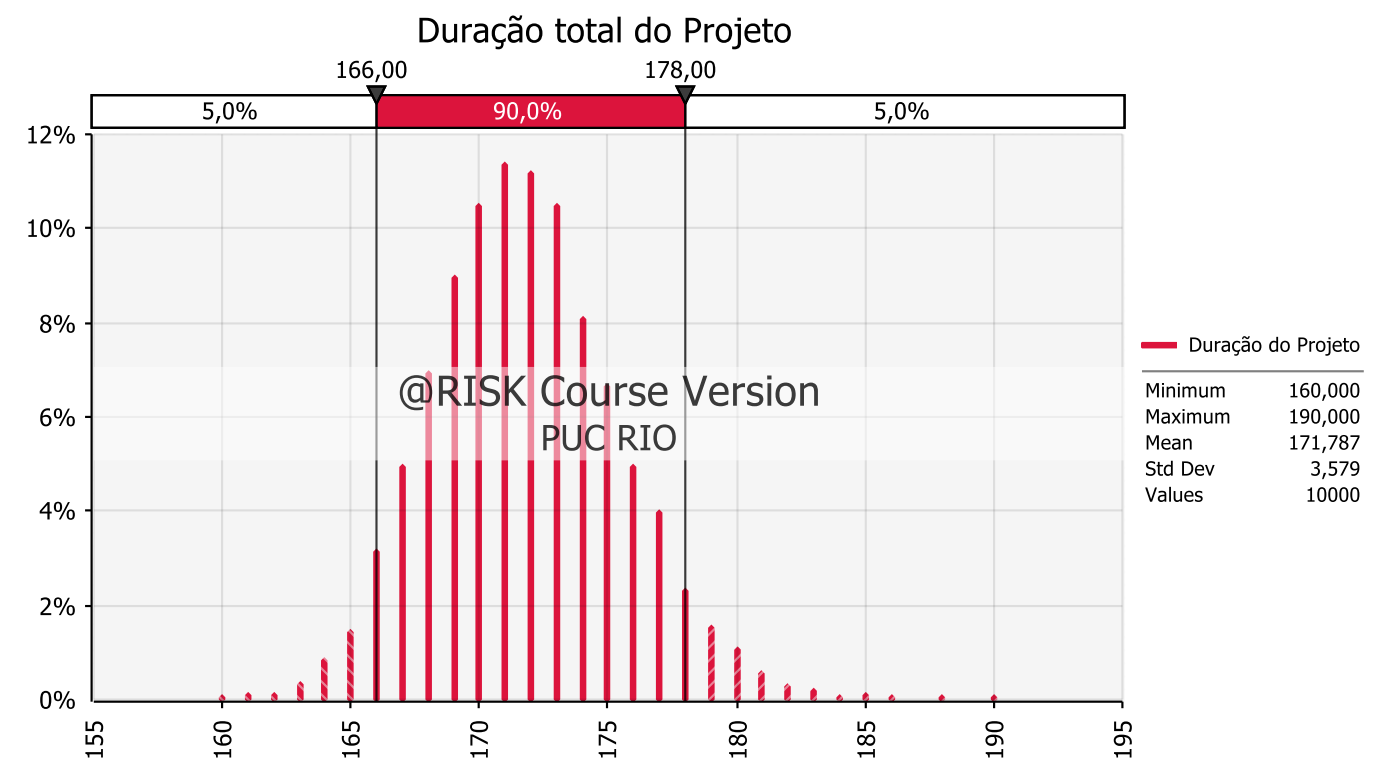

Figura 22 - Resultado da duração total do projeto simulada 
A Figura 22 demonstra os resultados obtidos para a duração total do projeto em dias úteis. Considerando o início do projeto em 02/Jan/23 e desconsiderando os dias da semana previstos para manutenção preventiva dos equipamentos e trabalho dos equipamentos em outras frentes, o projeto tem previsão na média de terminar em 22/Out/24 podendo terminar até 28/Jan/25 e com 95\% de probabilidade de terminar até $12 / \mathrm{Nov} / 24$.

Considerando os fatores de variação incluídos no modelo, é possível perceber que o projeto não tem variação tão expressiva em relação ao número de dias totais do projeto, dado que o desvio padrão é relativamente pequeno em número de dias.

No cenário de médio prazo conforme o desenhado as variações podem não parecerem não significativas, levando a um falso entendimento que o projeto está em uma condição mais sobre controle, porém as variações do dia-a-dia não gerenciadas podem acarretar em outras consequências não mapeadas na elicitação que podem impactar diretamente no andamento do projeto e no prolongamento do prazo, como falta de materiais devido a picos na produção não esperados, ineficiência na estimativa de recursos para manutenção dos equipamentos, dentro outros.

\subsubsection{Simulação do consumo de dormentes}

Ligado a atividade de Renovação de Linha, um dos principais insumos envolvidos no processo é o dormente de concreto. Nesse projeto, durante a atividade de renovação de linha prevê-se também a remodelação da linha, com a substituição da matriz do dormente de madeira para concreto, garantindo assim um custo de ciclo de vida (LCC - Life Cycle Cost $)$ menor para o componente e ganhos para a sustentabilidade da linha no longo prazo.

Dessa forma, o dormente de concreto trata-se um material crítico para a estratégia da cadeia de suprimentos do projeto, sendo definidas politicas especificas de estoque, ressuprimento e de acordos de atendimento junto aos fornecedores.

Dado a imprevisibilidade da abertura de frente pelo desguarnecimento, a demanda de dormentes para a frente subsequente também sofre influência, podendo variar ao longo do mês, impactando também na capacidade de produção do fornecedor. Desta forma conhecer os possíveis limites de variação da quantidade de dormentes aplicados e definir acordos de estoque e antecedência de fornecimento 
que atendam uma \% esperada de incerteza é uma estratégia muito importante para o gerenciamento do projeto e de suas aquisições.

No modelo de simulação desenvolvido, a quantidade de dormentes aplicada por dia foi calculada a partir da produtividade da atividade de renovação de linha, que é diretamente influenciada pela produtividade do desguarnecimento de linha, valor elicitado e inserido no modelo a partir da distribuição beta obtida.

Para tomada de decisão gerencial, foram calculadas as quantidades de dormentes mensais para todos os meses previstos do projeto, sendo que a informação de consumo de dormentes diária por si só não colabora tanto diretamente com o plano de suprimentos, dado que o nível de serviço de entregas de materiais normalmente é acordado por favores mensais ou quinzenais. Dessa forma entender a variação na quantidade de dormentes dentro do mês colabora mais para as ações necessárias para garantir o atendimento e levando em consideração o replanejamento do estoque já existente, tomar decisões para o próximo mês.

A Figura 24 demonstra o consumo de dormentes mensal para o mês de julho de 2023, mês tomado apenas como referência para exemplificar os resultados obtidos, porém a mesma informação foi calculada para os 25 meses de simulação do projeto, considerando como limite 200 dias de simulação.

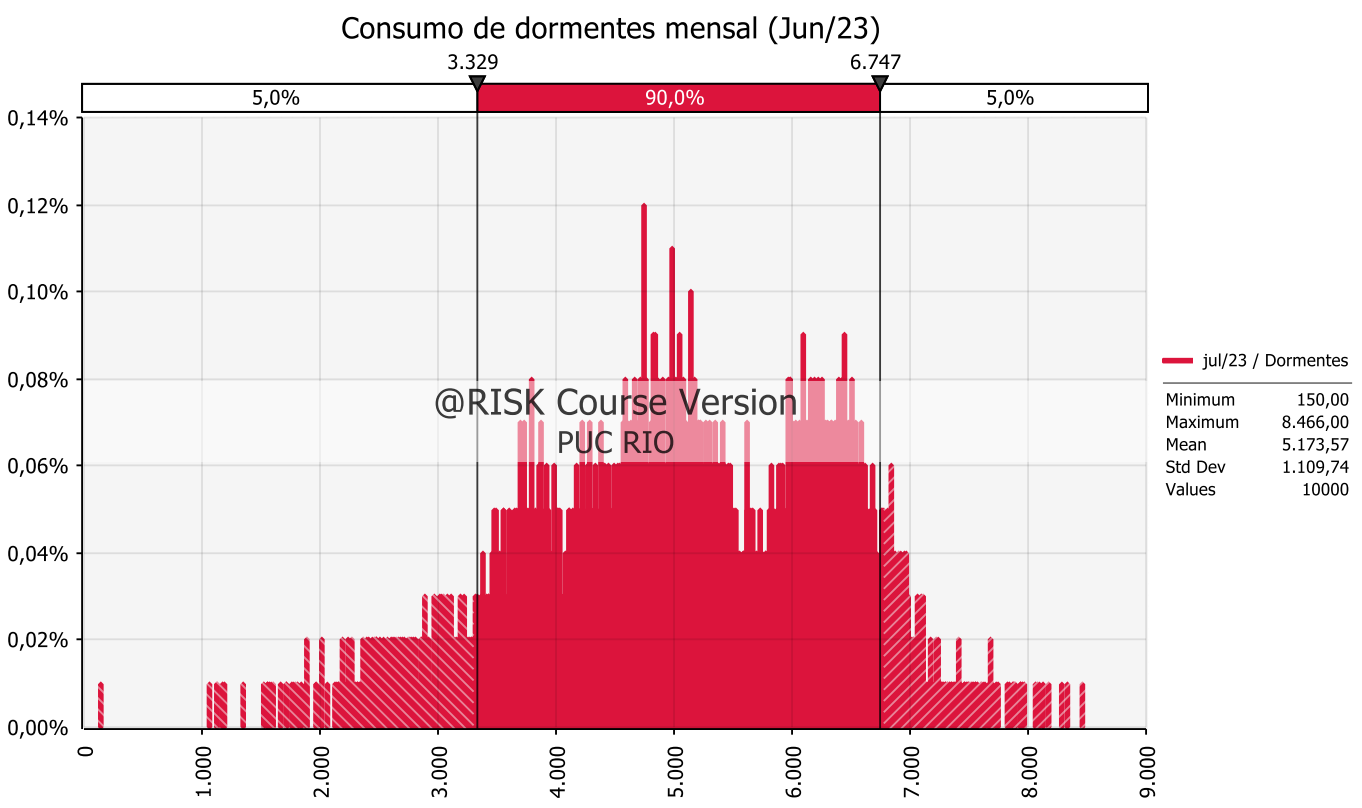

Figura 23 - Histograma de probabilidades para a quantidade de dormentes previstos para o mês de junho de 2023 
Conforme demonstrado na Figura 23 a variação da quantidade de dormentes necessário para a execução das atividades no mês é considerável, podendo variar entre 150 unidades no mínimo e 8466 unidades no máximo com um desvio padrão de aproximadamente 1110 unidades.

Porém 90\% da probabilidade se encontra entre as quantidades de 3329 e 6747 unidades, sendo provavelmente a variação que deve ser mais focada para análise de estoque, dado que cenários com $5 \%$ de probabilidade de ocorrência ou menos nesse caso podem ser desconsiderados.

Conjecturando um cenário de fornecimento de dormentes para o mês de junho de 2023 (vide Figura 23) é importante considerar o valor médio esperado para o mês que seria de 5174 unidades, porém desde que limitado a capacidade física do estoque, o fornecimento de dormentes deve cobrir um maior consumo no mesmo, levando em consideração a probabilidade de ocorrência, dado que a falta do dormente impactaria em paralisar as atividades do projeto e a produção pode variar ao longo do mês.

Um ponto importante a ser observado é que apesar de a variação da quantidade de dias no projeto não ser tão grande, em um cenário de volume de dormentes dentro do mês essa variação é muito expressiva. Isso se dá principalmente por conta do modelo de trabalho do projeto ser sempre ocupando apenas uma sessão, $\log 0$ ao entrar num trecho especifico é necessário a frente subsequente esperar a finalização da atividade para continuar para a próxima frente. Nesse modelo, os últimos dias de trabalho em uma frente acabam sendo menos produtivos e com a possibilidade de absorver parte dos desvios sem a necessidade de prolongar em muitos dias a atuação naquele ativo.

Porém a variação na quantidade de dormentes mensal mostra que o impacto no andamento do projeto pode vir de outras fontes não mapeadas no processo de elicitação, como por exemplo falta de materiais devido à uma variação muito expressiva na quantidade dentro do mês, fazendo assim que sejam agregas perdas que não estão representadas pela variação na produtividade elicitada pelo especialista. 


\subsubsection{Simulação do índice de utilização do intervalo}

Em um modelo de parada para a manutenção, o aproveitamento ao máximo do intervalo de tempo determinado para trabalho é um ponto muito importante para um projeto que atua desta forma. É crucial para o projeto buscar formas de otimizar ao máximo as atividades que ocupam o intervalo, porém não agregam valor para o avanço físico em quilômetros da atividade, abrindo frente de trabalho para demais.

As principais atividade mapeadas no modelo de simulação desenvolvido que impactam no tempo útil do intervalo são as atividades de setup: circulação, montagem, corretiva e desmontagem (essas atividades são aquelas representadas por linhas horizontais no diagrama de tempos do intervalo na Figura 20). A atividade de acabamento consiste no tempo necessário que deve ser parada as atividades de desguarnecimento e renovação para que as frentes de acabamento, descarga de brita e correção geométrica, consigam cobrir toda a frente aberta antes do fim do intervalo, logo essa atividade está diretamente ligada ao avanço físico do projeto e faz parte do escopo do mesmo, sendo considerada como tempo útil.

Para calcular o tempo útil do intervalo (TU) e consequentemente o Índice de utilização (IU) foi utilizada no modelo a formula abaixo:

$$
I U(\%)=\frac{T U}{T}=\frac{\left(T-T_{m}-T_{c o}-T_{d}-T_{c i}\right)}{T}
$$

Sendo:

$I U$ : Índice de utilização do intervalo (\%)

$T:$ Tempo total do intervalo (horas)

$T U$ : Tempo útil do intervalo (horas)

$T_{m}$ : Tempo da atividade de montagem (horas)

$T_{c o}$ : Tempo da atividade de corretiva (horas)

$T_{d}$ : Tempo da atividade de desmontagem (horas)

$T_{c i}$ : Tempo da atividade de circulação (horas)

O $I U$ calculado foi um dos outputs do modelo desenhado e a partir da simulação foi obtida a Figura 25 que representa o histograma de probabilidades para o índice de utilização do intervalo simulado. 
Levando em consideração a variação no tempo das atividades de setup elicitadas, o IU pode variar entre $63,16 \%$ e $81,46 \%$ sendo que em média é esperado um índice de $73,37 \%$, além de em $9 \%$ das vezes o índice ser $69,04 \%$ ou maior.

Conhecer o índice e controla-lo na execução do projeto é muito importante para a conformidade dos processos de execução, porque medidas podem ter tomadas para ganhos nos tempos de setup e consequentemente na quantidade de horas uteis do intervalo, segregando fatores de variação que são controláveis, como profissionais qualificados para a realização da atividade no tempo previsto, número de mão de obra ou equipamentos adequados, dos que são inerentes a variabilidade do projeto, influência de chuvas, condições do trecho trabalhado dentre outras.

Durante o processo de elicitação dos tempos de setup, os especialistas foram instigados à enquanto elicitavam as probabilidades para as faixas de tempo, procurasse mencionar e identificar quais fatores poderiam levar a essas variações.

Esse processo além de auxiliar na qualidade da própria elicitação, permite também que durante o controle das atividades sejam checadas se as variações esperadas pelo especialista estão se concretizando e se o impacto no tempo é o esperado, auxiliando assim a identificar melhorias nas distribuições elicitadas com o avanço do projeto e o uso das informações históricas.

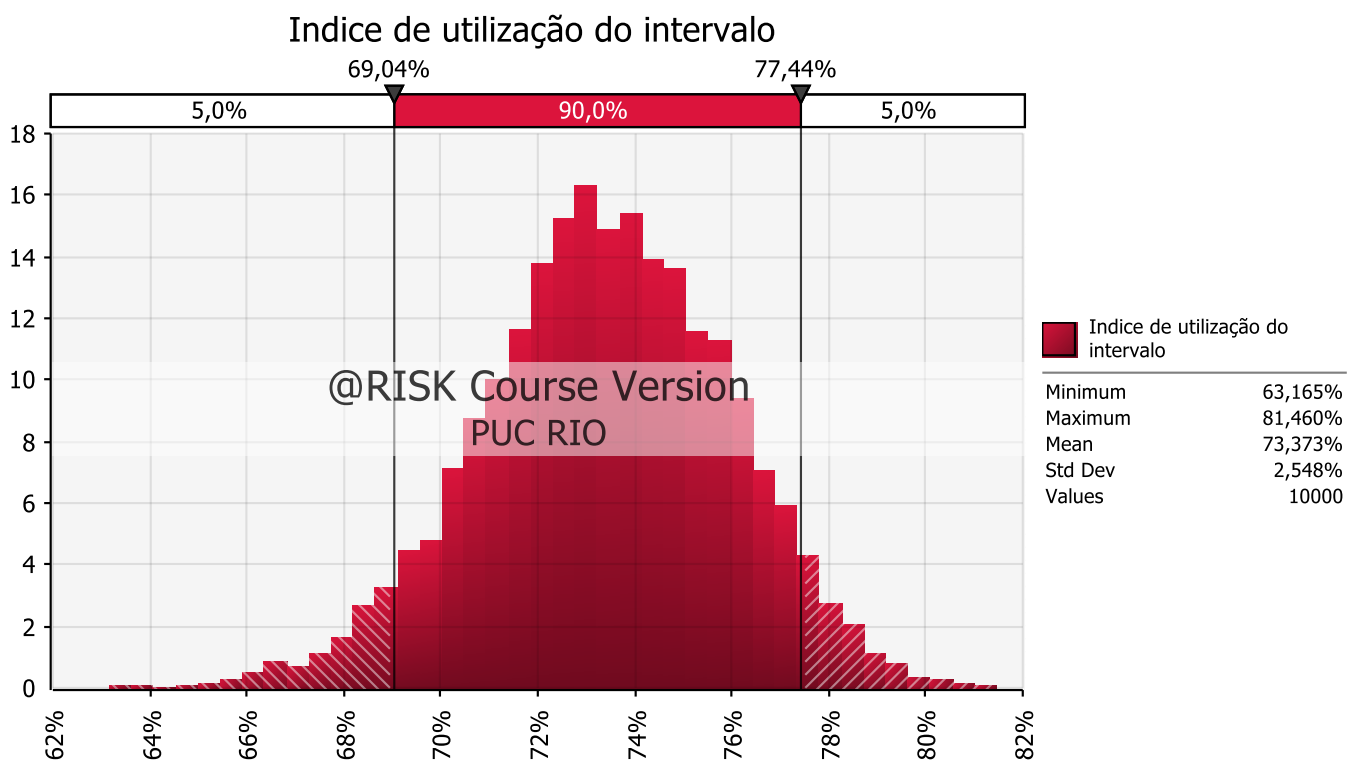
em $\%$.

Figura 24 - Histograma de probabilidades do Índice de utilização do intervalo simulado 
Assim como o índice de utilização a quantidade de horas úteis do intervalo também foi simulada e também é um item importante para controle do projeto. A Figura 25 traz os resultados obtidos para esse item e também permite a análise de pontos relevantes para o gerenciamento do projeto.

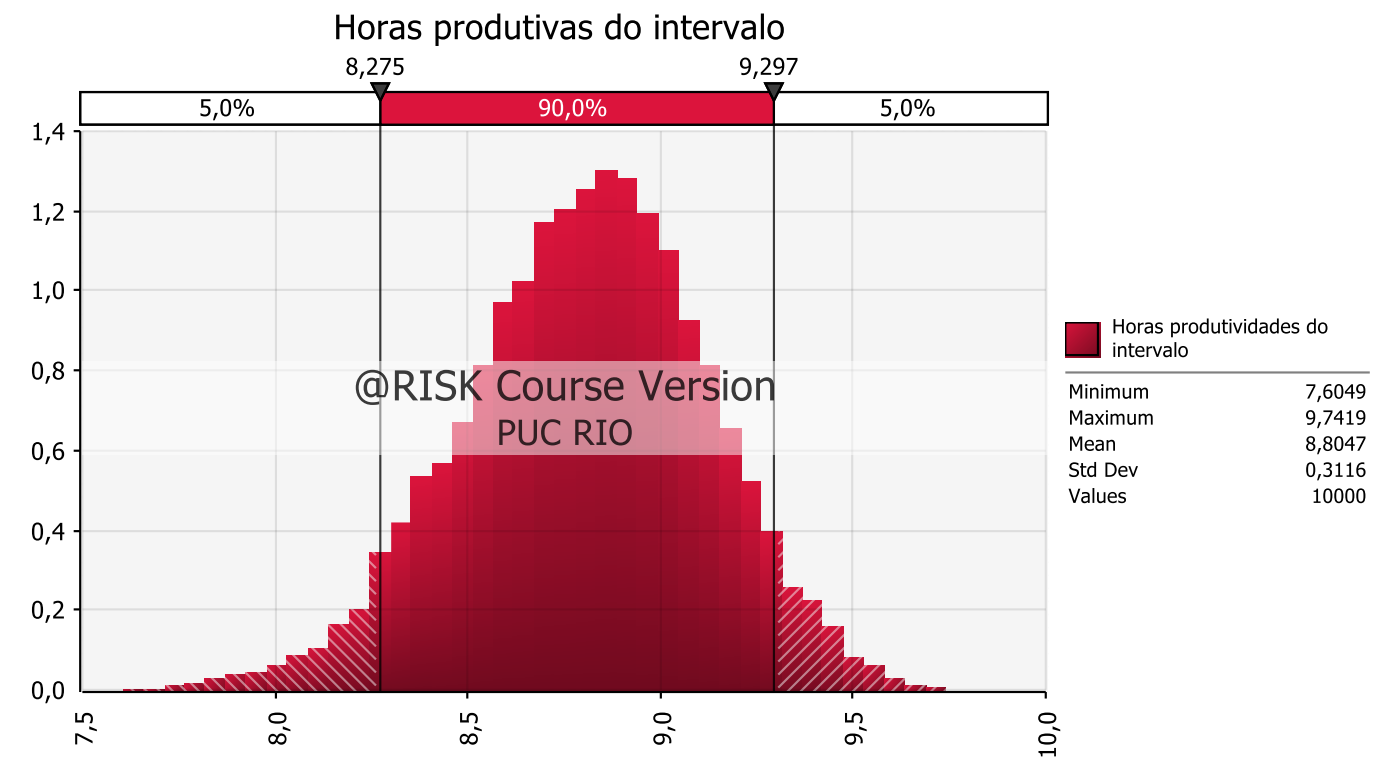

Figura 25 - Histograma de probabilidades das horas produtivas do intervalo simuladas

A partir da quantidade de horas úteis esperadas para o projeto que é definida a produtividade esperada do dia, logo é uma informação importante para compor os cronogramas e ser controlada dentro dos seus limites aceitáveis de variação, indicando inclusive limites de gatilho para tomada de decisão dentro do intervalo.

Conjeturando um cenário de um dia de intervalo onde a circulação para o local de atuação do projeto e a montagem do equipamento aconteçam dentro do planejado. Em dado momento onde a desguarnecedora já possua 300 metros de frente de trabalho aconteça a avaria da socadora, que é o equipamento que na sequência trabalha para reestabelecer a linha. Levantando em consideração o tempo que falta para o fim do intervalo é importante que o programador decida por paralisar ou não a atividade de desguarnecimento até que a socadora consiga se reestabelecer e garantir a retomada da circulação ao fim das 12 horas.

Logo o conhecimento dos tempos previstos para as atividades e das suas possibilidades de variações é muito importante para garantir a tomada de decisão no controle do projeto, podendo usar essas informações para a extrapolação de 
cenários mais estratégicos através da simulação para controle do seu andamento e a produtividade das atividades.

\subsubsection{Simulação de cenários na Linha de Balanço}

O modelo de simulação foi desenvolvido levando em consideração o sequenciamento das atividades e os conceitos de Linha de Balanço que permite o controle e visualização do avanço físico do projeto ao longo das datas.

O objetivo foi representar de forma gráfica a variação de cenários da atividade de desguarnecimento em relação a linha base do cronograma que foi desenvolvido com o valor mais provável para os parâmetros estimados.

O gráfico demonstrado na Figura 26 representa esses cenários e suas variações em relação ao cronograma base e os impactos decorrentes dessas variações para aproximadamente 3 meses de projeto, ou cerca de $13 \mathrm{~km}$ de avanço físico no cronograma do projeto, que corresponde aos 4 primeiros ativos a serem trabalhados. O corte no cronograma foi realizado com o intuito de ser mais fácil a visualização das varrições por questões de escala.

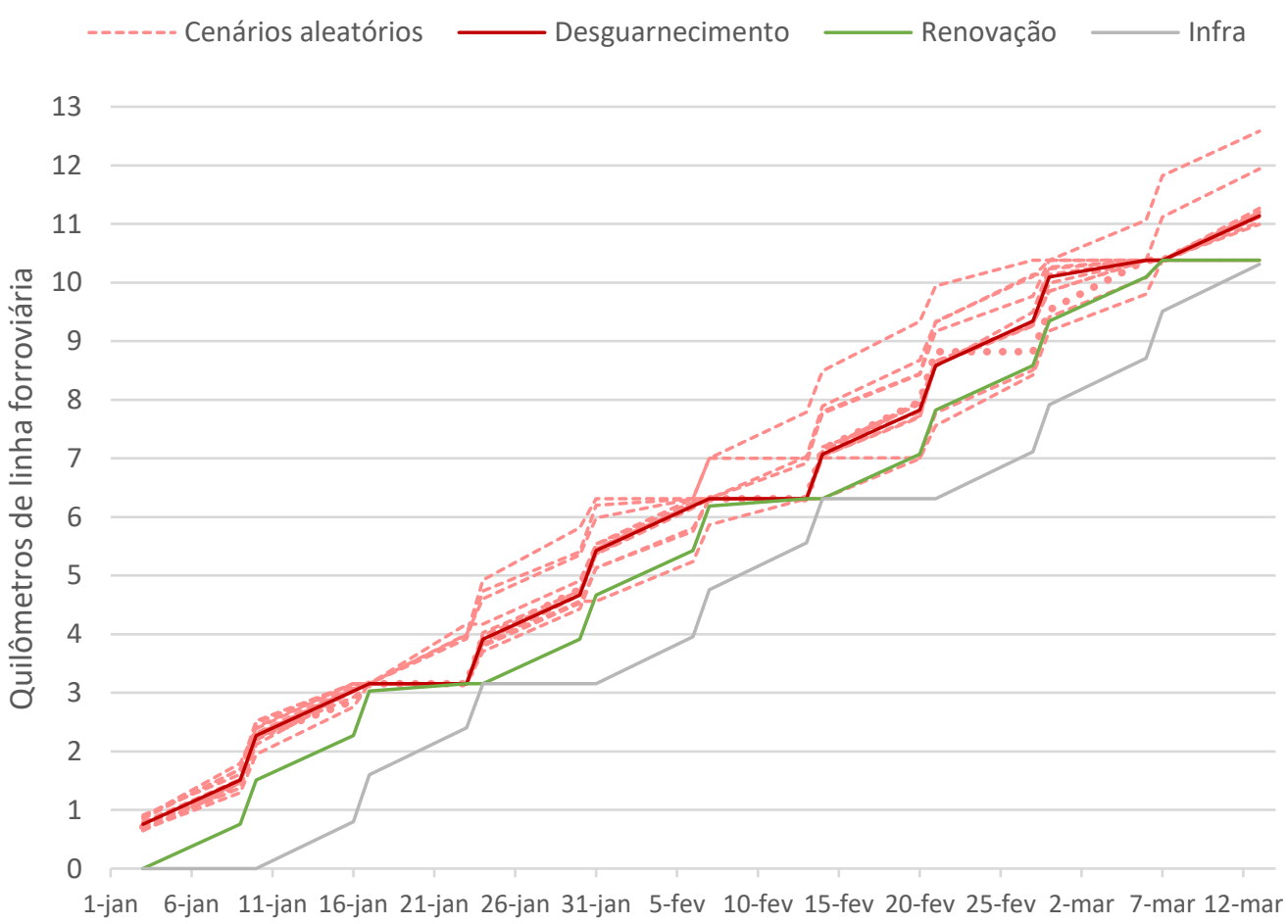

Figura 26 - Avanço físico das atividades do projeto e os cenários aleatórios para a atividade de desguarnecimento 
As linhas pontilhas em torno da linha principal que representa o avanço da atividade de desguarnecimento, demonstram 12 cenários aleatórios escolhidos entre as 10 mil interações realizadas no modelo, que representam variações no prazo de finalização da atividade.

Quantos mais cenários representados no gráfico, mais a sua representação vai se assemelhar a um cilindro de possibilidades dentro das variações definidas no modelo, conforme visualizado acima, algumas delas impactando diretamente em atraso para a realização das atividades subsequentes, já outras com variações aceitáveis dentro do limite que não impacta a próxima atividade.

Conhecer o limite que existe entre as atividades é um fator crucial a ser controlado no projeto, porque variações na produtividade inerentes ao processo sempre vão existir e muitas vezes uma maior conformidade no processo está diretamente relacionada a maiores investimentos, logo é importante entender qual a variabilidade do processo é aceitável sem extrapolar os limites e qual é aquela que deve ser combatida e mitigada.

\subsection{Perspectivas para controle do projeto}

Na estatística Bayesiana é comum o uso de distribuições de probabilidade $a$ priori que devem ser ajustadas com o avanço do processo e a obtenção de dados reais relacionados ao processo medido.

O mesmo é indicado para o gerenciamento de projetos, onde na fase de concepção do mesmo, antes de ser iniciada a execução, é muito importante a definição de um cronograma utilizando as informações de projetos anteriores, opinião especializada através da elicitação de especialistas, referências de produtividade conhecidas para processos mecanizados, dentre outras, porém com o avanço deste projeto e a obtenção de informações reais, principalmente para projetos de cunho repetitivo como a renovação de linha ferroviária, é importante a retroalimentação deste planejamento com os dados reais do projeto, atualizando as distribuições de probabilidade de entrada e simulando novos cenários para o longo prazo.

Neste ponto a estatística Bayesiana e o gerenciamento de projetos convergem para um mesmo ponto, podendo os conceitos desenvolvidos serem aplicado para garantir uma maior assertividade do planejamento do projeto. 
A própria Linha de Balanço consiste em uma ferramenta não apenas para o planejamento do projeto, mas também para o controle do mesmo, onde o acompanhamento do avanço esperado das atividades no curto prazo permite definir ações para os cenários de médio e longo prazo, quando as curvas do planejamento são atualizadas com as informações de entrada do modelo simulado que são controladas na execução do projeto.

Durante a elicitação dos tempos e produtividade com as informações dos especialistas, foi possível obter através das informações repassadas por eles várias informações críticas para controle do projeto na sua fase de execução, podendo assim com os dados reais acompanhar os impactos destes pontos no avanço do projeto e junto com o especialista atualizar as elicitações com as novas informações consideradas. Dentre essas informações obtidas, pontos importantes para controle futuro e atuação do modelo simulado são:

(i ) Impacto das chuvas na produtividade do desguarnecimento e qual o volume de chuva previsto que impossibilita a execução das atividades: com o conhecimento dessa informação, é possível desenvolver um modelo onde a probabilidade de trabalhar ou não em um intervalo por conta de chuvas, no presente modelo representada por uma distribuição de Bernoulli, esteja relacionada a probabilidade de chuva para a região acima de uma quantidade de milímetros conhecida. Essa condição enriquece a simulação do planejamento de médio prazo, podendo relacionar diretamente com informações de previsão meteorológica para cada trecho de trabalho;

( ii ) Relação entre os horímetros dos equipamentos e o tempo reservado para corretivas: para o presente modelo o tempo de corretivas foi elicitado com bases das referências de outros equipamentos ferroviários similares e considerada a mesma distribuição beta para o decorrer do projeto, porém os equipamentos terão paradas programadas 250 horas, 500 horas e 1000 horas de funcionamento, e assim sequencialmente e os tempos previstos para corretivas estão diretamente relacionados ao decorrer do horímetro tendendo a ter mais falhas quando este está próximo de vencer ou até mesmo já vencido para alguns componentes específicos, conhecer essa relação pode inclusive ajudar na melhor programação das paradas para a manutenção; 
( iii ) Retrabalhos e desvios de qualidade: o presente modelo não considera taxa de retrabalhos gerados por trechos que a atividade não foi realizada da melhor forma da primeira vez, sendo necessário refazer a mesma, porém também durante o controle do projeto, atividades desse tipo caso venha a acontecer, sendo conhecida necessidades de retrabalho principalmente levando em consideração os locais trabalhos, é possível também incluir a informação no modelo a partir do uso das informações reais como parâmetros para construção do input e verificar o impacto de retrabalhos no planejamento macro, tendo eles uma probabilidade de ocorrência.

Esses foram três dos principais pontos a serem controlados que podem retroalimentar o modelo de simulação e atualizar o planejamento do projeto, porém é importante mencionar que a simulação em projetos de grande duração e/ou grande impacto é uma ferramenta que deve integrar o planejamento do projeto em todos os níveis, devendo ser desenvolvida e atualizada com o decorrer do projeto, antecipando impactos, controlando processos e embasando a tomada de decisão para o gerenciamento.

\subsection{Ganhos no processo de gerenciamento}

O principal ganho relativo à aplicação do planejamento probabilístico vinculado à simulação no gerenciamento do projeto, consiste no melhor controle da cadeia de suprimentos e atividades de apoio ligadas a ele.

$\mathrm{Na}$ representação das atividades do projeto estão aquelas atividades que serão realizadas dentro do intervalo de manutenção concedido para trabalho, garantindo assim a realização das atividades de desguarnecimento e renovação do trecho, porém para suprir essa frente de materiais (como dormentes e brita) e garantir as atividades antecessoras necessárias de preparo para trabalho, vários outros processos são envolvidos no dia-a-dia, como carga e descarga de materiais, manutenção de equipamentos, abastecimento de equipamentos, atividades de outras frentes de manutenção que não podem coincidir ou tem que anteceder as atividades do projeto, dentre outros.

Desta forma conhecer o avanço físico do projeto é muito importante para garantir que todas essas atividades vão ocorrer também conforme a sua necessidade, 
permitindo dentro do planejamento probabilístico tratar as faixas de confiança esperadas e também os níveis de serviço necessários dentro de toda a cadeia de suprimentos para garantir o bom andamento do projeto.

A Figura 27 é representação da cadeia de suprimentos do projeto, a partir da fabricação de dormentes de concreto para atendimento do projeto, na sequencia o transporte desses materiais e outros como brita e fixações de dormente por meio rodoviário e ferroviário para pátios de apoio, o armazenamento desses materiais e carga nos comboios de trabalho para aplicação no trecho em dias de intervalo considerando os tempos definidos para parada do trecho, e interferência com comunidades, para depois o fluxo de retirada dos materiais que vão sair do trecho, sucata de dormentes e fixações e rejeito de brita usada, para posterior fluxo de retirada desses materiais do pátio de apoio.

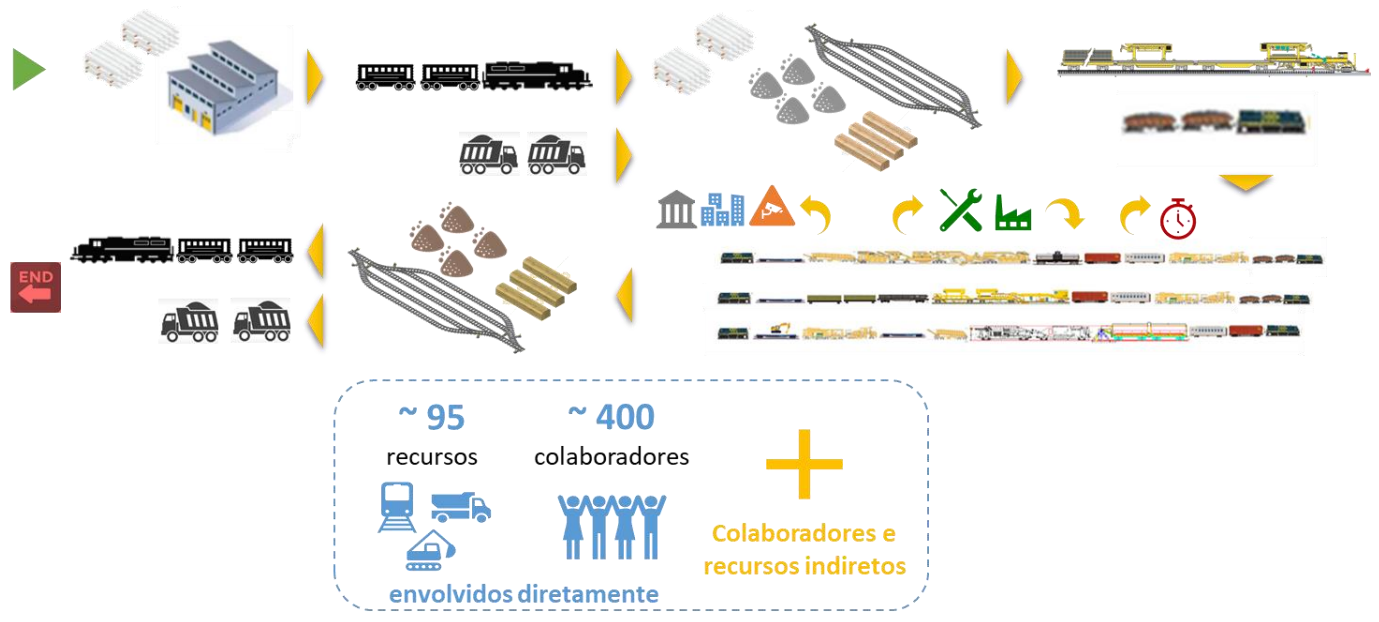

Figura 27 - Representação esquemática da cadeia de suprimentos do projeto.

Todo o correto funcionamento desde fluxo, envolvendo cerca de 95 recursos e 400 colaboradores diretamente, depende da perspectiva de avanço físico do projeto para definição das suas programações mensais, semanais e diárias, desde quantos dormentes deverão ser fabricados e entregues a quantos caminhões serão necessários para a saída do rejeito.

Quando esse planejamento é trabalhado de forma determinística gera uma falsa sensação de conformidade da produtividade que sabemos que não acontece no dia-a-dia devido aos impactos externos que existem diretamente na ferrovia, como a chuva e características de qualidade do lastro de cada trecho, desta forma o 
planejamento probabilístico traz grandes ganhos para a desdobramento para todos os elos de atendimento da cadeia do projeto.

Como o projeto ainda não foi iniciado não foi possível medir quais são esses ganhos, porém estima-se ganhos principalmente relacionados ao processo de fornecimento de dormente de concreto, podendo trabalhar os níveis de estoque conforme a grande variabilidade esperada na quantidade de dormentes dentro do mês, assunto demostrado no item 4.6.3. Simulação do consumo de dormentes, podendo assim controlar o estoque sem gerar estoque muito alto para a companhia (item de grande valor agregado) mas também evitar que a falta de dormentes impacte a frente de trabalho gerando a perda de um dia de trabalho.

Estima-se que cada dia de trabalho previsto envolva o gasto de $\mathrm{R} \$ 650 \mathrm{mil}$ entre materiais, serviços, insumos e manutenção, sendo que cerca de $30 \%$ desses gastos são relacionados a equipes e aluguel de equipamentos, que não estão diretamente ligados a produção do dia, logo esse valor é perdido se por motivos de gestão o projeto não trabalhe em um dia determinado.

Pretende-se com a evolução do projeto em 2023 ter o controle financeiro do projeto e dos ganhos relativos ao planejamento probabilístico para medir o ganho real da aplicação da metodologia.

Segundo a percepção do gerente do projeto, a aplicação desta metodologia permite principalmente trazer mais informações quantitativas para a discussão com as áreas de interface, munindo melhor a tomada de decisão ligada aos recursos do projeto. A abordagem da incerteza tolera o trabalho com cenários dentro dos dados estudados, e cenários mais dinâmicos que as estimativas de três pontos se considerarmos a aplicação da simulação unida à elicitação de especialistas.

Além disso, os ganhos qualitativos já são vislumbrados na troca de informação com áreas de interface e através da percepção do gerente do projeto. Esse é um dos maiores projetos de manutenção ferroviária da companhia, em termos financeiros e de recursos envolvidos, logo ele recebe muita atenção da alta gestão e envolve muitas áreas diferentes nas suas discussões de recursos e defesas orçamentárias.

A evolução desse trabalho, trazendo para o modelo mais fatores estimados ou medidos com informações reais de variabilidade, incluindo informações obtidas por outras áreas que atendem o projeto, podendo essas assim contribuírem diretamente com o planejamento e seus cenários permite uma maior robustez do planejamento 
e o processo de aprimoramento do mesmo com a evolução das atividades e o aumento do know-how dos envolvidos em relação aos fatores de impacto e as atividades do dia-a-dia da sua execução, antecipando a tomada de decisão. 


\section{5 \\ Conclusão}

Tendo em vista o contexto apresentado e as perspectivas, o trabalho teve relevância e aplicabilidade no meio que está inserido, permitindo através da sua aplicação uma aproximação do ambiente empresarial e acadêmico, através da integração de ferramentas e métodos a abordagens inovadoras com relevância acadêmica.

Inserido no contexto de projetos de manutenção de via ferroviária, muito similar devido às suas características a projetos da indústria de construção, o presente trabalho apresenta integração com as ferramentas ligadas a gerenciamento de projetos, como também de importante contribuição acadêmica para os últimos trabalhos que relacionam a aplicação de Linha de Balanço para projetos repetitivos e como tratar a incerteza nesses projetos, sendo um trabalho de diferencial na sua forma e ramo de aplicação.

A integração de ferramentas da estatística bayesiana através do protocolo para tratar opinião de especialistas, com o gerenciamento de projetos e a simulação de processos num ambiente de incertezas do planejamento, é o principal ganho do trabalho proposto, permitindo a priori uma análise mais crítica do planejamento construído e abrindo possibilidades para maiores desenvolvimentos no ambiente de controle do projeto, atualizando as informações e integrando o planejamento à incerteza da execução.

Constatou-se ser essencial integrar aos métodos quantitativos estudados, boas práticas de gerenciamento, agindo em pontos cruciais para garantir a confiabilidade da informação obtida, buscando elicitar quantidades ou informações que os especialistas entendam bem, e ao elaborar as perguntas e apresentar a metodologia, usar linguagem simples e assertiva, sempre questionando através de exemplos e aferições se as informações levantadas estão refletindo a sua opinião.

O mesmo se aplica a simulação e controle do projeto, bons modelos matemáticos associados a boas práticas gerenciais é um fator crucial para garantir 
a qualidade da informação, e que seja aplicada a realidade empresarial e seja possível o seu uso para a tomada de decisão em projetos.

Como proposta de trabalhos futuros, pretende-se desenvolver o modelo com novas aplicações, atreladas ao início do projeto e a obtenção de informações históricas que possibilitem expandir a aplicação do modelo para um cenário de curto prazo, utilizando-se por exemplo parâmetros da Bernoulli para o impacto da chuva na atividade de desguarnecimento de forma mensal e relacionados a probabilidade de chuva na região de trabalho do projeto.

Outro desenvolvimento futuro consiste em aplicar inferência Bayesiana nas distribuições beta a priori estimadas, utilizando-se de dados históricos para aprimorar a estimativa e consequentemente desenvolver um modelo de aplicação em gestão de projetos. 


\section{Referências bibliográficas}

ABADIE, J. Generalization of the Wolfe reduced gradient method to the case of nonlinear constraints. Optimization, p. 37-47, 1969.

AMMAR, M. A. Resource optimisation in line of balance scheduling. Construction Management and Economics, v. 38, n. 8, p. 715-725, 2 ago. 2020.

AMMAR, M. A.; ABDEL-MAGED, A. F. Modeling of LOB scheduling with learning development effect. International Journal of Construction Management, v. 18, n. 6, p. 517-526, 2 nov. 2018.

AMMAR, M. A.; MOHIELDIN, Y. A. Resource constrained project scheduling using simulation. Construction Management and Economics, v. 20, n. 4, p. 323330, jun. 2002.

ANDREWS, M.; BAGULEY, T. Prior approval: The growth of Bayesian methods in psychology. British Journal of Mathematical and Statistical Psychology, v. 66, n. 1, p. 1-7, 2013.

ARDITI, D.; TOKDEMIR, O. B.; SUH, K. Challenges in Line-of-Balance Scheduling. Journal of Construction Engineering and Management, v. 128, n. 6, p. 545-556, dez. 2002.

AZZOLINA, D. et al. Prior Elicitation for Use in Clinical Trial Design and Analysis: A Literature Review. International Journal of Environmental Research and Public Health, v. 18, n. 4, p. 1833, 2021.

BORSHCHEV, A. The Big Book of Simulation Modeling: Multimethod Modeling with AnyLogic 6. [s.I.] AnyLogic North America, 2013.

CAETANO, L. F.; TEIXEIRA, P. F. Optimisation model to schedule railway track renewal operations: a life-cycle cost approach. Structure and Infrastructure Engineering, v. 11, n. 11, p. 1524-1536, 2 nov. 2015.

CAETANO, L. F.; TEIXEIRA, P. F. Strategic Model to Optimize RailwayTrack Renewal Operations at a Network Level. Journal of Infrastructure Systems, v. 22, n. 2, p. 04016002, jun. 2016.

CHARISSE FARR, A. et al. Combining Opinions for Use in Bayesian Networks: A Measurement Error Approach. International Statistical Review, p. insr.12350, 29 dez. 2019. 
COUGHLAN, P.; COGHLAN, D. Action research for operations management. International Journal of Operations \& Production Management, v. 22, n. 2, p. 220-240, fev. 2002.

FIROUZI, A.; KHAYYATI, M. Bayesian Updating of Copula-Based Probabilistic Project-Duration Model. Journal of Construction Engineering and Management, v. 146, n. 5, p. 04020046, 2020.

GOIENETXEA URIARTE, A.; NG, A. H. C.; URENDA MORIS, M. Bringing together Lean and simulation: a comprehensive review. International Journal of Production Research, v. 58, n. 1, p. 87-117, 2 jan. 2020.

GOLDSMAN, D.; NANCE, R. E.; WILSON, J. R. A brief history of simulation revisited. Proceedings of the 2010 Winter Simulation Conference. Anais...IEEE, 7 dez. 2010.

GOROD, A. et al. Evolving Toolbox for Complex Project Management. [s.l.] CRC Press, 2019.

GUPTA, A. K.; NADARAJAH, S. Handbook of Beta Distribution and Its Applications. [s.I.] Taylor \& Francis, 2004.

HANEA, A. M. et al. Classical meets modern in the IDEA protocol for structured expert judgement. Journal of Risk Research, v. 21, n. 4, p. 417-433, 2018.

HANEA, A. M.; NANE, G. F. Calibrating experts' probabilistic assessments for improved probabilistic predictions. Safety Science, v. 118, n. June, p. 763771, 2019.

HASSAN, A. A. A. Risk management of repetitive construction projects. [s.I.] University of Illinois at Urbana-Champaign, 2019.

HEMMING, V. et al. A practical guide to structured expert elicitation using the IDEA protocol. Methods in Ecology and Evolution, v. 9, n. 1, p. 169-180, 5 jan. 2018.

KHAMOOSHI, H.; ABDI, A. Project Duration Forecasting Using Earned Duration Management with Exponential Smoothing Techniques. Journal of Management in Engineering, v. 33, n. 1, p. 04016032, 2017.

KIM, B.; REINSCHMIDT, K. F. Probabilistic Forecasting of Project Duration Using Bayesian Inference and the Beta Distribution. Journal of Construction Engineering and Management, v. 135, n. 3, p. 178-186, 2009.

KÖKSOY, O.; YALCINOZ, T. Mean square error criteria to multiresponse process optimization by a new genetic algorithm. Applied Mathematics and Computation, v. 175, n. 2, p. 1657-1674, 2006. 
LAW, A. M. et al. Simulation Modeling and Analysis. [s.I.] McGraw-Hill Higher Education, 2014. v. 78

LINDLEY, D. V.; BEDFORD, T.; COOKE, R. Probabilistic Risk Analysis: Foundations and Methods. [s.I: s.n.]. v. 86

LIU, M. et al. System Dynamics Modeling for construction management research: critical review and future trends. Journal of Civil Engineering and Management, v. 25, n. 8, p. 730-741, 22 ago. 2019.

LUCKO, G.; GATTEI, G. Line-of-balance against linear scheduling: critical comparison. Proceedings of the Institution of Civil Engineers - Management, Procurement and Law, v. 169, n. 1, p. 26-44, fev. 2016.

MOALA, F. A.; PENHA, D. LUZIA. ELICITATION METHODS FOR BETA PRIOR DISTRIBUTION. REVISTA BRASILEIRA DE BIOMETRIA, v. 34, p. 4962, 2016.

O'HAGAN, A. Eliciting expert beliefs in substantial practical applications. Journal of the Royal Statistical Society Series D: The Statistician, v. 47, n. 1, p. 21-35, 1998.

O'HAGAN, A. Expert Knowledge Elicitation: Subjective but Scientific. American Statistician, v. 73, n. sup1, p. 69-81, 2019.

PARGAR, F.; KAUPPILA, O.; KUJALA, J. Integrated scheduling of preventive maintenance and renewal projects for multi-unit systems with grouping and balancing. Computers and Industrial Engineering, v. 110, p. 43-58, 2017.

POLAT, G.; BUYUKSARACOGLU, Y.; DAMCI, A. Scheduling asphalt highway construction operations using the combination of line-of-balance and discrete event simulation techniques. 2009 IEEE International Conference on Industrial Engineering and Engineering Management, p. 1126-1130, dez. 2009.

REZAKHANI, P. Hybrid fuzzy-Bayesian decision support tool for dynamic project scheduling and control under uncertainty. International Journal of Construction Management, v. 0, n. 0, p. 1-13, 2020.

SZWED, P. S. Expert Judgment in Project Management: Narrowing the Theory-Practice Gap. [s.I.] Project Management Institute, 2016.

TOKDEMIR, O. B.; EROL, H.; DIKMEN, I. Delay Risk Assessment of Repetitive Construction Projects Using Line-of-Balance Scheduling and Monte Carlo Simulation. Journal of Construction Engineering and Management, v. 145, n. 2, p. 04018132, fev. 2019.

TOMAR, A.; BANSAL, V. K. Scheduling of repetitive construction projects using geographic information systems: an integration of critical path method and 
line of balance. Asian Journal of Civil Engineering, v. 20, n. 4, p. 549-562, 1 jun. 2019.

VOSE, D. Risk Anaysis - A quantitative guide. [s.I: s.n.].

WILLIS, J. W. Action Research: Models, Methods, and Examples. Charlotte, NC: Information Age Publishing, 2014.

ZOU, X.; ZHANG, L. A constraint programming approach for scheduling repetitive projects with atypical activities considering soft logic. Automation in Construction, v. 109, n. October 2019, p. 102990, 2020. 


\section{APÊNDICE 1 - Distribuição Beta}

A distribuição beta pode gerar uma quantidade grande de formas diferentes com o uso de apenas dois parâmetros: $\alpha$ e $\beta$. Por esse motivo a mesma vem sendo amplamente aplicada na engenharia e no gerenciamento de projetos, para representar dados históricos ou estimados (KIM; REINSCHMIDT, 2009).

Denotada por $X \sim \operatorname{Beta}(\alpha, \beta)$ a distribuição beta é mais comumente usada entre o intervalo $[0,1]$, porém também pode ser representada, assim como no presente trabalho, entre um intervalo finito $[L, U]$ ampliando assim ainda mais sua aplicabilidade. Abaixo está representada a função de densidade de probabilidade (PDF) para uma distribuição beta de parâmetros $\alpha$ e $\beta$, para um intervalo $[L, U]$ de uma variável aleatória $X$, adaptado do que foi apresentado por Kim e Reinschmidt (2009) em seu estudo:

$$
f(x ; \alpha, \beta)=\frac{1}{B(\alpha, \beta)} \frac{(x-L)^{\alpha-1}(U-x)^{\beta-1}}{(U-L)^{\alpha+\beta-1}}
$$

Onde:

$$
\begin{aligned}
& \alpha>0, \beta>0, \mathrm{~L} \leq \mathrm{x} \leq \mathrm{U} \\
& B(\alpha, \beta)=\int_{0}^{1} t^{\alpha-1}(1-t)^{\beta-1} d t
\end{aligned}
$$

A representação da sua função de distribuição acumulada também para os parâmetros $\alpha$ e $\beta$, para um intervalo $[L, U]$ (KIM; REINSCHMIDT, 2009). 


$$
F(x ; \alpha, \beta)=\frac{B\left(\frac{x-L}{U-L} ; \alpha, \beta\right)}{B(\alpha, \beta)}=I_{z}(\alpha, \beta)
$$

Onde:

$I_{x}(\alpha, \beta)$ é a função beta incompleta regularizada

$B(s ; \alpha, \beta)=\int_{0}^{s} t^{\alpha-1}(1-t)^{\beta-1} d t$

Como toda distribuição de probabilidade a distribuição beta possuiu suas propriedades que podem ser obtidas a partir dos parâmetros e limites da distribuição, conforme demonstradas abaixo adaptadas de Gupta e Nadarajah (2004).

Média:

$$
\mu=E[X]=L+\frac{a}{\alpha+\beta} *(U-L)
$$

Variância:

$$
\begin{gathered}
\operatorname{var}(X)=E\left[x-\mu^{2}\right] \\
\operatorname{var}(X)=\frac{a * \beta}{(\alpha+\beta)^{2}(\alpha+\beta+1)} *(U-L)^{2}
\end{gathered}
$$

Moda:

$$
M o(X)=L+\frac{\alpha-1}{\alpha+\beta-2} *(U-L)
$$

para:

$\alpha, \beta>1$

Mediana:

$$
x=I_{z}{ }^{[-1]}(\alpha, \beta)
$$

Sendo:

$$
\begin{aligned}
& z=\frac{x-L}{U-L} \\
& x=\frac{1}{2}
\end{aligned}
$$

